REMOVAL OF AIRBORNE FISSION PRODUCTS BY RECIRCULAT ING FILTER SYSTEMS IN THE CONTAINMENT SYSTEMS EXPERIMENT
J. D. McCormack (a)
R. K. Hilliard (b)
A. K. Postma

Mechanical Engineering Department

$$
\text { June } 1971
$$

(a) J. D. McCormack is presently with WADCO Corporation, Richland, Washington.

(b) Chemical Technology Department.

BATTELLE MEMORIAL INSTITUTE

PACIFIC NORTHWEST LABORATORIES

RICHLAND, WASHINGTON 99352 
REMOVAL OF AIRBORNE FISSION PRODUCTS BY RECIRCULATING

FILTER SYSTEMS IN THE CONTAINMENT SYSTEM EXPERIMENT

J. D. McCormack

R. K. Hilliard

A. K. Postma

\section{ABSTRACT}

Five large-scale demonstration tests were carried out in the 26,500 cubic foot Containment Systems Experiment vessel, using an internal recirculating filter loop to remove airborne fission product simulants. Loop components were nominal $2 \mathrm{ft}$ by $2 \mathrm{ft}$, commercially available units including a heat exchanger, demister, roughing filter, high efficiency particulate filter, and impregnated charcoal adsorbers. Flow through the loop was either 1000 or 1800 CFM and in four of the tests the containment atmosphere was saturated steam-air at $250^{\circ} \mathrm{F}, 48 \mathrm{psig}$. This system performed satisfactorily, removing both particulate and gaseous fission products, including methyl iodide. Elemental iodine was removed initially at a rate somewhat faster than predicted for $100 \%$ efficiency, due to wall deposition. Particles were removed with an efficiency of $100 \%$, and methyl iodide with an efficiency of $80 \%$. At long times, the airborne concentration of all fission products approached equilibrium levels equivalent to decontamination factors greater than 10,000. 


\section{TABLE OF CONTENTS}

LIST OF FIGURES

LIST OF TABLES

INTRODUCTION

OBJECTIVES OF FILTER SYSTEM EXPERIMENTS

SUMMARY AND CONCLUSIONS.

BACKGROUND INFORMATION

MACROSCOPIC MODEL OF CLEANUP WITH A FILTER LOOP • 3

DISCUSSION OF ASSUMPTIONS USED IN REMOVAL MODEL . 6

TRAPPING OF FISSION PRODUCTS BY FILTER LOOP COMPONENTS 8

Particle Removal by High Efficiency Filters . . 8

Adsorption of Elemental Iodine by Charcoal . . 9

Adsorption of Methyl Iodide by Charcoal . . 10

Heating of Charcoal Beds in Containment otmospheres 11

EXPERIMENTAL FACILITIES AND PROCEDURE $\quad$ • $\quad$ • $\quad$. 12

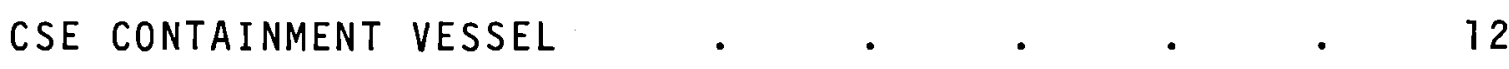

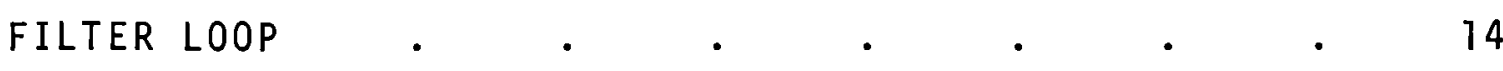

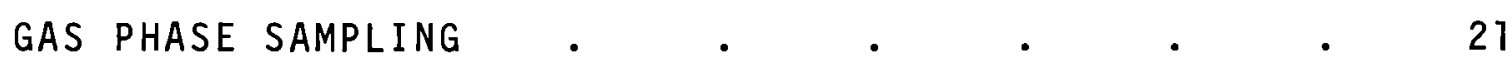

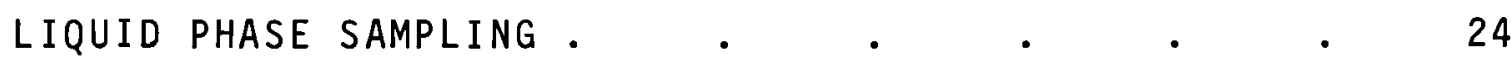

GENERATION OF FISSION PRODUCT SIMULANTS • • • $\quad$ • 24

EXPERIMENTAL TEST SEQUENCE

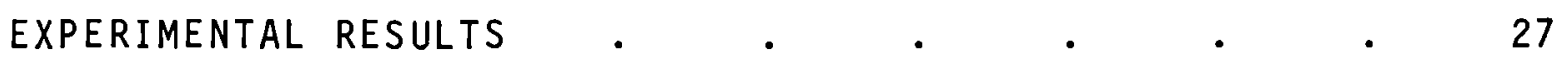

NUMERICAL VALUE OF TEST PARAMETERS $\quad \cdot \quad \cdot \quad \cdot \quad \cdot 27$

REMOVAL OF AIRBORNE FISSION PRODUCT SIMULANTS • . 28

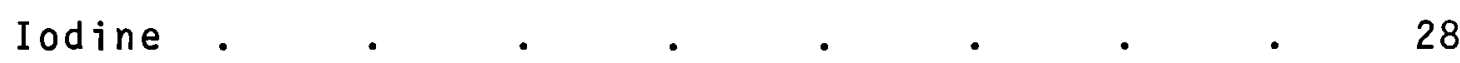

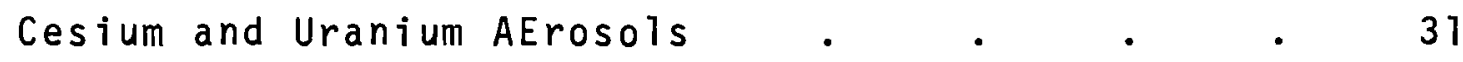

FISSION PROUDCT DISTRIBUTION WITHIN CONTAINMENT COMPONENTS

Concentration in Liquid Condensate . $\quad . \quad$. 35

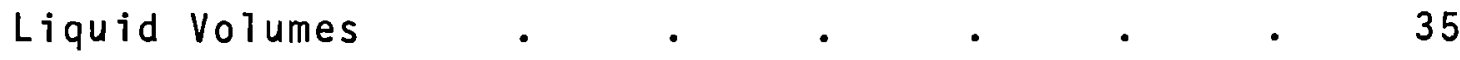

Retention by Loop Components $\quad . \quad$. $\quad . \quad$. 38

Fission Product Material Balances . $\quad . \quad$. 39

REMOVAL EFFICIENCIES FOR FILTER LOOP COMPONENTS • 45

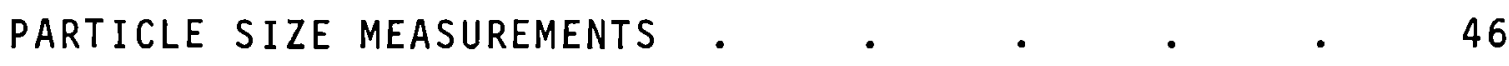


VISUAL OBSERVATIONS OF CONTAINMENT ATMOSPHERE $\quad \cdot \quad \cdot \quad \cdot \quad 47$ MECHANICAL ASPECTS OF LOOP OPERATION

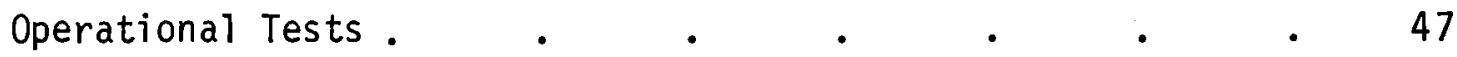

Loop Flow and Pressure Drop . $\quad . \quad$. $\quad . \quad . \quad 4 \quad 49$

Heat Removal by Finned Tubes . $\quad . \quad$. $\quad . \quad$. 49

Iodine and Steam Adsorption by Charcoal Beds . . . 53

Mechanical Reliability of Loop . $\quad . \quad$. $\quad . \quad . \quad 54$

EFFECT OF HUMIDITY ON METHYL IODIDE REMOVAL BY CHARCOAL BEDS • 55

DEPOSITION OF FISSION PRODUCTS ON EXPOSED SURFACES • $\quad \cdot \quad 58$

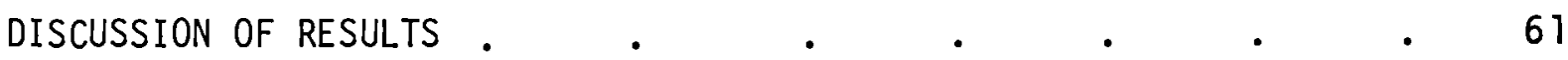

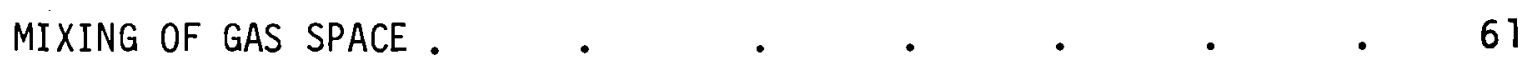

COMPARISON OF MEASURED REMOVAL RATE WITH THEORY ..$\quad \cdot 61$

APPROACH TO EQUILIBRIUM GAS CONCENTRATION .

EFFECT OF HEAT EXCHANGER AND MIST ELIMINATOR

ON LOOP OPERATION

INFLUENCE OF RELATIVE HUMIDITY ON METHYL IODIDE ADSORPTION $\bullet 73$

FILTER LOOP CLEANUP IN PWR CONTAINMENT VESSELS •

ACKNOWLEDGEMENTS

NOMENCLATURE

REFERENCES

APPENDIX 


\section{LIST OF FIGURES}

1 Schematic Diagram of Fission Product Removal By a Filter Loop in the CSE Vessel

2 Equipment Arrangement Used in CSE Filter Loop Tests 13

3 Schematic Diagram of Filter Loop Instrumentation 15

4 View of a Loop Module Showing Interstage

Samplers and Charcoal Filter

5 Air Cleaning Loop Assembled in CSE Vessel 19

6 Air Cleaning Loop in CSE Vesse 1

7 Location of Maypack Clusters in CSE

Filter Loop Tests

8 Schematic Diagram of a CSE Maypack Showing Filter and Adsorber Arrangement

9 Iodine Concentrations in the Main Room Gas Space in CSE Run A-17

10 Concentration of Airborne Fission Products in the Middle Room of the CSE Vessel

11 Cesium and Uranium Concentrations in the Main Room Gas Space in CSE Run A-17

12 Iodine Concentration in Liquid Sumps in CSE Run A-14 36

13 Water Volumes Accumulated in CSE Run A-17

14 Total Iodine Material Balance vs. Time for CSE Run A-17

15 Cesium Material Balance vs. Time for CSE Run A-17 42

16 Thermodynamic Conditions and Loop Flow for CSE Run A-17 50

17 Pressure Drop Across Loop Components in CSE Run A-17 51

18 Heat Transfer Coefficient to Finned Tubes 52

Heating Due to Moisture Adsorption on Charcoal Beds
in CSE Run A-15

20 Methyl Iodide REmoval by Impregnated Charcoal in CSE Run A-15

21 Iodine Concentration in the Main Room Gas Space in CSE Run A-14

22 Comparison of Iodine Removal Rate with Theory 66

23 Comparison of Cesium Removal Rate with Theory 67

24 Model of Surface Desorption Influence $\quad 70$

25 Effect of Heat Exchanger and Mist Eliminator on
Loop Pressure Drop 
A-1 Iodine Concentration in the Main Room Gas Space in CSE Run A-13

A-2 Iodine Concentration in the Main Room Gas Space in CSE Run A-14

A-3 Iodine Concentration in the Main Room Gas Space in CSE Run A-15

A-4 Iodine Concentration in the Main Room Gas Space in CSE Run A-16

A- 9

A-5 Iodine Concentration in the Main Room Gas Space in CSE Run A-17

A-6 Cesium and Uranium Concentrations in the Main Room Gas Space in CSE Run A-13

A-7 Cesium and Uranium Concentrations in the Main Room Gas Space in CSE Run A-14

A-8 Cesium and Uranium Concentrations in the Main Room Gas Space in CSE Run A-15

A-9 Cesium and Uranium Concentrations in the Main Room Gas Space in CSE Run A-16

A-10 Cesium and Uranium Concentrations in the Main Room Gas Space in CSE Run A-17

A-11 Iodine Concentration in Liquid Sumps in CSE Run A-13

A-12 Iodine Concentration in Liquid Sumps in CSE Run A-14

A-13 Iodine Concentration in Liquid Sumps in CSE Run A-15

A-14 Iodine Concentration in Liquid Sumps In CSE Run A-16

A-15 Iodine Concentration in Liquid Sumps in CSE Run A-17

A-16 Cesium Concentration in Liquid Sumps in CSE Run A-13

A -21

A-17 Cesium Concentration in Liquid Sumps in CSE Run A-14

$A-22$

A-18 Cesium Concentration in Liquid Sumps in CSE Run A-15

A -23

A-19 Cesium Concentration in Liquid Sumps in CSE Run A-16

A- 24

A-20 Cesium Concentration in Liquid Sumps in CSE Run A-17

$A-25$

A-21 Water Volumes Accumulated in CSE Run A-14

A -26

A-22 Water Volumes Accumulated in CSE Run A-15

$A-27$

A-23 Water Volumes Accumulated in CSE Run A-16

A -28

A-24 Water Volumes Accumulated in CSE Run A-17

A -29

A-25 Total Iodine Material Balance vs. Time for CSE Run A-13

$A-30$

A-26 Total Iodine Material Balance vs. Time for CSE Run A-14

$A-31$

A-27 Total Iodine Material Balance vs. Time for CSE Run A-15

A-32 
A-28 Total Iodine Material Balance vs. Time for CSE Run A-16 A-33

A-29 Total Iodine Material Balance vs. Time for CSE Run A-17 A-34

A-30 Cesium Material Balance vs. Time for CSE Run A-13 A-35

A-31 Cesium Material Balance vs. Time for CSE Run A-14 A-36

A-32 Cesium Material Balance vs. Time for CSE Run A-15 A-37

A-33 Cesium Material Balance vs. Time for CSE Run A-16 A-38

A-34 Cesium Material Balance vs. Time for CSE Run A-17 A-39

A-35 Thermodynamic Conditions and Loop Flow for CSE Run A-13 A-40

A-36 Pressure Drop Across Loop Components in CSE Run A-13 A-41

A-37 Thermodynamic Conditions and Loop Flow for CSE Run A-14 A-42

A-38 Pressure Drop Across Loop Components in CSE Run A-14 A-43

A-39 Thermodynamic Conditions and Loop Flow for CSE Run A-15 A-44

A-40 Pressure Drop Across Loop Components in CSE Run A-15 A-45

A-41 Thermodynamic Conditions and Loop Flow for CSE Run A-16 A-46

A-42 Pressure Drop Across Loop Components in CSE Run A-16 A-47

A-43 Thermodynamic Conditions and Loop Flow For CSE Run A-17 A-48

A-44 Pressure Drop Across Loop Components in CSE Run A-17 A-49 


\section{LIST OF TABLES}

1 Physical Conditions Common to All Filter Loop Experiments 14

2 Summary of Air Cleaning Run Conditions 27

3 Early Removal Half-Times for Airborne Iodine In Filter 30 Loop Experiments

4 Iodine Decontamination Factors Achieved in Filter Loop Tests 30

5 Early Removal Half-Times for Cesium and Uranium in 34

Filter Loop Experiments

6 Decontamination Factors Achieved in Filter Loop Tests 34

7 Post-Run Loop Iodine Inventory 38

$8 \quad$ Post-Run Loop Cesium Inventory 39

9 Iodine Material Balances 43

10 Cesium Material Balances 44

11 Measured Loop Decontamination Factors For Run A-17 45

12 Cesium Particle Size in Filter Loop Tests 46

13 Operational Tests on Loop and Components 48

14. Stable Iodine on Charcoal Beds After Use, Wt\% 53

15 Moisture Pickup by Charcoal at End of Run, Wt\% 54

16 Iodine Deposition on Various Noncondensing Surfaces 59

17 Cesium Deposition on Various Noncondensing Surfaces 60

18 Comparison of Observed and Predicted Fission Product Removal Rates by Filter Loop 64

19 Measured Loop Decontamination Factors, Run A-16 69

20 Methyl Iodide Removal By Charcoal 74

A-1 Measured Loop Decontamination Factors, Run A-13 A-1

A-2 Measured Loop Decontamination Factors, Run A-14 A-2

A-3 Measured Loop Decontamination Factors, Run A-15 A-3

A-4 Measured Loop Decontamination Factors, Run A-16 A-4

A-5 Measured Loop Decontamination Factors, Run A-17 A-5 


\title{
REMOVAL OF AIRBORNE FISSION PRODUCTS BY RECIRCULATING FILTER SYSTEMS IN THE CONTAINMENT SYSTEMS EXPERIMENT
}

\author{
J. D. McCormack \\ R. K. Hilliard \\ A. K. Postma
}

\section{INTRODUCTION}

This report describes the results of large scale experiments on removal of airborne fission products from post-accident containment atmospheres by recirculating filter systems. This work was carried out as part of the Containment Systems Experiment (CSE) program sponsored by the USAEC Division of Reactor Development and Technology. In addition to the filter systems tests described in this report, the CSE program also provided extensive data on fission product removal by natural processes and by sprays. Hilliard $(1,2)$ has discussed the removal of aerosols and gases by surface deposition which would occur in a large containment vessel following a postulated accident. Hilliard ${ }^{(3)}$, and Postma $(4,5)$ have described the washout of airborne fission products by containment vessel sprays.

The trend in the nuclear power industry is for more reliance on engineered safety features to meet the licensing requirements set forth by the AEC reactor site criteria $(6,7)$. Filter systems and sprays are two engineered safety systems currently used to reduce the potential for leakage of radioactive materials from a containment vessel following a design basis accident (DBA).

Filter systems operate to reduce leakage potential in two ways. First, they clean the containment vessel atmosphere. This reduces the mass concentration of fission products in leaked gas. Second, the filter system may include a heat exchanger which cools the containment atmosphere and lowers the pressure. This reduces the calculated leak rate, which reduces the mass of fission products leaked to the atmosphere.

Filter systems have an advantage over sprays in that methy 1 iodide is removed nearly as rapidly as elemental iodine. Sprays are capable of 
removing elemental iodine much more rapidly than can be achieved by a practical filter system. Aerosol particles are effectively removed by both sprays and filter systems.

\section{OBJECTIVES OF FILTER SYSTEM EXPERIMENTS}

The objectives of the filter system experiments were as follows:

- Measure the rate of removal of fission products from the containment atmosphere and compare with simple models based on a wellmixed atmosphere.

- Determine the loop component efficiencies, using full scale, commercially available components.

- Measure pressure drop and mechanical reliability for a loop operating in a post-accident environment.

\section{SUMMARY AND CONCLUSIONS}

Five large scale demonstration tests were carried out as part of the Containment Systems Experiment using a recirculating filter loop to remove airborne fission product simulants. The objectives of the tests were to assess the rate and extent to which the containment atmosphere was cleaned, and to measure loop performance in typical post-accident atmospheres.

Full sized, commercially available filters and charcoal adsorbers were used in a loop operating at $1000 \mathrm{cfm}$ and $1800 \mathrm{cfm}$. One experiment was carried out at $80^{\circ} \mathrm{F}$ and the other four used saturated steam-air at $250^{\circ} \mathrm{F}$. The loop was operated for 24 or 48 hours following injection of fission product simulants.

The results of the five experiments support the following conclusions.

- The filter loop removed airborne fission products with an initial rate which was in agreement with that predicted on the basis of a well-mixed containment volume.

- After the gas phase concentration was reduced to about $1 \%$ of initial concentration, desorption of fission products which had deposited by natural processes reduced the net rate at which the loop removed airborne materials. 
- The charcoal beds effectively removed iodine-131 which was combined chemically as methyl iodide. At 100\% relative humidity, the removal efficiency was about $80 \%$, and at lower relative humidities the removal efficiency was greater than $99 \%$.

- The loop components performed as expected in all atmospheric conditions tested. Deletion of the heat exchanger and moisture separator caused only minor effects on the filter pressure drop.

\section{BACKGROUND INFORMATION}

The filter system experiments were designed to give information which could be used in full scale containment vessels. Extrapolation to other situations requires a mathematical model based on theoretical concepts. The theory concepts which were considered important in the experimental design are briefly described in this section of the report. MACROSCOPIC MODEL OF CLEANUP WITH A FILTER LOOP

The rate at which fission products are removed from the gas phase may be related to the system parameters by making a material balance on the gas phase. The source and sink terms are depicted graphically in Figure 1. The differential equation for a particular species in one of the rooms may be obtained by balancing input and output terms, on the assumption that the gas phase is well mixed.

The input rate is

$$
\begin{aligned}
\text { input rate }= & G+F C_{g}(1-E)+R \\
\text { where } G= & \text { simulant injection rate, } \\
F= & \text { flow rate through filter loop, } \\
C_{g}= & \text { airborne concentration in main room, } \\
E= & \text { fraction of airborne specie removed by } \\
& \text { filter in single pass, } \\
R= & \text { rate of production of specie by vapor phase } \\
& \text { reaction. }
\end{aligned}
$$


BNWL-1587

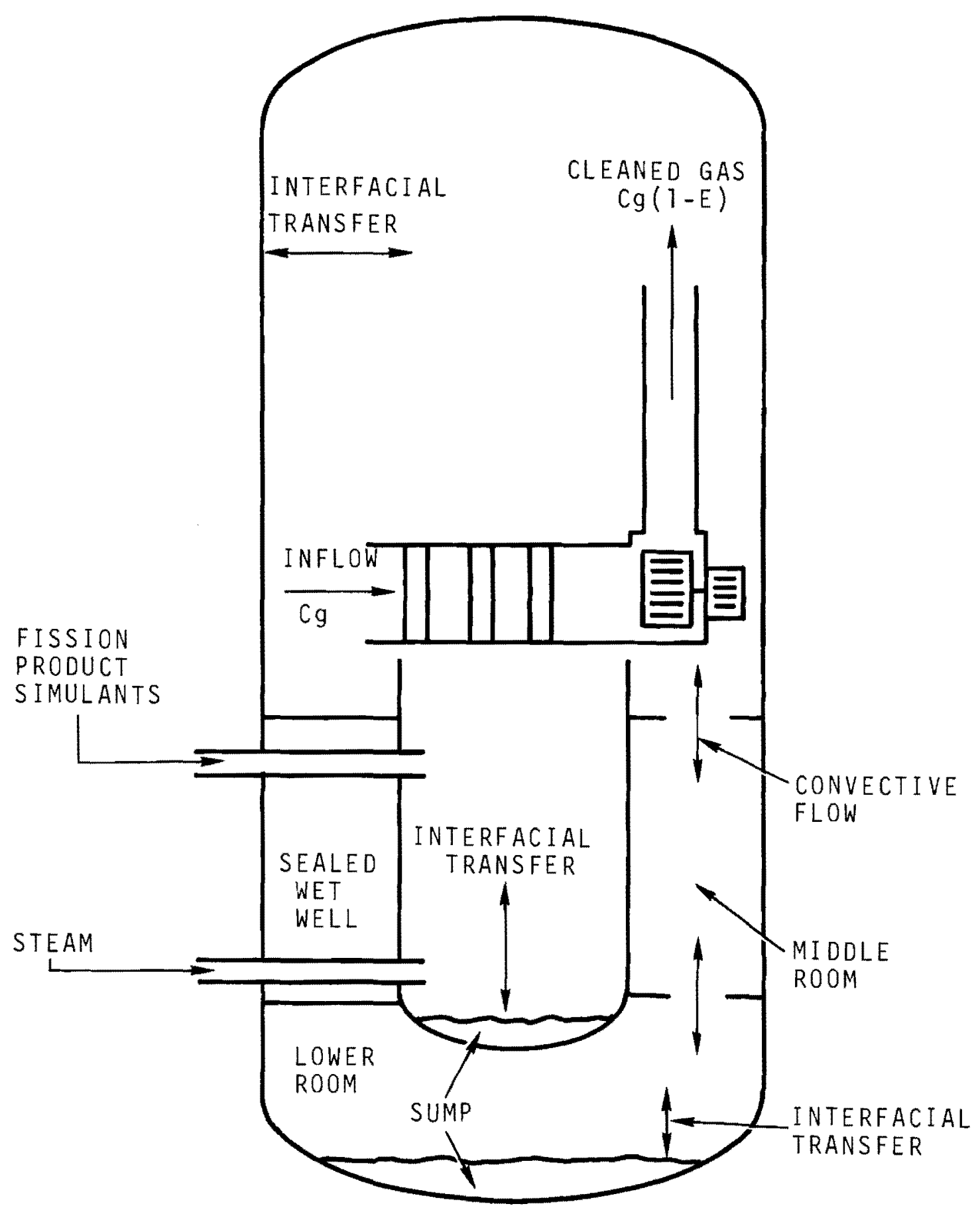

FIGURE 1. Schematic Diagram of Fission Product Removal by a Filter Loop in the CSE Vessel 
The output rate is

$$
\begin{aligned}
& \text { output rate }=F C_{g}+k_{g} A\left(C_{g}-C_{g i}\right)+B_{1}\left(C_{g}-C_{g l}\right) \\
& \text { where } k_{g}=\text { interfacial mass transfer coefficient, } \\
& A=\text { interfacial area for mass transfer, } \\
& C_{g i}=\text { solute concentration at interface, } \\
& \mathrm{B}_{1}=\text { inter-room transport coefficient, } \\
& \mathrm{C}_{\mathrm{g} 1}=\text { concentration in gas of adjacent room. }
\end{aligned}
$$

The accumulation rate of a specie in a well mixed volume, $V$, is

$$
\text { accumulation rate }=\mathrm{V} \frac{\mathrm{dC}}{\mathrm{dt}} \text {. }
$$

A mass balance based on Equations (1), (2), and (3) is

$$
G+F C_{g}(1-E)+R=F C_{g}+k_{g} A\left(C_{g}-C_{g i}\right)+B_{1}\left(C_{g}-C_{g i}\right)+V \frac{d C_{g}}{d t}
$$

This equation is the mass balance for only one room. Similar equations for other rooms would also have to be written. In addition, similar balances on the liquid phase to account for equilibrium are needed to evaluate the quantity $\mathrm{C}_{\mathrm{gi}}$. Fortunately, for early and late times, many of the terms in Eq. (4) are small compared to the dominant ones.

Most of the filter systems tests were carried out using short term releases of simulants. Early in the run, the generation rate, $R$, may be neglected compared to removal. Also, inter-room transport is small compared to removal for early times. For early times then, Eq. (4) may be written as

$$
\frac{d C_{g}}{d t}=-\frac{F E}{V} C_{g}-k_{g} A\left(C_{g}-C_{g i}\right) .
$$

Thus the initial removal rate is the sum of the cleanup caused by the filter loop, and that due to surface deposition. Hilliard ${ }^{(2)}$ has shown that for elemental iodine, the perfect sink assumption, $c_{g i}=0$, applies until the gas phase concentration falls to 0.01 of the initial concentration. For particles, one would expect the perfect sink assumption to be true for all times. For methyl iodide, the quantity $\left(\mathrm{C}_{\mathrm{g}}-\mathrm{C}_{\mathrm{gi}}\right)$ is very small so that surface deposition is negligible compared to removal by the 
filter system. Thus for early times, the removal rate for elemental iodine and particles is

$$
\frac{d C_{g}}{d t}=-\frac{F E}{V} C_{g}-\frac{k_{g} A C_{g}}{V}
$$

For methyl iodide, surface deposition is negligible, giving

$$
\frac{d C_{g}}{d t}=-\frac{F E}{V} C_{g}
$$

Equations (6) and (7) describe the removal rate in terms of specified or readily calculable parameters. These equations are easily integrated if one assumes that $F, E$, and $V$ are constants. Equation (6) becomes

$$
\frac{C_{g}}{C_{g o}}=\exp \left[-\left(\frac{F E}{V}+\frac{k_{g} A}{V}\right) t\right]
$$

where $\mathrm{C}_{\mathrm{go}}=$ concentration in gas at $\mathrm{t}=0$.

Equation (7) becomes

$$
\frac{C_{g}}{C_{g o}}=\exp \left[-\left(\frac{F E}{V}\right) t\right]
$$

DISCUSSION OF ASSUMPTIONS USED IN REMOVAL MODEL

Several assumptions were used to develop the removal rate equations, Eq. (8) and Eq. (9). We will briefly note the basis for the assumptions and the conditions for which the assumptions would apply.

The gas phase of an individual room was assumed to be well mixed. Earlier tests in CSE have shown this a good assumption. Samplers located throughout the gas space indicated a uniform concentration within a few minutes after fission product injection had ceased. This was true where only natural convection currents caused mixing. Filter loops cause mechanical mixing of air, hence the gas space within a room would surely be well mixed.

Inter-room transport was neglected for early times. This will be true if the quantity, $\mathrm{FEC}_{g}$, is much larger than $\mathrm{B}_{1}\left(\mathrm{C}_{\mathrm{g}}-\mathrm{C}_{\mathrm{gl}}\right)$. Initially 
the concentration in the connected room, $\mathrm{C}_{\mathrm{gl}}$, is 0 . Hence inter-room transport at early times will be of minor importance if $\mathrm{FE}$ is much larger than the inter-room transport coefficient, $B_{1}$. The latter is surely true for all time periods, and hence it is concluded that inter-room transport will be negligible until $C_{g}<C_{g l}$. Experience in the CSE has shown that the maximum concentration attained in the connected rooms is never more than a few percent of the initial main room concentration. Thus neglecting inter-room transport would introduce little error until main concentrations were reduced to less than $1 \%$ of the initial concentration. For long times, the main room concentration will be reduced to a leve 1 such that $C_{g}$ is less than $C_{g l}$. At this point inter-room transport will be significant. Models which apply for long times must account for this.

The perfect sink assumption, $C_{g i}=0$, has been shown to apply for elemental iodine until the main room concentration is reduced to less than $1 \%$ of the initial concentration. At longer times, the interfacial concentration, $C_{g i}$ would likely become larger than that of the bulk gas phase. When this happens, the deposited material becomes a source which will limit the removal achieved by the filter loop. For particles, this kind of desorption would not occur, hence the perfect sink assumption should hold for all times.

Although aerosol particles are not reversibly absorbed as are gases, they can become airborne from solution by physical processes which mechanically disperse small liquid drops. Examples of such process include the breaking of bubbles and formation of drops. Both of these processes would occur within containment vessels. The generation rate of nonvolatile particles by mechanical dispersion is very small on an absolute scale. The gas phase concentration would have to be reduced to very low levels before this generation rate were important. In summary, particles could become resuspended to a smal1 degree by mechanical dispersion processes. The resuspension rate would be of negligible consequence until the gas phase concentration were reduced to a very low level. The mechanical resuspension would limit the ultimate decontamination factor which could be achieved. 
Gas phase generation of fission product types has been neglected. This is a good assumption for CSE tests. For accident conditions, high radiation fields might cause some change. Current calculations by personnel in the AEC Regulatory Branch are based on the assumption that airborne elemental iodine forms methyl iodide. The impact of this formation is minor because the filter system is capable of removing methyl iodide nearly as fast as elemental iodine.

Finally, the flow rate and removal efficiency were assumed constant. Since flow rate is an independent, specified parameter, assumption of constancy is justified. For elemental iodine and particles, removal efficiency is greater than 95\%. Since removal efficiency is a linear multiplier in the exponential terms of the removal equation, the removal rate is influenced to only a minor extent as efficiency varies between $95 \%$ and $100 \%$. For methyl iodide, removal efficiency is potentially lower and more variable. Performance data will require analysis to justify the assumption of constant removal efficiency.

In summary, it appears that a simple first order theory for fission product removal by recirculatory filter loops should apply until airborne concentrations are reduced to about $1 \%$ of the initial concentration. Thus 2-hour dose reduction factors can be reliably predicted from the simple first order, perfect sink theory. For longer time periods, one must account for the approach to equilibrium.

TRAPPING OF FISSION PRODUCTS BY FILTER LOOP COMPONENTS

Particle Removal By High Efficiency Filters

The high efficiency filters used in air cleaning systems are built to standards for use in reactor containment systems. Performance specifications require an efficiency greater than $99 \%$ for $0.3 \mu$ diameter droplets. For nuclear safety systems, Burchsted ${ }^{(8)}$ 1ists performance specifications which require maximum penetration to less than $0.03 \%$ when the filter is operated at rated flow. The increase in penetration when tested at $20 \%$ of rated capacity must not exceed $0.01 \%$. These efficiency requirements are based on $0.3 \mu$ particles, the most difficult to capture. Hence for 
aerosols encountered in a containment system, the removal efficiency should be $99.97 \%$ or higher. Thus, one can use $E=1.0$ in the removal equation and be assured that it applies for all particle sizes for all time periods.

Adsorption of Elemental Iodine by Charcoal

Elemental iodine is efficiently adsorbed by activated charcoal. When exposed as a packed bed of granules, the removal efficiency depends on mass transfer parameters and on the equilibrium adsorption capability of the charcoal. Steps in retention include:

- diffusion across the gas film at the surface of each granule

- diffusion in gas capillaries within the granule (pore diffusion)

- solid phase diffusion along the pore surface or within the solid matrix

- reaction at the solid surface or within the solid matrix.

If the mass of iodine adsorbed is small, the last three steps listed are fast compared to the first. The adsorption is then governed by mass transfer in the gas phase. Dale and $\mathrm{Klotz}{ }^{(9)}$ have published a correlation for adsorption in a packed bed for the case in which gas phase mass transfer limits the adsorption.

$$
\log _{e} \frac{c_{1}}{c_{2}}=\frac{1.82 x_{0} a}{\left(\operatorname{Re}_{p}\right)^{0.51}(S c)^{0.67}}
$$

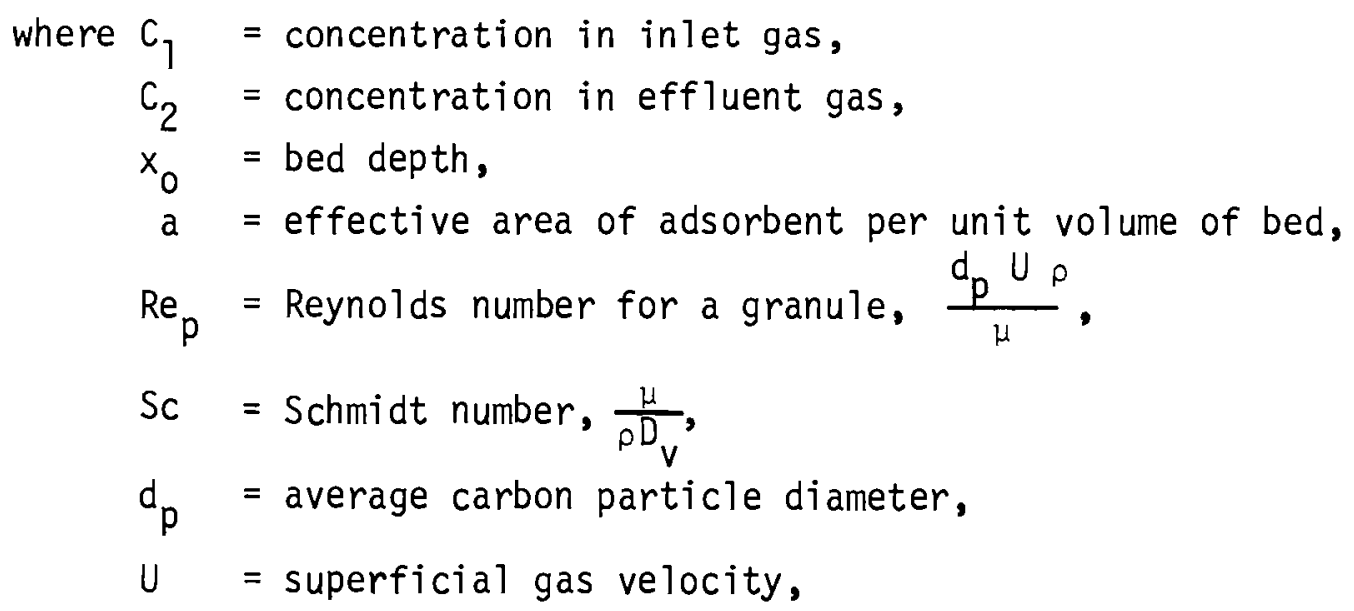




$$
\begin{aligned}
& \rho \quad=\text { density of gas, } \\
& u \quad=\text { absolute viscosity of gas, } \\
& D_{v} \quad=\text { diffusivity of iodine in gas phase. }
\end{aligned}
$$

This predictive equation has been independently verified by Prigge(10) who measured removal efficiencies of elemental iodine in steam-air mixtures as a function of gas velocity, bed thickness, temperature, and iodine concentration, for several types of charcoal. Charcoal beds can be highly efficient for iodine removal. Prigge ${ }^{(10)}$ consistently measured removal efficiencies greater than $99.97 \%$ for his test conditions.

The gas phase limited efficiency indicated in Eq. (9) cannot be expected to continue indefinitely in a recirculating filter system. A very small fractional desorption would be expected to occur. After the gas phase concentration had been reduced to a very low level, this desorption should lower the overall removal efficiency. Relatively little data is available $(11,12)$ on desorption; hence it is not possible to pin-point the concentration level at which desorption would be important. It is certainly true that desorption would not be a factor until the airborne concentration had decreased by a large factor $\left(>10^{3}\right)$.

Adsorption of Methyl Iodide by Charcoal

Methyl iodide is adsorbed less readily by activated charcoal than is elemental iodine. Experiments reported by Adams, et al ${ }^{(13)}$ and by Ackley and Adams ${ }^{(14)}$ showed that under dry conditions methy 1 iodide retention by charcoal was less than for elemental iodine, and that the efficiency approached zero as the relative humidity of the gas stream approached $100 \%$.

It has been found that methyl iodide will exchange iodine atoms while deposited temporarily on activated charcoal. This exchange reaction is currently used to ensure worthwhile removal efficiencies of methyl iodide. The chemical reaction may be written as

$$
\mathrm{CH}_{3} \mathrm{I}^{131}+\mathrm{I}^{127} \text { (on charcoal) }=\mathrm{CH}_{3} \mathrm{I}^{127}+\mathrm{I}^{131} \text { (on charcoal). }
$$

Iodine added to the charcoal as an impregnant exchanges with I-131 bound chemically as methyl iodide. This effects a net decontamination even though 
methyl iodide is not permanently trapped. Kovach ${ }^{(15)}$ reviewed available information on methyl iodide trapping under accident conditions and concluded that single pass systems would give removal efficiencies of the order of $70 \%$. It was recognized that carbon beds might, under very exceptional conditions, become temporarily flooded with water, which reduces the activity removal efficiency, but that properly designed air handling systems, consisting of moisture separators and HEPA filters, would prevent water droplet carry through the carbon bed. Heating of Charcoal Beds in Containment Atmospheres

Charcoal bed heating is important from two viewpoints. First, if the bed is warmed initially by flowing steam-air mixtures, one can imagine the bed becoming flooded with condensate. This condensate, if it should form, would inhibit methyl iodide removal. Second, charcoal will burn if heated above the ignition temperature in the presence of oxygen. The following heat transfer mechanisms must be considered.

- heat of adsorption of water vapor

- heat of adsorption of iodine and other trace gases

- heat transfer to the flowing gas

- decay heat of adsorbed fission products.

The CSE tests can be expected to provide information on the first three mechanisms. The last mechanism listed, fission product decay heat, cannot be duplicated in the CSE tests because the radioactive material inventories are low. 


\section{EXPERIMENTAL FACILITIES AND PROCEDURE}

CSE CONTAINMENT VESSEL

The CSE experimental equipment comprises a model containment vessel with provision for generating fission product simulants and measuring their behavior under accident conditions. The components of this system are described in detail by Linderoth $(16)$. The containment vessel as arranged for the air cleaning tests is shown in Figure 2.

The containment vessel is composed of three interconnected vessels. An outer vessel, called the main containment vessel, 30,680 $\mathrm{ft}^{3}$, an inner vessel, called the drywe11, $2286 \mathrm{ft}^{3}$, and a vessel composing two-thirds of the annular space between the drywell and the main containment vessel, called the wetwel1, $4207 \mathrm{ft}^{3}$. The main containment vessel is $25 \mathrm{ft}$ in diameter, and $66.7 \mathrm{ft}$ in overall height. All interior surfaces are coated with a modified phenolic paint, Phenoline $302^{*}$.

The top of the wetwell forms a solid deck which effectively separates the contained gases into what is termed the "main room" above the deck and the lower rooms below the deck. For the filter loop experiments discussed here, the 1id of the 11-ft diameter drywell was raised so that its volume was common to the main room. The combined volume of this "main room" is $21,005 \mathrm{ft}^{3}$. One-third of the annular space between the drywell and main containment vessel is a small access area called the "middle room", 2089 $\mathrm{ft}^{3}$ in volume. Below the middle room, drywell, and wetwell is a third space called the "lower room", $3384 \mathrm{ft}^{3}$ in volume. The wetwell volumes were sealed off and not exposed to steam or fission product simulants in these experiments. Two 4-ft diameter holes in the deck connect the main room to the middle room; one $4 \mathrm{ft}$ diameter opening connects the middle room to the lower room.

Steam condensate accumulates in two places: the drywell pool and the main vessel pool located in the lower room. These pools were stirred and sampled.

*Manufactured by the Carboline Co., St. Louis, Missouri. 
BNWL- 1587

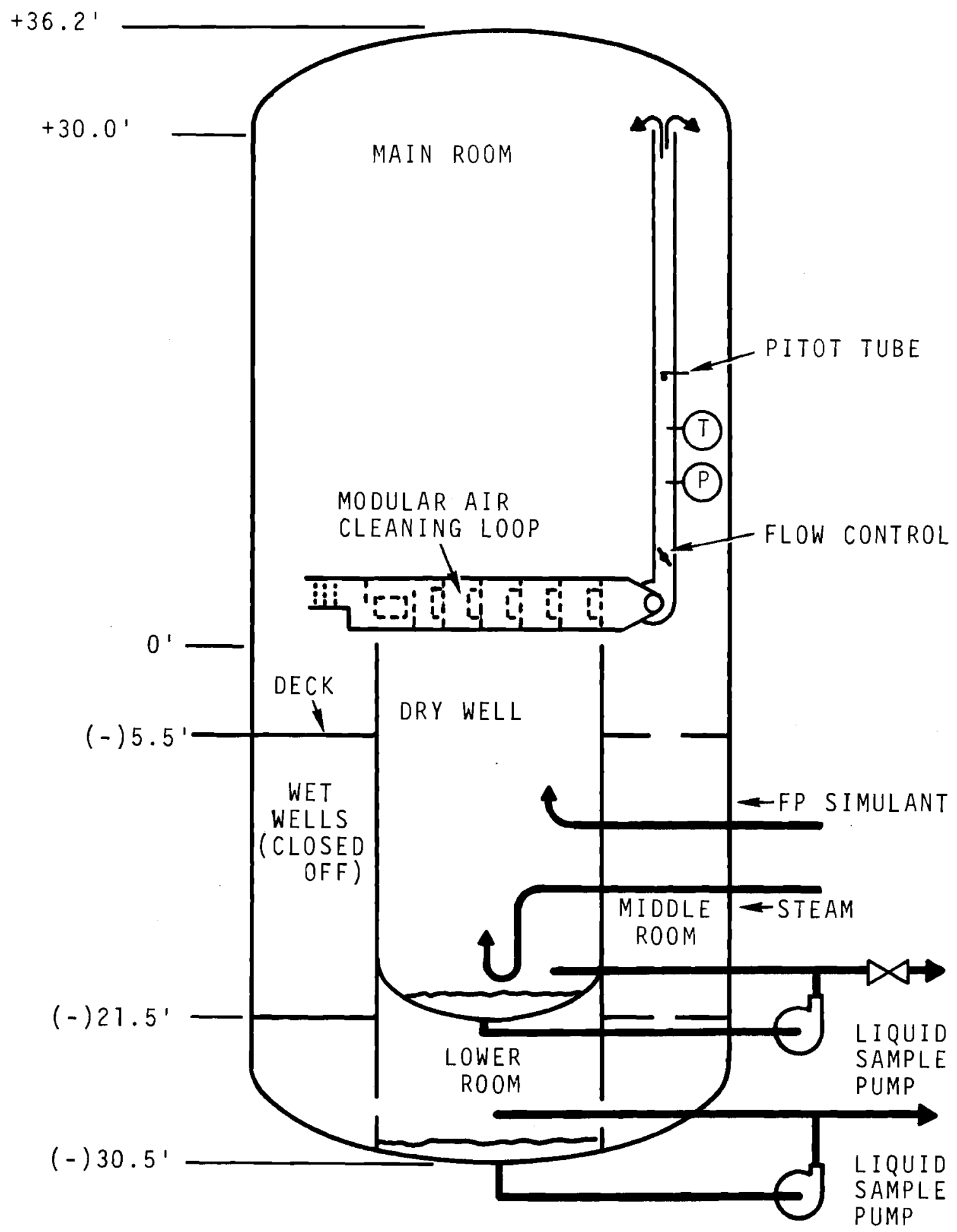
FIGURE 2. Equipment Arrangement Used in CSE Filter Loop
Tests 
A line from the plant steam boiler, terminated near the bottom of the drywe11, provides steam input to heat the vessel and its atmosphere.

Important physical data which apply to all filter loop tests are listed in Table 1.

TABLE 1. Physical Conditions Common To All Filter Loop Experiments

Volume above deck including Drywell

Surface area above deck including Drywel1

$$
21,005 \mathrm{ft}^{3}
$$

$595 \mathrm{~m}^{3}$

Surface area/volume $6,140 \mathrm{ft}^{2} \quad 569 \mathrm{~m}^{2}$

Cross section area, main vessel $0.293 \mathrm{ft}^{-1}$ $0.958 \mathrm{~m}^{-1}$

cross section area, drywell $490 \mathrm{ft}^{-1} \quad 45.5 \mathrm{~m}^{2}$

Volume, middle room $95 \mathrm{ft}^{2}$ $8.8 \mathrm{~m}^{2}$

Surface area, middle room $2,089 \mathrm{ft}^{3} \quad 59 \mathrm{~m}^{3}$

Volume, lower room

Surface area, lower room $1,363 \mathrm{ft}^{2} \quad 127 \mathrm{~m}^{2}$

Total volume of all rooms

Total surface area, all rooms $3,384 \mathrm{ft}^{3} \quad 96 \mathrm{~m}^{3}$ $2,057 \mathrm{ft}^{2} \quad 191 \mathrm{~m}^{2}$

Loop intake centerline elevation Loop stack discharge elevation $26,477 \mathrm{ft}^{3} \quad 751 \mathrm{~m}^{3}$ $9,560 \mathrm{ft}^{2} \quad 888 \mathrm{~m}^{2}$

Thermal Insulation

$$
\begin{array}{rl}
1.3 \mathrm{ft} & 0.4 \mathrm{~m} \\
30 \mathrm{ft} & 9.4 \mathrm{~m}
\end{array}
$$

All exterior surfaces covered with 1 in. fiberglass insulation $(a)$

(a) $k=0.027 \mathrm{Btu} /(\mathrm{hr})\left(\mathrm{ft}^{2}\right)\left({ }^{\circ} \mathrm{F} / \mathrm{ft}\right)$ at $200^{\circ} \mathrm{F}$, Type PF-615, Owens-Corning Fiberglass Corp.

\section{FILTER LOOP}

The filter loop was made of modular units. Each component was located within a $3 \mathrm{ft}$ diameter stainless steel cylindrical shell. The steel cylinders were connected together by flanges. The loop was instrumented to provide measurements of air flow rate, temperature, and fission product removal efficiency. The instrumentation arrangement used in the loop as assembled for Run A-15 is shown in Figure 3. 


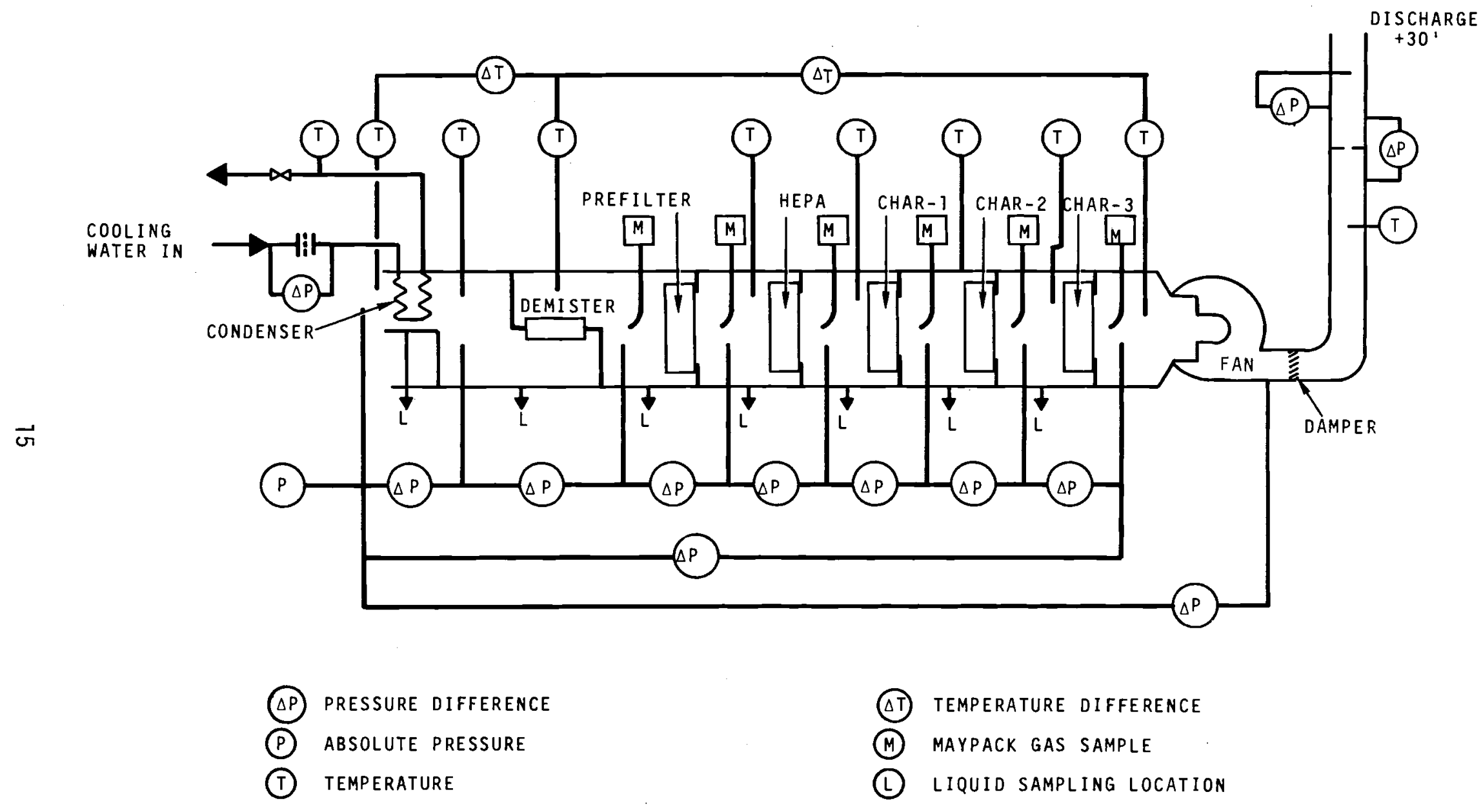

FIGURE 3. Schematic Diagram of Filter Loop Instrumentation 
Pressure difference across each component and across the entire loop was measured to show changes in flow resistance with time. Loop flow was measured using both a calibrated orifice and a pitot tube installed in the discharge duct. A small flow of compressed air was used to ensure that no water condensed in the sensor lines. Absolute pressure was measured to permit evaluation of the thermodynamic state of the contained gas.

Temperature was measured upstream and downstream from each of the loop components. The temperature and flow rate of cooling water fed to the condenser was measured to evaluate the heat removal.

Liquid sampling stations were installed downstream from each component of the loop to ensure that all liquid effluents were accounted for.

Gas samples were withdrawn downstream from each of the loop components. Each sample collector was a Maypack sampling train. Six Maypack gas samples were installed at each location to permit sample withdrawal at 5 times. The remaining sampler was used as a blank to help assess background contamination. A view of the interstage samplers is shown in Figure 4 . The samples were all withdrawn from near the center of the loop. One of the pleated charcoal beds is visible behind the sample probes.

The loop components were selected to be typical of those used in power reactor containment systems. Existing and planned reactors include some or all of the following components.

- heat exchanger

- moisture separator

- prefilter

- high efficiency particulate air filter (HEPA filter)

- activated charcoal beds

The CSE loop used nominal $2 \mathrm{ft} \times 2 \mathrm{ft}$ commercially available components, operating at the design flow of $1000 \mathrm{cfm}$. At $1000 \mathrm{cfm}$, the air in the main room of the CSE vessel is turned over about 2.8 times per hour. This is within the range used in PWR containment vessels.

The heat exchanger used in the CSE tests was constructed with finned copper tubes. The fins were 0.75 inches high, with a 0.25 inch spacing 


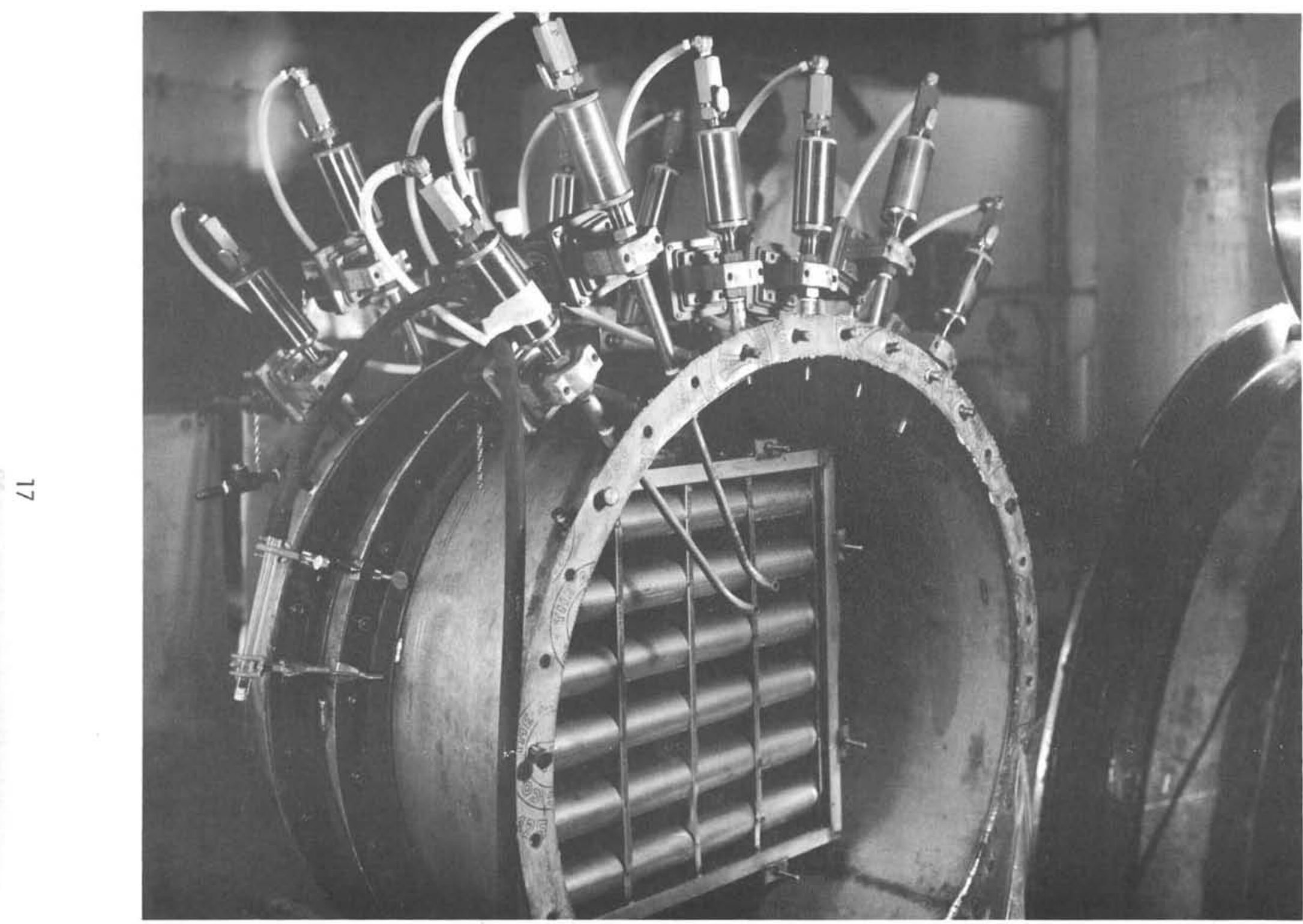

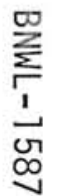

PNL 0692689-4

FIGURE 4. View of a Loop Module Showing Interstage Samplers and Charcoal Filter 
along a 1 inch tube. Six tubes made three passes per unit, and two of these units were arranged in series. The face area was $4.1 \mathrm{ft}^{2}$. A concurrent flow of water was adjusted to provide a temperature drop of $2-3^{\circ} \mathrm{F}$ in the flowing gas stream. Under typical conditions, heat removal was $3000 \mathrm{Btu} / \mathrm{min}$.

The moisture separator was made from stainless steel and Teflon fibers*. It was $2 \mathrm{in.} \mathrm{thick.} \mathrm{For} 1000 \mathrm{cfm}$, an $18 \mathrm{in}$. diameter pad was installed horizontally so that airflow was upward. A $2 \mathrm{ft}$ square pad was installed vertically for the higher airflow test $(1800 \mathrm{cfm})$. Water draining from the moisture separator was sampled.

A prefilter**, designed to protect the HEPA filter from mechanical damage and needless loadings of lint and dust, was installed downstream from the moisture separator. This filter was $2 \mathrm{ft} \times 2 \mathrm{ft}$, and made from expanded aluminum sheet. It was 2 in. in thickness.

The high efficiency particle filter was purchased from specifications given by Burchsted and Fuller ${ }^{(8)}$. This filter had a water-proof glass fiber medium, a cadmium plated steel frame, aluminum separators, and neoprene bond and gaskets. All filters used were tested for pressure drop and particle retention by the USAEC Western Quality Assurance Station after arrival on site.

Pleated charcoal beds were purchased from specifications similar to those listed by Burchsted and Fuller ${ }^{(8)}$. The units obtained ${ }^{+\dagger}$ were loaded with 50 1b of 8-16 Tyler mesh charcoal. The charcoal was impregnated with $5 \%$ iodine.

The loop as assembled within the containment vessel just prior to a test is shown in Figure 5. Figure 6 shows the 1oop as seen through the access door on the containment vessel.

* Type 321-SR Demister, 0tto H. York Company, New York, N. Y. ** Type BAA-45, American Air Filter Corp., Louisville, Ky. + Type A24J6R2. American Air Filter Corp., Louisville, Ky. t+ Type FE, with BC-727 charcoal, Barneby Cheney Company, Columbus, Ohio. 


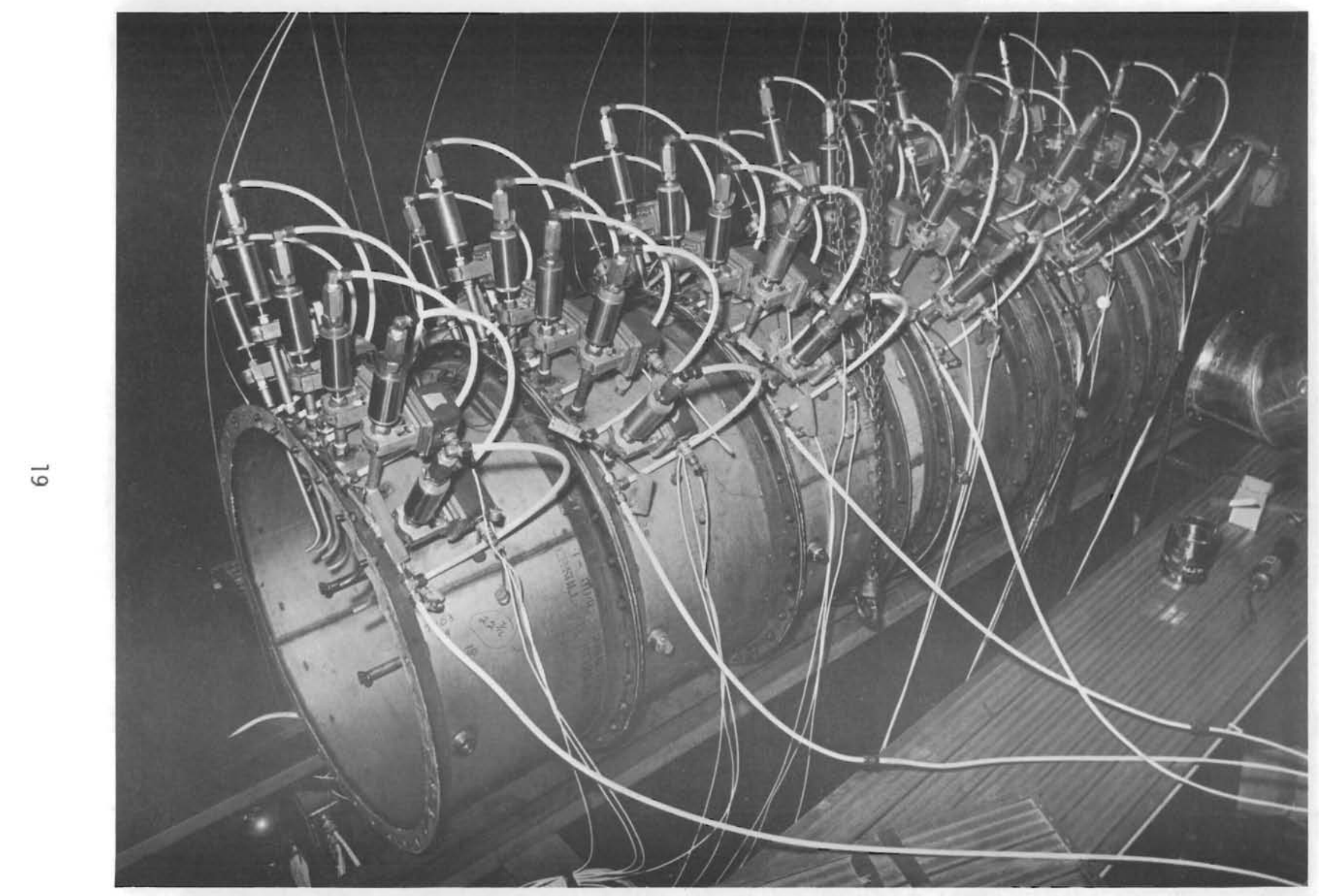

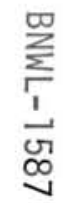

PNL 0693288-5

FIGURE 5. Air Cleaning Loop Assembled in CSE Vessel 


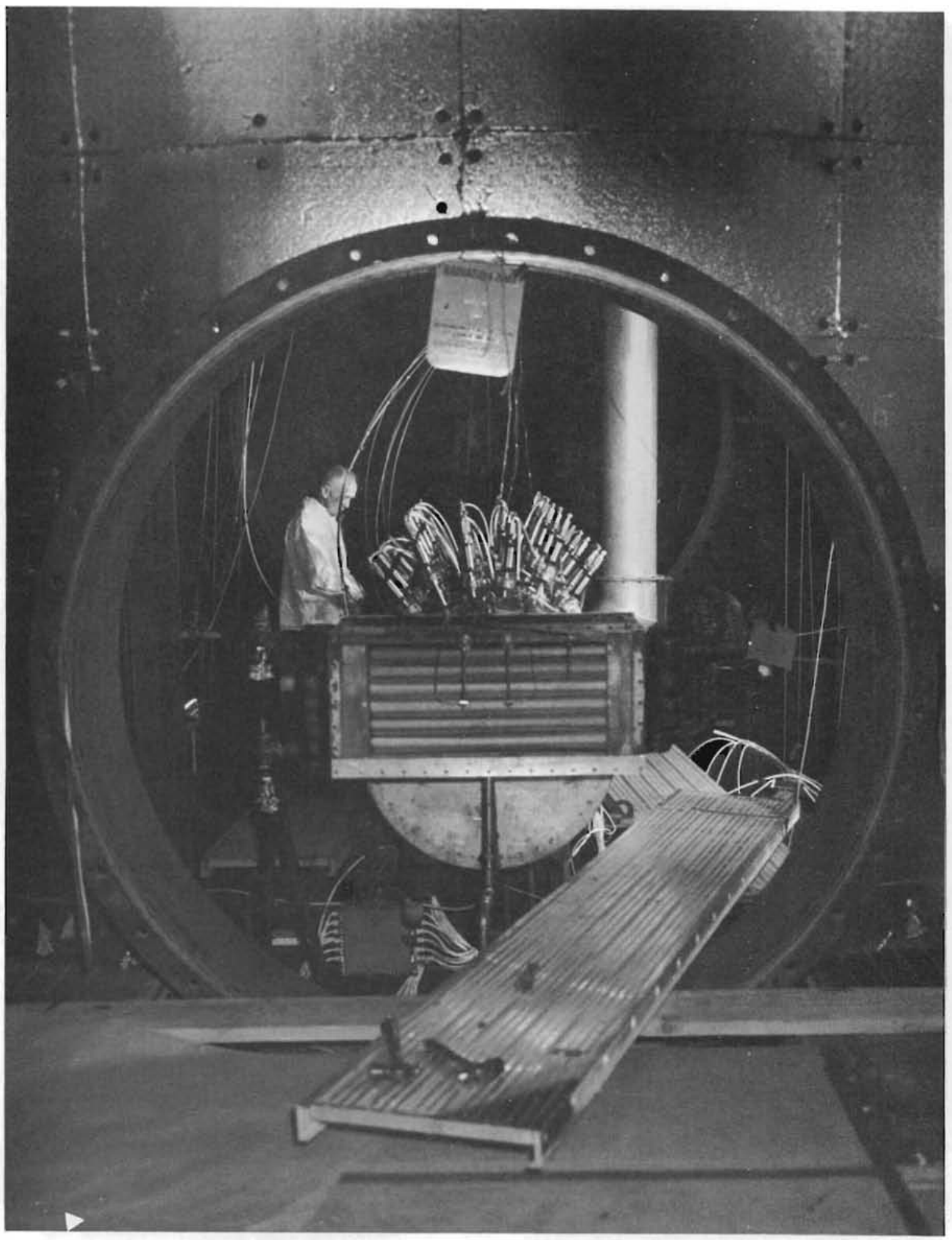

PNL 0694495-5

FIGURE 6. Air Cleaning Loop in CSE Vessel 


\section{GAS PHASE SAMPLING}

The airborne concentration of iodine, cesium, and uranium was measured using Maypack samplers. Twelve individual Maypack samplers were clustered together and placed at selected positions in the containment vesse1. Eleven of the twelve samplers within each cluster were used to obtain samples at 11 discrete time periods. The remaining sampler was retained as a blank to assess background contamination levels. The 10 cluster locations used in the filter loop tests are shown in Figure 7.

In addition to the cluster samples, "thief" samples were obtained by inserting individual Maypack samplers into the vessel atmosphere through an airlock. These thief samples provided independent data for conditions where background contamination was very low.

The Maypack sampler is designed to characterize airborne iodine according to its chemical identity. It is composed of several adsorbents in series, as depicted in Figure 8. Briefly stated, the iodine distributes within the sampler as follows. Particles are captured by the inlet filter. Elemental iodine deposits on the silver components which follow the particulate filter. Heavy organic iodides, and perhaps HOI, deposit on the charcoal impregnated filter paper. Methyl iodide is retained within the charcoal granule bed. This idealized deposition sequence is not fully achieved in practice. A small part of elemental iodine is retained by the inlet filter. Also, a small fraction of the methyl iodide is retained by the adsorbants upstream from the charcoal beds. In addition, the disposition of HOI within the Maypack has not been studied. Although the CSE Maypack is not a perfect sampling tool, it has been highly useful in the CSE program. McCormack ${ }^{(17)}$ has given a detailed analysis of the design rationale and performance of this sampler.

Airborne particles were collected with a cascade impactor which had been preheated and then inserted into the vessel atmosphere. As Postma ${ }^{(4)}$ has noted, the process of sampling by this technique may cause droplet evaporation and thereby alter the particle size. 

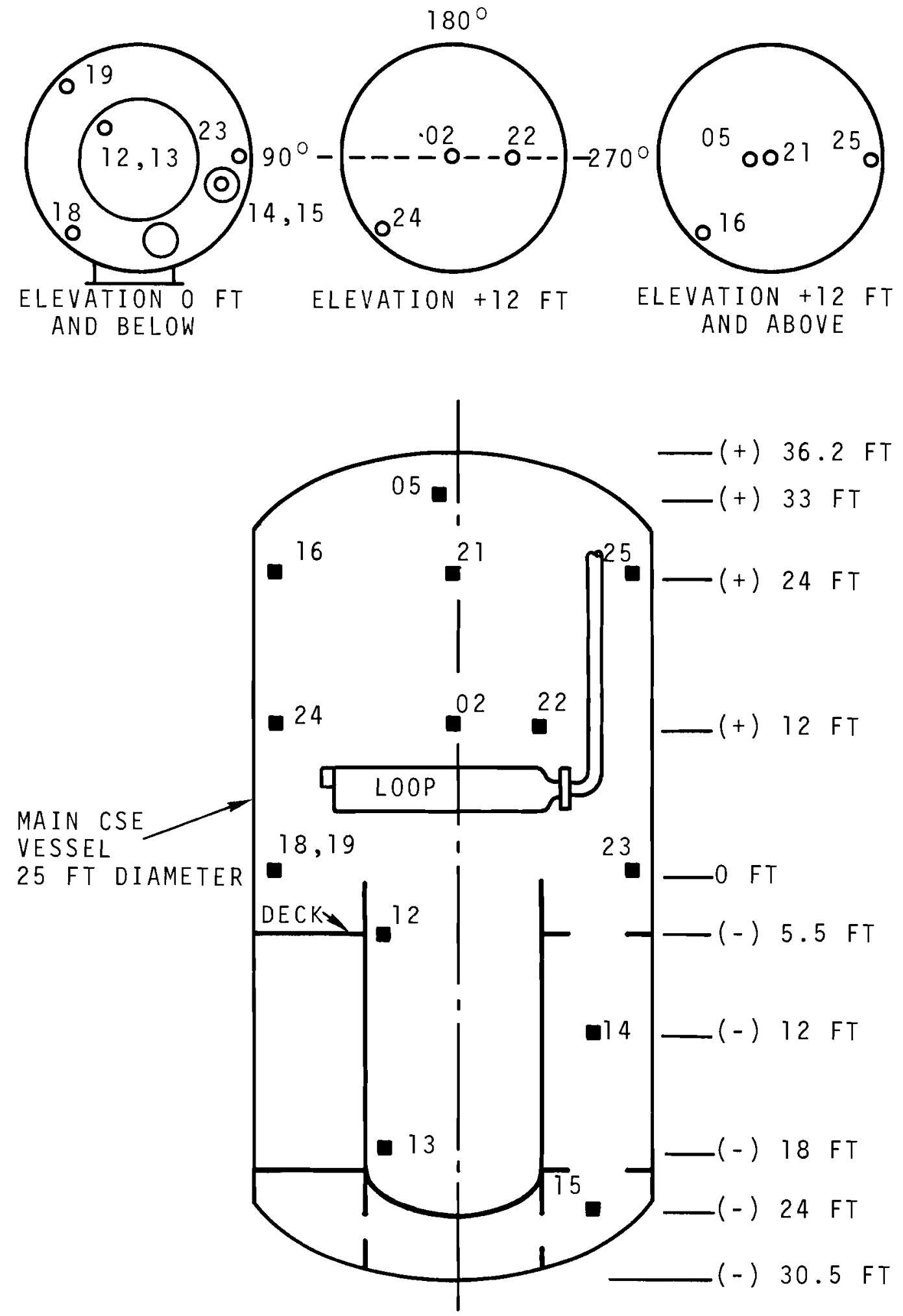

FIGURE 7. Location of Maypack Clusters in CSE Filter Loop Tests 


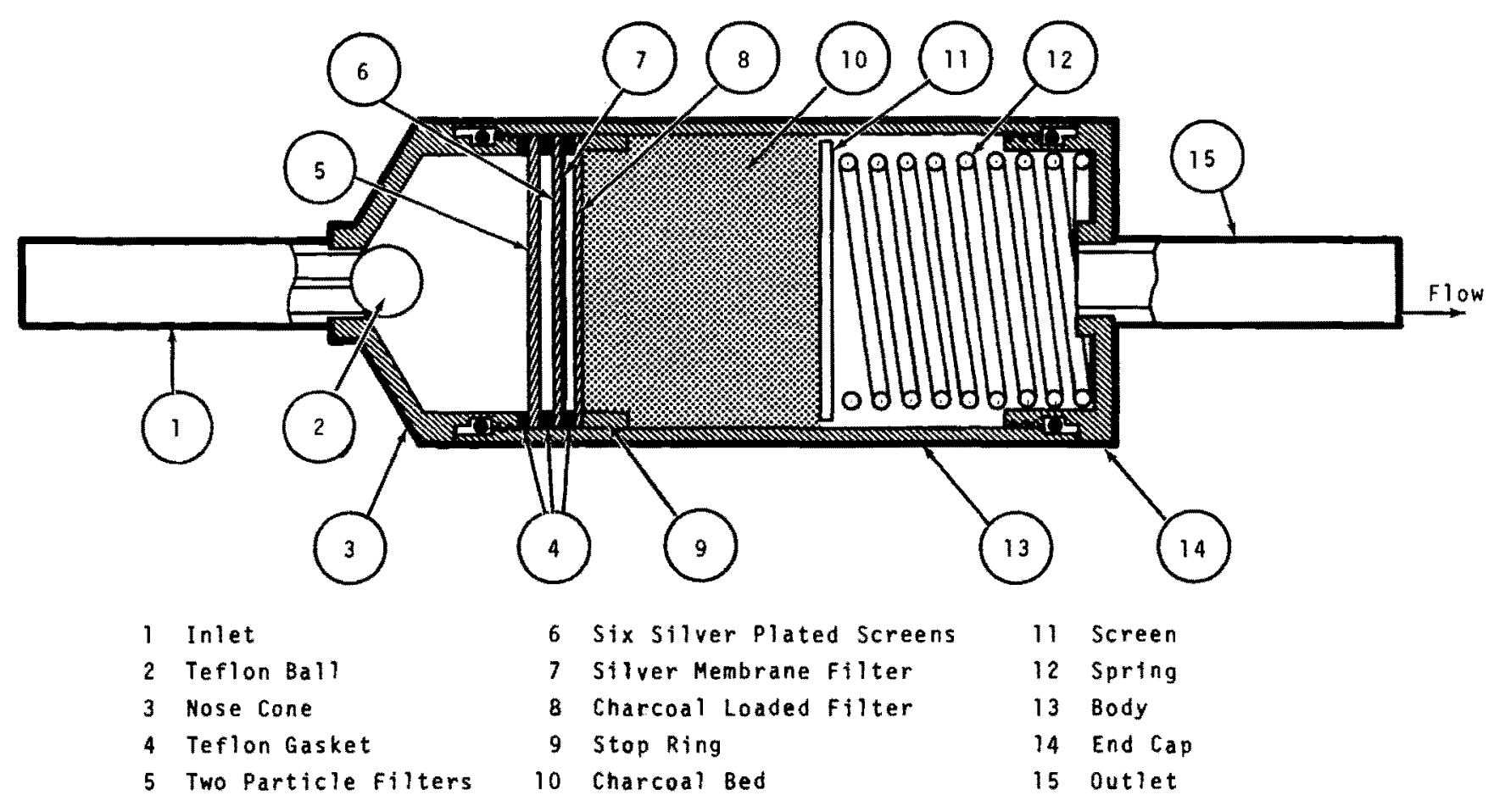


BNWL-1587

\section{LIQUID PHASE SAMPLING}

Sample delivery lines were installed to allow periodic sampling of the drywell sump, the main vessel sump, wall condensate, condensate formed within the loop heat exchanger, and the liquid removed by the mist eliminator. A11 liquid, except that in the drywell sump, eventually was combined in the main vessel sump. Condensed moisture from between loop sections was sampled during loop disassembly after completion of a test run. GENERATION OF FISSION PRODUCT SIMULANTS

Coleman ${ }^{(18)}$ has described the method of generating the fission product simulant in detail. Four materials were released in these tests to permit mass transfer measurements. They were: elemental iodine, methy 1 iodide, cesium, and particles formed by melting unirradiated Zircaloy-clad $\mathrm{UO}_{2}$. Stable elemental iodine was equilibrated with ${ }^{131}$ I as described by Coleman ${ }^{(18)}$, and when release was desired, the flask containing the iodine was heated electricaliy and air swept through the flask. This carried the elemental iodine through the hot zone of the $\mathrm{UO}_{2}$ melting furnace. Some particulate associated iodine and organic iodides were always produced. Methy 1 iodide was in addition purposely added through a separate line not connected to the $\mathrm{UO}_{2}$ furnace.

Stable cesium was equilibrated with ${ }^{137} \mathrm{Cs}$ as $\mathrm{CsCO}_{3}$ in a nickel boat and dried at $<400{ }^{\circ} \mathrm{C}$. When release was desired, the boat was heated inductively to $\sim 1200^{\circ} \mathrm{C}$ with an air stream carrying the volatized cesium and cesium oxide through the $\mathrm{UO}_{2}$ furnace into the containment vessel.

A steam jet located in the drywe11 served as a compressor for injecting the volatilized simulant into the pressurized vessel. The injection line was a nominal $2 \mathrm{in}$. stainless steel pipe, electrically heated to $150^{\circ} \mathrm{C}$.

The suitability of the fission product simulant generated by these methods to represent actual fission products in the containment environment was demonstrated by small scale tests in the Aerosol Development Facility $(A D F)^{(19)}$. Roberts, et. a). ${ }^{(20)}$ at Oak Ridge National Laboratory completed an extended study of the suitability of the CSE simulant with the conclusion that the use of this simulant is warranted. 
Two types of aerosol releases were used: a short term "puff" release, and a longer "linear" release. The puff release simplifies the fission product generation equipment and the mathematical models of removal. The longer linear release provides higher aerosol concentrations of cesium and uranium to be attained and permits evaluation of the source term in the removal model.

Iodine concentrations, based on the released iodine, of $160 \mathrm{mg} / \mathrm{m}^{3}$ were used in all filter loop tests. Maximum airborne concentrations were about $100 \mathrm{mg} / \mathrm{m}^{3}$. The release concentration corresponds closely to those predicted for hypothetical "design basis accidents" in pressurized water reactors. Methyl iodide equal in mass to about $5 \%$ of the total iodine was released. Cesium and uranium aerosol concentrations were appreciably lower than predicted for the DBA.

EXPERIMENTAL TEST SEQUENCE

The work sequence for all filter loop tests was substantially as follows.

1. The loop was loaded with new components (Demister was re-used).

2. The loop was tested for leaks and components were tested for penetration of methyl iodide and DOP aerosol.

3. Maypack samplers were installed in the containment vessel.

4. The containment vessel was leak tested.

5. The containment vessel was brought to operating temperature with boiler house steam.

6. Fission product simulants were released.

7. Sampling of gas and liquids was begun.

8. Filter loop blower was turned on.

9. The test run was carried out as per run plan.

10. Steam was shut off and vessel allowed to cool.

11. Loop flow was stopped.

12. Loop components tested for DOP aerosol penetration.

13. Gas and liquid samples with in containment vessel were recovered.

14. Loop was disassembled and components removed for sampling.

15. Containment vessel and loop housing was decontaminated by additional steaming. 
In four of the five tests, the loop was started 30 to 40 minutes after completion of the fission product release. This delay allowed measurement of airborne removal due to surface deposition. This is essential for assessing the removal by the loop alone. In Run A-16, an extended linear release was used. This prevented measurement of the rate of fission product removal by natural processes.

The test runs typically lasted for two days--one day at steady temperature and pressure, and one day of decreasing temperature and pressure. The loop flow noted was kept constant for the whole run by manually adjusting the flow control damper. 


\section{EXPERIMENTAL RESULTS}

\section{NUMERICAL VALUES OF TEST PARAMETERS}

The five filter loop tests completed in CSE covered a range of conditions and component arrangements. These are described in Table 2.

\section{TABLE 2. Summary of Air Cleaning Run Conditions}

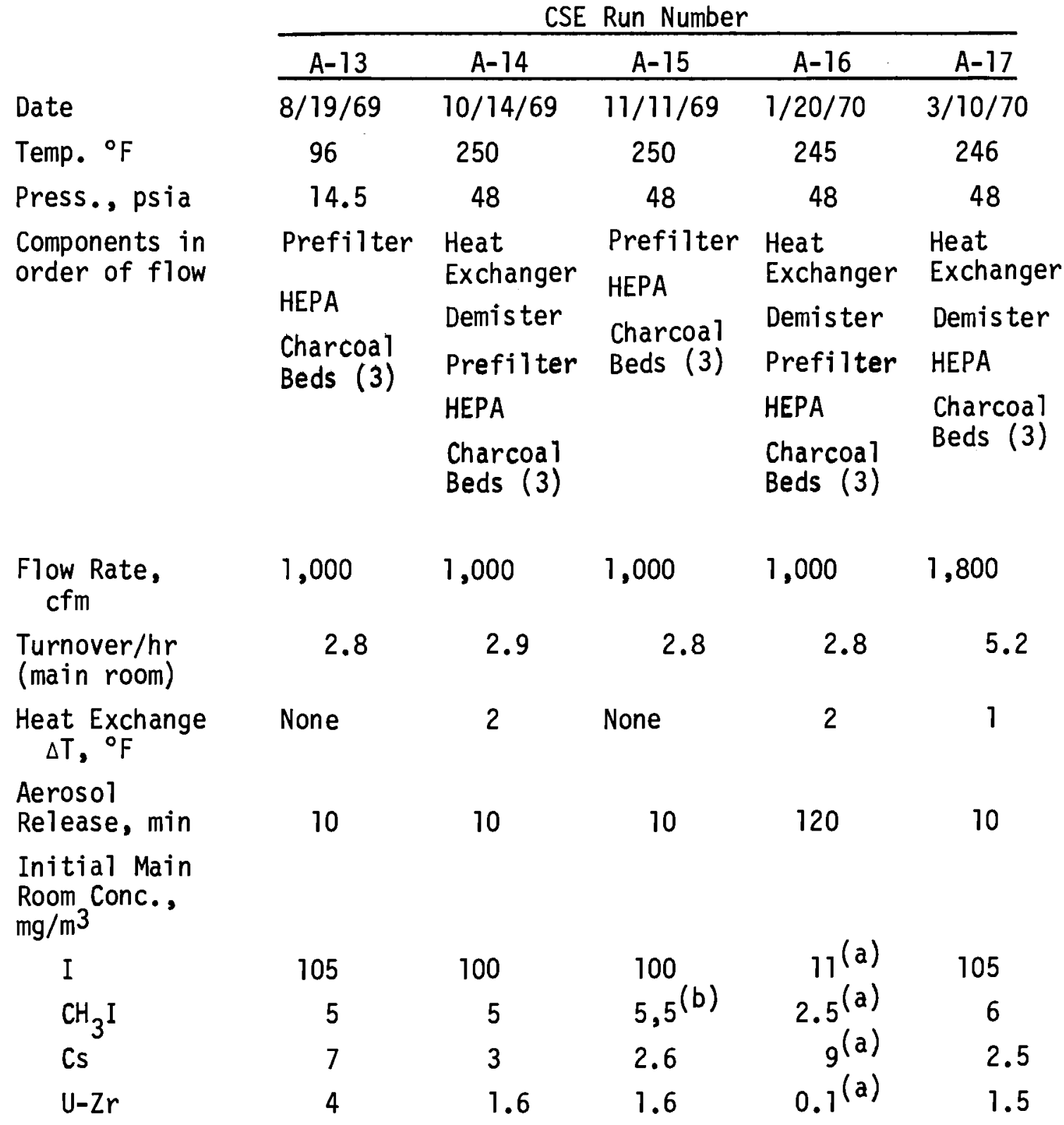

(a) Max. Conc. reached. Loop operated during release.

(b) Two methyl iodide releases were made. 
BNWL-1587

\section{REMOVAL OF AIRBORNE FISSION PRODUCT SIMULANTS}

The purpose of a filter loop system is to remove fission products which might become airborne as a result of hypothetical accidents. Thus the most important measurements made in the CSE experiments involved the rate of decrease in gas phase concentration of the several fission product forms as a result of loop operation. In this section of the report, the observed rates at which airborne fission products were removed will be summarized. The measured removal rates will be compared to theory in the discussion section of this report.

Iodine

Airborne iodine was assayed by Maypack samples withdrawn at 8 locations in the main room of the containment vessel, and from samplers suspended in the other two connected containment volumes. A typical time-concentration history is presented in Figure 9. These data are for Run A-17, which used a loop flow rate of $1800 \mathrm{cfm}$. Several features of this plot are important and typical of other runs. These will be briefly noted.

The airborne concentration attains a maximum at the end of the fission product generation period. The concentration of elemental iodine then decreases due to wall deposition, prior to loop operation. Methyl iodide is removed only very slowly by wall deposition, as expected. $(3,4,5)$ when the loop fan is turned on, both elemental iodine and methyl iodide are rapidly removed. Elemental iodine is removed more rapidly than methyl iodide due to wall deposition and due to the fact that the removal efficiency for methyl iodide is appreciably less than 100\%. After the airborne concentration is reduced to about $1 \%$ of the initial concentration, the removal rate decreases. This decrease in removal rate is presumably due to a source term caused by desorption of iodine from containment surfaces.

The removal of airborne iodine is summarized in Table 3. 
BNWL-1587

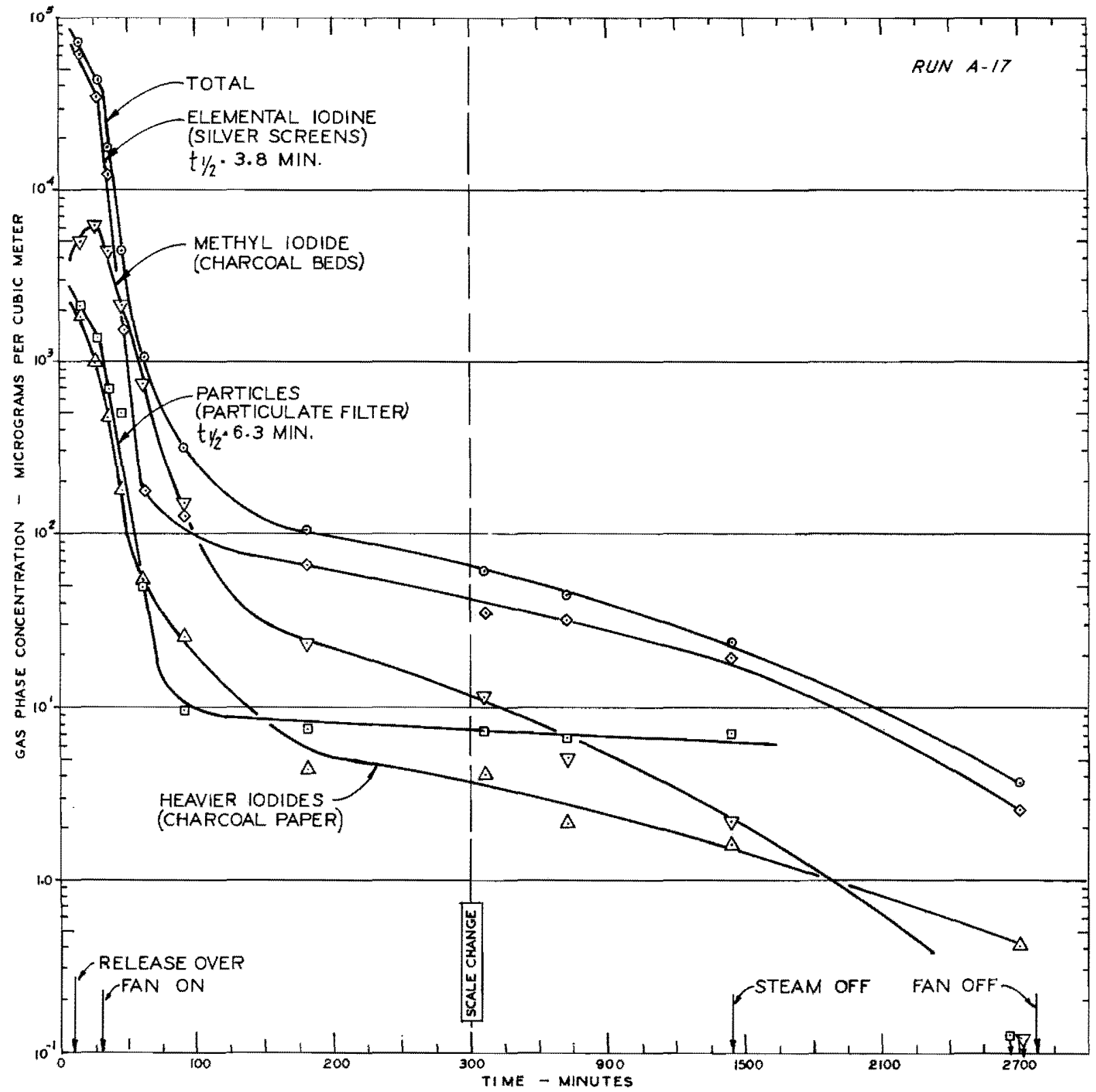

FIGURE 9. Iodine Concentrations in the Main Room Gas Space in CSE Run A-17 
TABLE 3. Early Removal Half-Times for Airborne Iodine In Filter Loop Experiments

\begin{tabular}{|c|c|c|c|c|c|c|c|c|c|c|c|c|c|c|c|}
\hline CSE Run No. & \multirow{2}{*}{\multicolumn{3}{|c|}{$\begin{array}{l}A-13 \\
1000 \\
\end{array}$}} & \multirow{2}{*}{\multicolumn{3}{|c|}{$\begin{array}{l}A-14 \\
1000 \\
\end{array}$}} & \multirow{2}{*}{\multicolumn{3}{|c|}{$\begin{array}{l}A-15 \\
1000 \\
\end{array}$}} & \multirow{2}{*}{\multicolumn{3}{|c|}{$\begin{array}{l}A-16 \\
1000 \\
\end{array}$}} & \multirow{2}{*}{\multicolumn{3}{|c|}{$\begin{array}{r}\text { A-17 } \\
1820 \\
\end{array}$}} \\
\hline \multirow[t]{2}{*}{ Loop Flow Rate, cfm } & & & & & & & & & & & & & & & \\
\hline & $\underline{N}$ & $\mathrm{~N}+\mathrm{L}$ & $\underline{L}$ & $\underline{N}$ & $\mathrm{~N}+\mathrm{L}$ & $\underline{L}$ & $\underline{\mathrm{N}}$ & $\mathrm{N}+\mathrm{L}$ & $\mathrm{L}$ & $N$ & $\mathrm{~N}+\mathrm{L}$ & $L$ & $\underline{\mathrm{N}}$ & $\mathrm{N}+\mathrm{L}$ & $L$ \\
\hline Elemental Iodine & 26 & 7.3 & 10.1 & 16 & 4.9 & 7.1 & 27 & 6.0 & 7.7 & 15 & 7.3 & 14.3 & 13 & 3.8 & 5.4 \\
\hline Particulate I & 50 & 11.0 & 74.1 & 27 & 9.0 & 13.5 & 27 & 10.3 & 16.7 & 36 & 15.0 & 25.7 & 25 & 6.3 & 8.7 \\
\hline AC Paper Form & 50 & 16.0 & 21.0 & $39^{(a)}$ & 9.0 & 11.8 & 58 & 10.0 & 12.5 & 39 & 13.7 & 14.2 & 20 & 7.7 & 12.5 \\
\hline Methyl Iodide & long & 15.0 & 15 & long & 14.3 & $14.3^{(c)}$ & long & $\begin{array}{l}14.7 \\
19.0\end{array}$ & $\begin{array}{l}14.7^{(\mathrm{c})} \\
19.0^{(\mathrm{b})}\end{array}$ & long & 16.0 & 16.0 & long & 11.0 & $11^{(b)}$ \\
\hline
\end{tabular}

$\mathrm{N}=$ Natural, $\mathrm{L}=$ Loop Only

(a) Natural t]/2 not measured this run. Value given is avg. of 8 CSE runs under similar conditions.

(b) Bed equilibrated with $100 \%$ relative humidity air.

(c) "Ory" bed.

A measure of the degree to which iodine was removed may be obtained by comparing the iodine airborne at the end of the test to that initially released. The decontamination factor measured for each of the filter loop tests is given in Table 4 .

TABLE 4. Iodine Decontamination Factors
Achieved in Filter Loop Tests

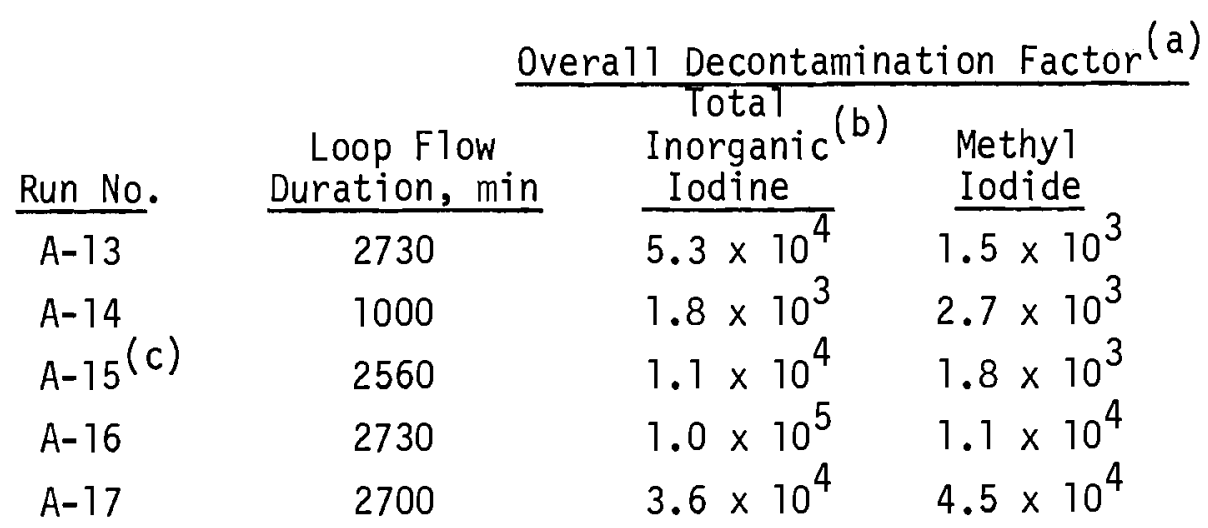

(a) Overall decontamination factor $=\frac{\text { Mass of Iodine Released to Containment }}{\text { Mass of Iodine Airborne at Run Termination }}$

(b) Total inorganic iodine defined as total iodine minus methyl iodide.

(c) In Run A-15, methyl iodide was released at $t=0$ and at $t=1350$ min. 
The decontamination factors achieved in a 11 runs are large, showing that gas cleanup by the loop is effective. Methy 1 iodide was removed to a slightly lesser extent than total inorganic iodine in 3 of the 5 runs. Although the observed decontamination factors are large, they are much smaller than would be predicted if the initial removal rate had continued for the whole run duration. The numerical value of the two hour dose reduction factor depends only on the initial removal rate. For times longer than about 24 hours, the slower removal rate observed at low concentrations would reduce the dose reduction factor calculated on the basis of the initial exponential removal.

Gas phase concentrations of iodine in the main room of the CSE vesse1 are shown in Figures $A-1$ through $A-5$ in the Appendix to this report.

Samples withdrawn from the connected containment volumes permitted the concentration to be determined for these rooms. Typical results are shown in Figure 10, where the iodine concentration in the middle room in Run $A-14$ is presented. The airborne concentrations increase rapidly following fission product injection into the main room, and attain a maximum at about 120 minutes. They then fall off with the main room concentration. These results are typical of those obtained in a11 CSE experiments, hence we will not list the data in detail. Cesium and Uranium Aerosols

Cesium and uranium aerosols were removed by the loop with essentially a $100 \%$ efficiency. These materials, as aerosol particles, were also removed by wall deposition and gravitational settling. A typical airborne depletion curve is shown in Figure 11. Both cesium and uranium are removed at about the same rate after the loop is turned on. This rate is similar to the removal rate for iodine. At long times, the removal rates decrease. This net decrease in removal rate is explained in terms of small sources. Aerosol particle could be formed, for example, by breaking of bubbles in the sumps.

The observed removal rates for cesium and uranium aerosols are summarized in Table 5 . 


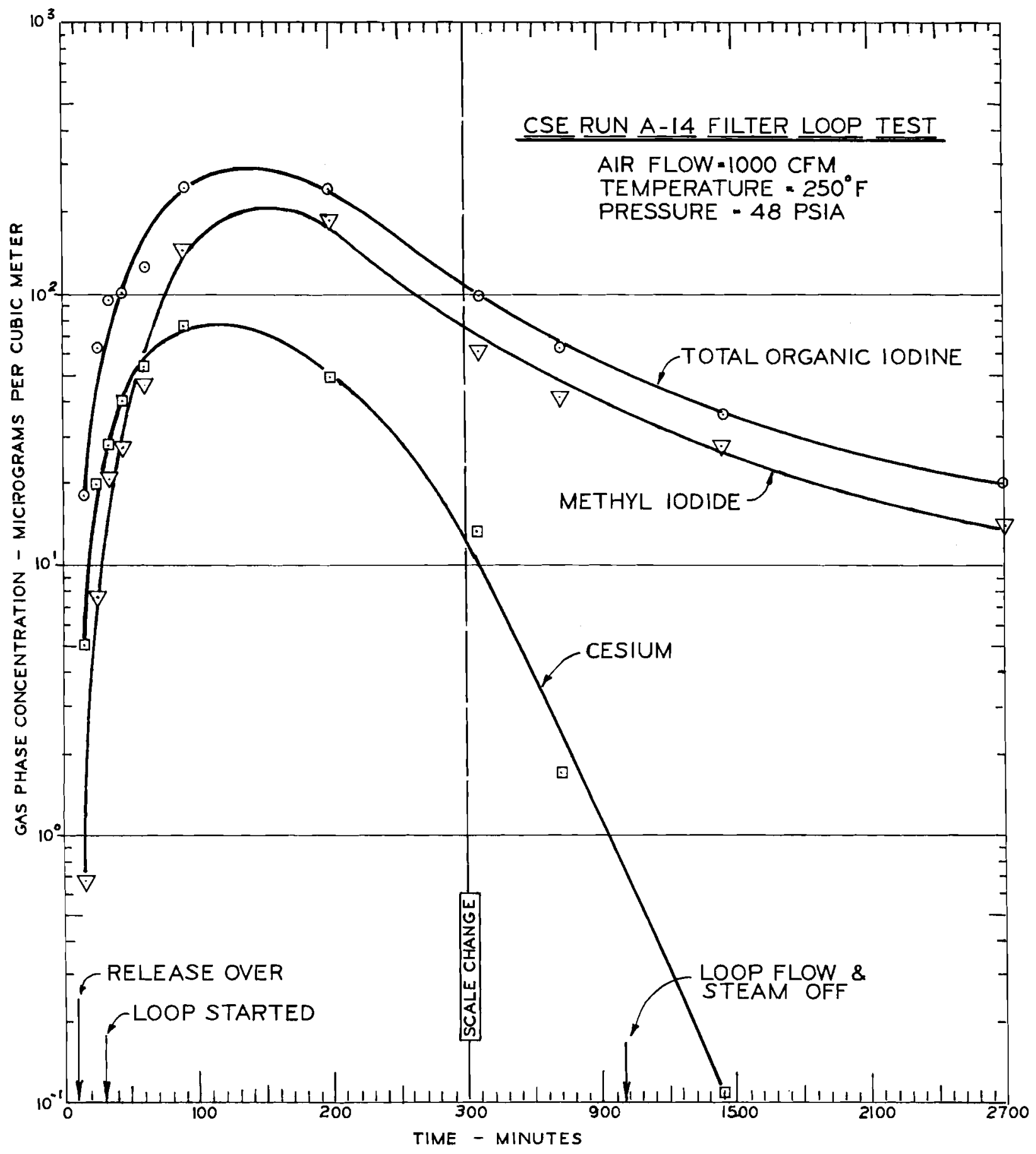

FIGURE 10. Concentration of Airborne Fission Products in the Middle Room of the CSE Vessel 


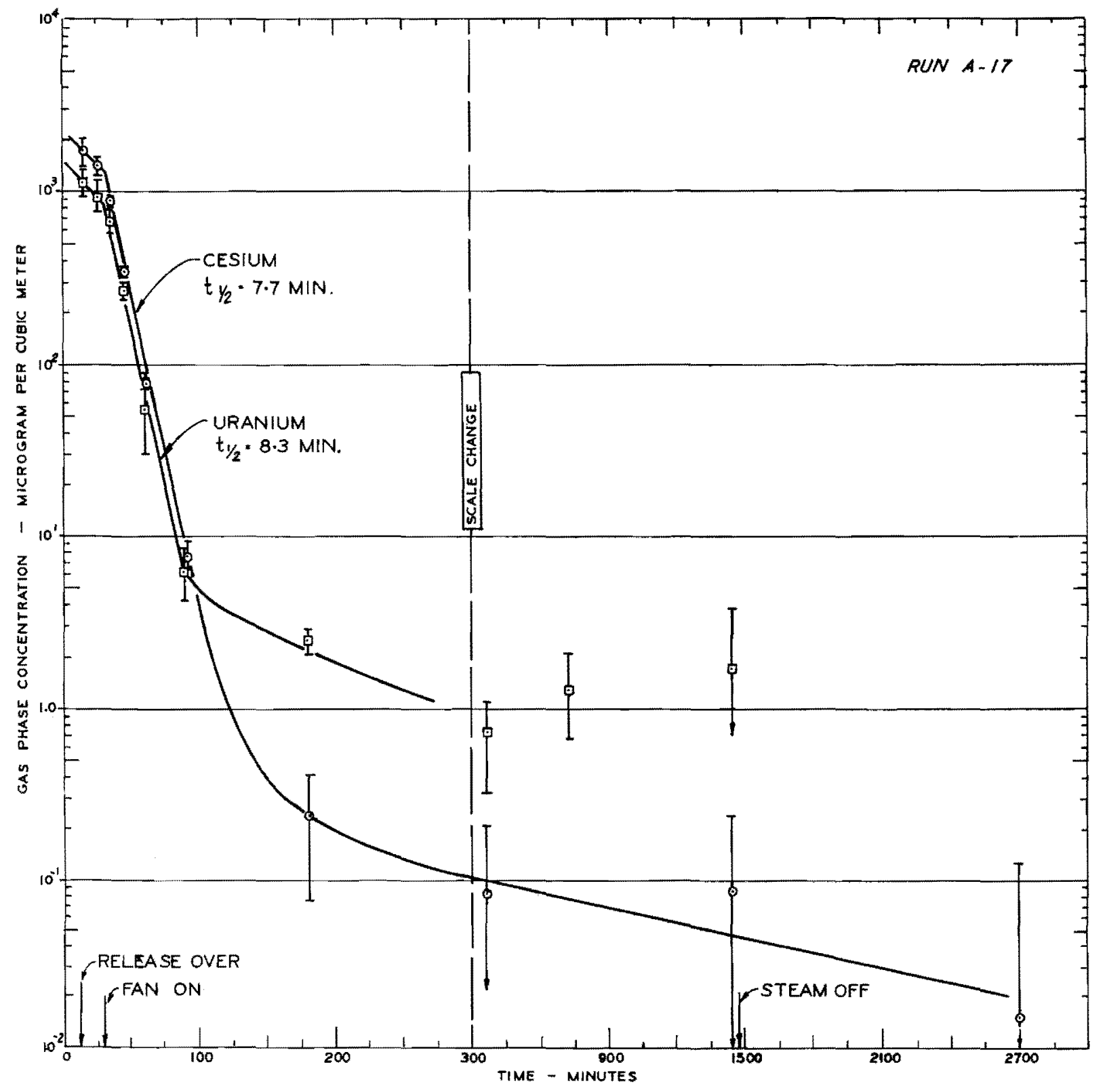

FIGURE 11. Cesium and Uranium Concentrations in the Main Room Gas Space in CSE Run A-17 
TABLE 5. Early Removal Half-Times for Cesium and Uranium in Filter Loop Experiments

\begin{tabular}{|c|c|c|c|c|c|c|c|c|c|c|c|c|c|c|c|}
\hline \multicolumn{16}{|c|}{ Removal Half-Time, } \\
\hline CSE Run No. & & $A-13$ & & & 14 & & & $A-75$ & & & $A-16$ & & & $A-17$ & \\
\hline Loop Flow Rate, cfm & & 1000 & & & 00 & & & 1000 & & & 1000 & & & 1820 & \\
\hline & N & $\mathrm{N}+\mathrm{L}$ & $\mathrm{L}$ & $\mathrm{N}$ & $\mathrm{N}+\mathrm{L}$ & $\mathrm{L}$ & $\underline{N}$ & $\mathrm{~N}+\mathrm{L}$ & $\mathrm{L}$ & $\underline{N}$ & $\mathrm{~N}+\mathrm{L}$ & $L$ & N & $\mathrm{N}+\mathrm{L}$ & $\mathrm{L}$ \\
\hline Cesium & 62 & 11.0 & 13.7 & $42^{(a)}$ & 12.3 & 17.4 & 70 & 13.0 & 16.0 & 47 & 9.3 & 11.5 & 33 & 7.7 & 10.0 \\
\hline Uranium & 80 & 14.0 & 17.0 & 85 & 13.0 & 15.4 & 70 & 12.0 & 14.5 & 31 & 16.0 & 33.0 & 41 & 8.3 & 10.4 \\
\hline
\end{tabular}

$N=$ Natural, $L=$ Loop Only

(a) Natural t1/2 not measured this run. Value given is avg. of 8 CSE runs under similar conditions.

The long term removal of cesium particles is summarized in Table 6 .

TABLE 6. Decontamination Factors

Achieved in Filter Loop Tests

$\begin{array}{ccc}\text { Run No. } & \begin{array}{c}\text { Loop Flow } \\ \text { Duration, min }\end{array} & \begin{array}{c}\text { Overall } \\ \text { Decontamination } \\ \text { Factor a) }\end{array} \\ \text { A-13 } & 2730 & 1.3 \times 10^{5} \\ \text { A-14 } & 1000 & 1.5 \times 10^{5} \\ \text { A-15 } & 2560 & >2.7 \times 10^{4} \\ \text { A-16 } & 2730 & 2.0 \times 10^{5} \\ \text { A-17 } & 2700 & 1.6 \times 10^{5}\end{array}$

(a) Overall decontamination factor $=\frac{\text { mass released }}{\text { mass airborne at run termination }}$

These results show that aerosol particles are removed to a greater extent than gaseous iodine. This is reasonable because gaseous fission products can desorb from liquid solution, whereas particles can be resuspended only by mechanical disintegration processes. The lower analytical sensitivity for uranium prevented reliable detection of the fraction airborne at the termination of the tests, hence results for uranium aerosols could not be included in Table 6 . For the earlier part of each test, cesium and uranium were removed at comparable rates.

The time-concentration histories for cesium and uranium aerosols are shown in Figures A-6 through A-10 in the Appendix to this report. 


\section{FISSION PRODUCT DISTRIBUTION WITHIN CONTAINMENT COMPONENTS}

\section{Concentration in Liquid Condensate}

Liquid condensate formed in three places: the drywell sump, the containment vessel sump, and the heat exchanger. The drywell sump collected liquid formed by condensation on the vertical wall of the drywell vessel and liquid drops which fell from the surfaces above the drywell opening. The main vessel sump accumulated condensate formed on the outer walls of the vessel. The third place condensate formed was with in the heat exchanger which was incorporated as a loop component in several experiments. The condensate from the heat exchanger was allowed to drain into the main vessel sump.

Typical condensate concentrations for iodine are shown in Figure 12. These data show that the concentration in the heat exchanger condensate closely parallels the airborne iodine concentration. The drywell concentration peaks soon after iodine injection at a level about ten times higher than main vessel sump. This higher concentration results from absorption of iodine close to the injection point which is located within the drywell. Also, the volume of liquid which accumulates within the drywell is small compared to the liquid in the main sump. The concentration in both sumps decreases with time due to dilution. Similar behavior was observed for cesium. The liquid concentrations for the five filter loop tests are shown in detail in Figures A-11 through A-20 in the Appendix.

Liquid Volumes

The volumes of liquid were measured as a function of time. In the experiments in which the heat exchanger was used, the condensate flow rate was measured. Results of these measurements are shown in Figure 13 for Run A-17. The main vessel sump accumulates liquid at a constant rate until the steam is turned off. Since the condensate formed on the outer walls of the vessel drains to the main sump, the main sump volume accumulates most of the condensate. The heat exchanger condensate 
BNWL-1587

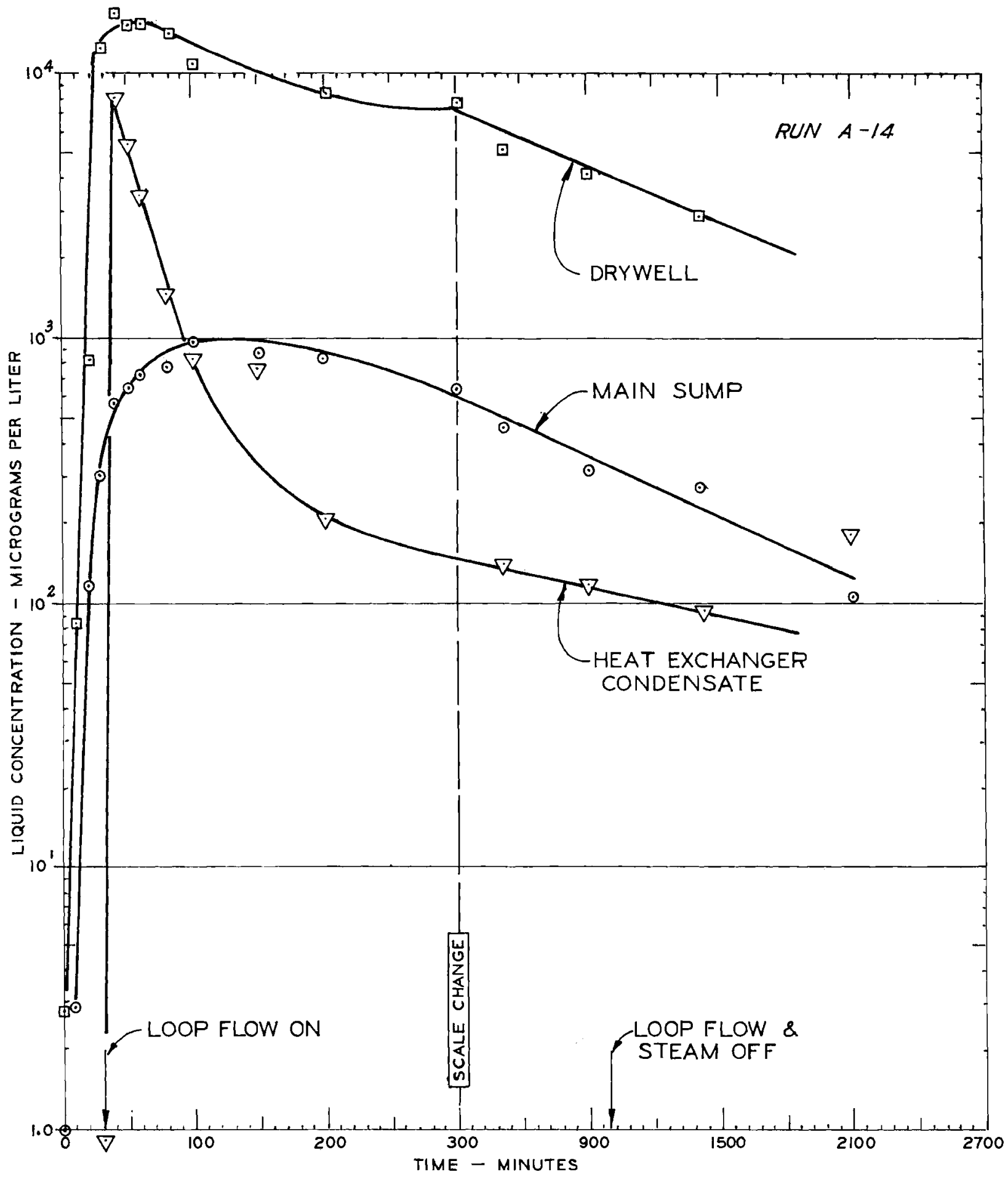

FIGURE 12. Iodine Concentration in Liquid Sumps in CSE Run A-14 


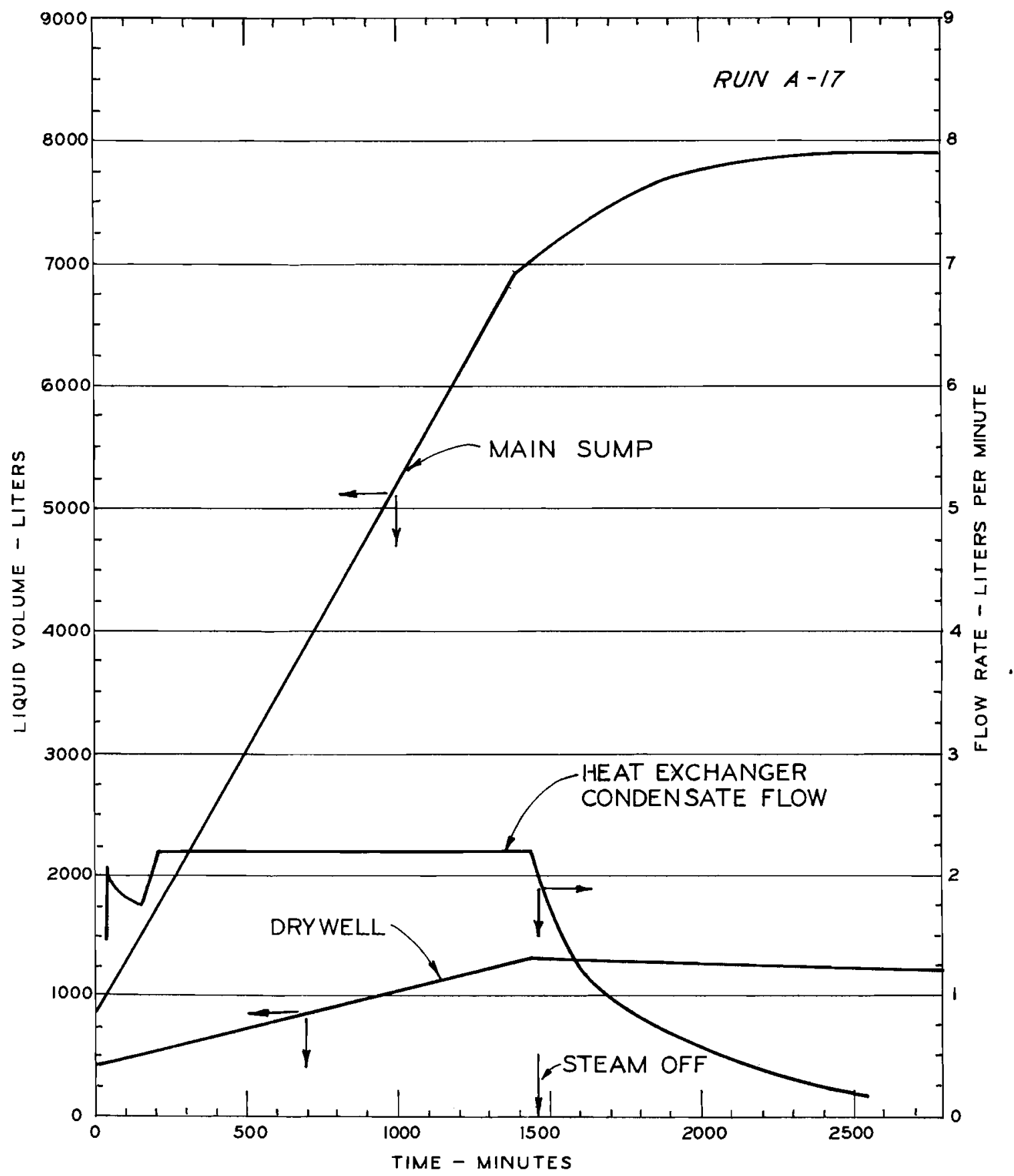

FIGURE 13. Water Volumes Accumulated in CSE RUn A-17 
flow is essentially constant after the fan was turned on, and up until the time the steam flow was turned off.

At the time the steam flow was terminated, the vessel contained about 8000 liters of water. This volume represents about $1 \%$ of the volume of the gas space. This amount of liquid is relatively less than for PWR plants which use containment spray as well as a filter loop. One would expect a liquid/gas volume of about 0.03 for full scale PWR nuclear plants.

The liquid volumes which accumulated in the four filter loop experiments are shown in detail in Figures $A-21$ through A-24 in the Appendix. Data for Run A-13 are not included because no steam was added. For the latter run, the liquid volumes were established before the run at $330 \ell$ in the main sump and $400 \ell$ in the drywe 11.

Retention by Loop Components

After each run, the loop was disassembled and the components analyzed to assess the quantity of fission products retained. The moisture separator was decontaminated and the washings analyzed. For the other components, samples were taken, and the total fission product load estimated from the sample analysis. The amounts of iodine on each loop component for the five tests are listed in Table 7.

\section{TABLE 7.- Post Run Loop Iodine Inventory}

\begin{tabular}{|c|c|c|c|c|c|}
\hline & $\begin{array}{c}\text { Run No. } \\
13 \\
\end{array}$ & $\begin{array}{r}\text { Run No } \\
\quad 14(a) \\
\end{array}$ & $\begin{array}{c}\text { Run No. } \\
15 \\
\end{array}$ & $\begin{array}{c}\text { Run No. } \\
16 \\
\end{array}$ & $\begin{array}{c}\text { Run No. } \\
17 \\
\end{array}$ \\
\hline $\begin{array}{l}\text { Heat Exchanger } \\
\text { Liquid }\end{array}$ & ---- & 0.036 & --- & 2.82 & 0.90 \\
\hline $\begin{array}{l}\text { Moisture Separator } \\
\text { Washings }\end{array}$ & ---- & 0.43 & ---- & 9.32 & 0.17 \\
\hline Prefilter & 0.052 & 0.019 & 0.0053 & 0.40 & --- \\
\hline HEPA Filter & 2.39 & 2.90 & 5.53 & 8.62 & 6.07 \\
\hline \multirow{2}{*}{$\begin{array}{r}\text { 1st Char Bed } 1 / 2 \\
2 / 2\end{array}$} & 18.5 & 5.52 & 9.81 & 4.88 & 9.3 \\
\hline & 2.46 & 2.47 & 4.07 & 1.87 & 2.9 \\
\hline \multirow[t]{2}{*}{ 2nd Char Bed } & 1.61 & 0.086 & 2.00 & 1.23 & 1.3 \\
\hline & 1.12 & 0.036 & 1.56 & 0.76 & 0.93 \\
\hline \multirow[t]{2}{*}{ 3rd Char Bed } & 0.61 & 1.09 & 1.38 & 0.38 & 0.60 \\
\hline & 0.34 & 0.546 & 0.99 & 0.23 & 0.47 \\
\hline Total, g & 27.08 & 13.13 & 25.36 & 30.50 & 22.6 \\
\hline
\end{tabular}

(a) Corrected for Post Run $\mathrm{CH}_{3} \mathrm{I}$ Test. 
As one would expect, most of the iodine was retained on the first charcoal bed, except for Run A-16. In Run A-16 the mass of cesium released was large compared to the iodine mass and as a result, the cesium reacted with much of the airborne iodine to form an aerosol of CSI. For this reason more than $50 \%$ of the iodine was retained by the filter components of the 1oop.

The retention of cesium by the loop components is given in Table 8 . Interestingly, an appreciable fraction of the cesium was trapped by the

TABLE 8. Post-Run Loop Cesium Inventory

\begin{tabular}{|c|c|c|c|c|c|}
\hline Component & $\begin{array}{c}\text { Cesium } \\
\text { Run No. } \\
13 \\
\end{array}$ & $\begin{array}{l}\text { tained } 1 \\
\text { Run No. } \\
14\end{array}$ & $\begin{array}{c}\text { Run No. } \\
15 \\
\end{array}$ & $\begin{array}{l}\text { Run No. } \\
16\end{array}$ & $\begin{array}{c}\text { Rup, go. } \\
\begin{array}{l}\text { Run } \\
17\end{array} \\
\end{array}$ \\
\hline $\begin{array}{l}\text { Heat Exchanger } \\
\text { Liquid }\end{array}$ & --- & 0.031 & ---- & 3.4 & 0.05 \\
\hline $\begin{array}{l}\text { Moisture Separator } \\
\text { Washings }\end{array}$ & ---- & 0.76 & ---- & 16.0 & 0.50 \\
\hline Prefilter & 0.021 & 0.0002 & 0.011 & 0.91 & --- \\
\hline HEPA Filter & $\underline{2.88}$ & 0.43 & $\underline{0.735}$ & 10.67 & $\underline{0.41}$ \\
\hline Total, $\mathrm{g}$ & 2.90 & 1.22 & 0.746 & 30.98 & 0.96 \\
\hline
\end{tabular}

moisture separator. This demonstrates that the aerosol particlesin the containment atmosphere were larger than one micron in size. Submicron aerosols do not have sufficient inertia to be captured as was observed.

Fission Product Material Balances

After the Maypack samplers and loop components had been removed from the vessel following cool-down, the vessel was decontaminated by steaming. The decontamination procedure removed the contaminants which were reversibly attached to surfaces. Material balances were then made, accounting for the masses contained in liquid pools, that remaining airborne, and that within the loop. The quantity of material on surfaces was taken as the difference between the mass injected and that accounted for. 
The disposition of iodine in Run A-17 is shown in Figure 14. These data show that after 30 minutes, most of the iodine is attached to wall surfaces. This occurs because a major fraction of the iodine injected mass deposits on wall surfaces by natural transport before the loop flow begins. Much of the deposited iodine was irreversibly retained by the wal1. Similar behavior was observed in all five tests. The disposition of iodine in the containment vessel is given in Figures $A-25$ through $A-29$ in the Appendix.

Cesium is retained less effectively by wall surfaces than is iodine. This is shown in Figure 15 where the cesium mass distribution is given for Run A-17. Most of the cesium is retained by the loop filters for times longer than 50 minutes. The distribution of cesium within the containment vessel for the five filter loop tests is presented in Figures A-30 through A-34 in the Appendix.

The final material balance for iodine in the filter loop tests is summarized in Table 9. These results show that about half of the iodine initially deposited on the walls is removable by steaming. The mass of iodine remaining on surfaces is in agreement with that predicted from small deposition coupons exposed to the containment atmosphere.

The final cesium material balances for the filter loop tests are summarized in Table 10. Cesium is retained by wall surfaces to a lesser extent than is iodine. This is reasonable since it is present as a salt and is thus highly soluble in water. 


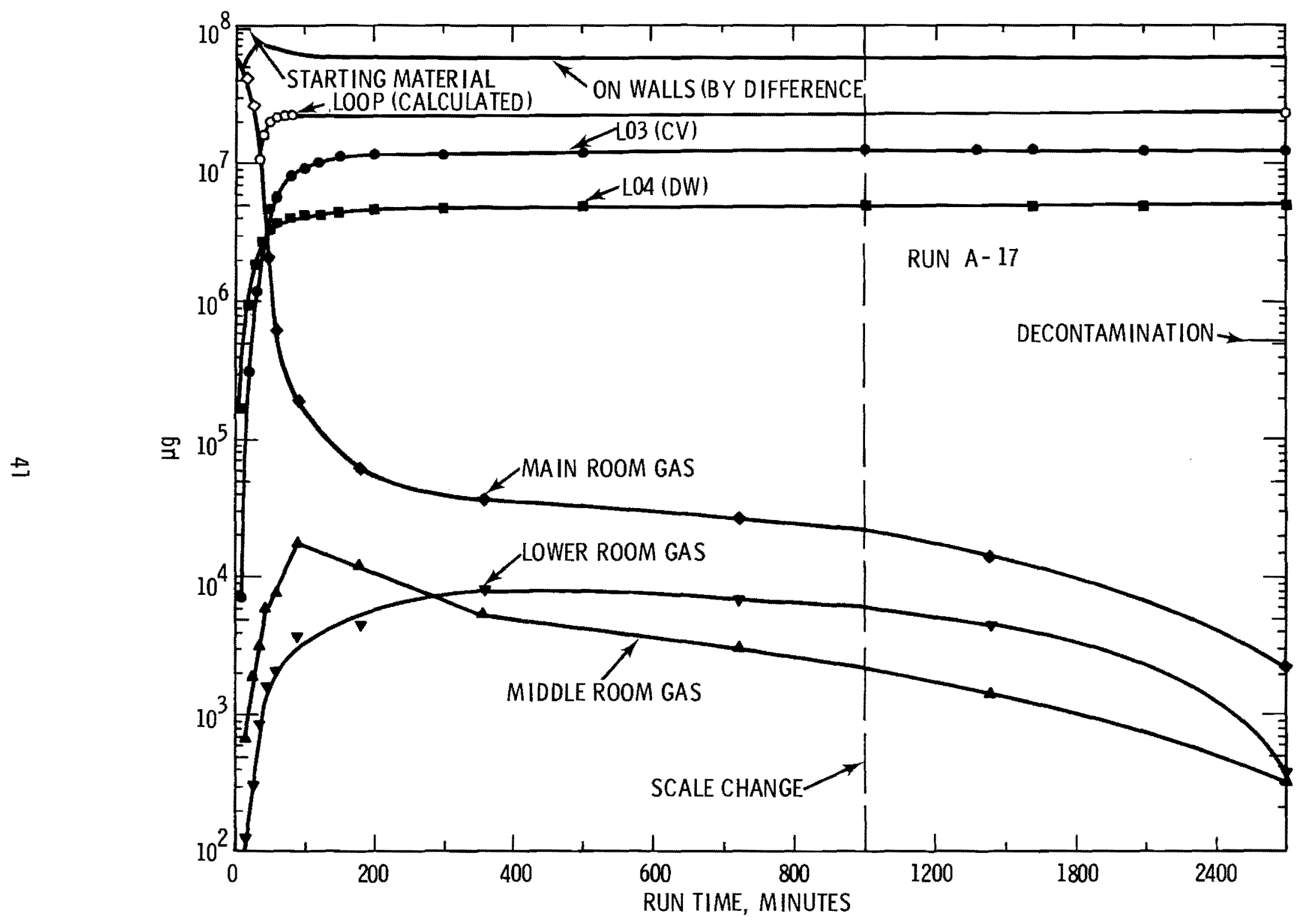

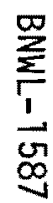

FIGURE 14. Total Iodine Material Balance vs. Time for CSE Run A-17 


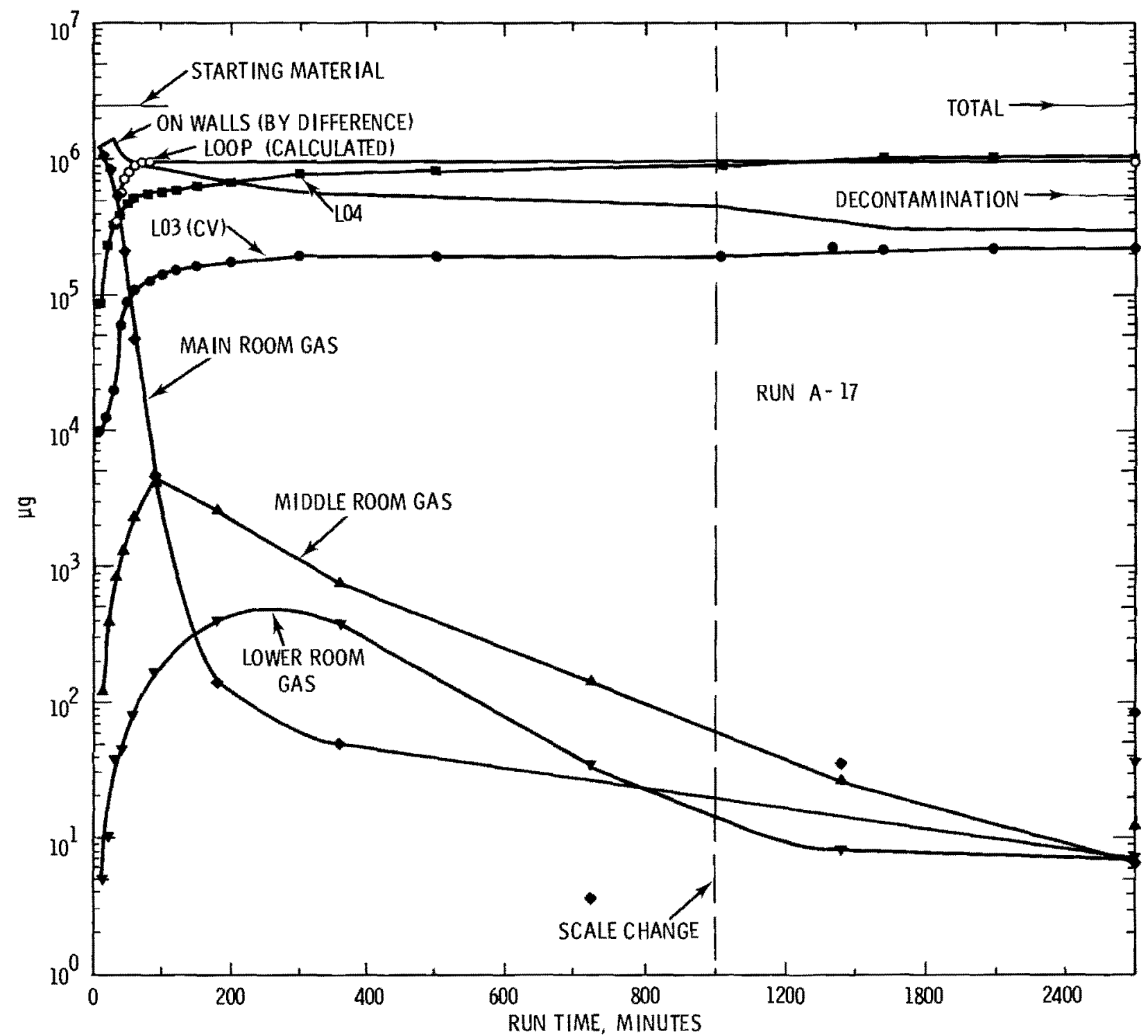

FIGURE 15. Cesium Material Balance vs. Time for CSE Run A-17 
TABLE 9. Iodine Material Balances

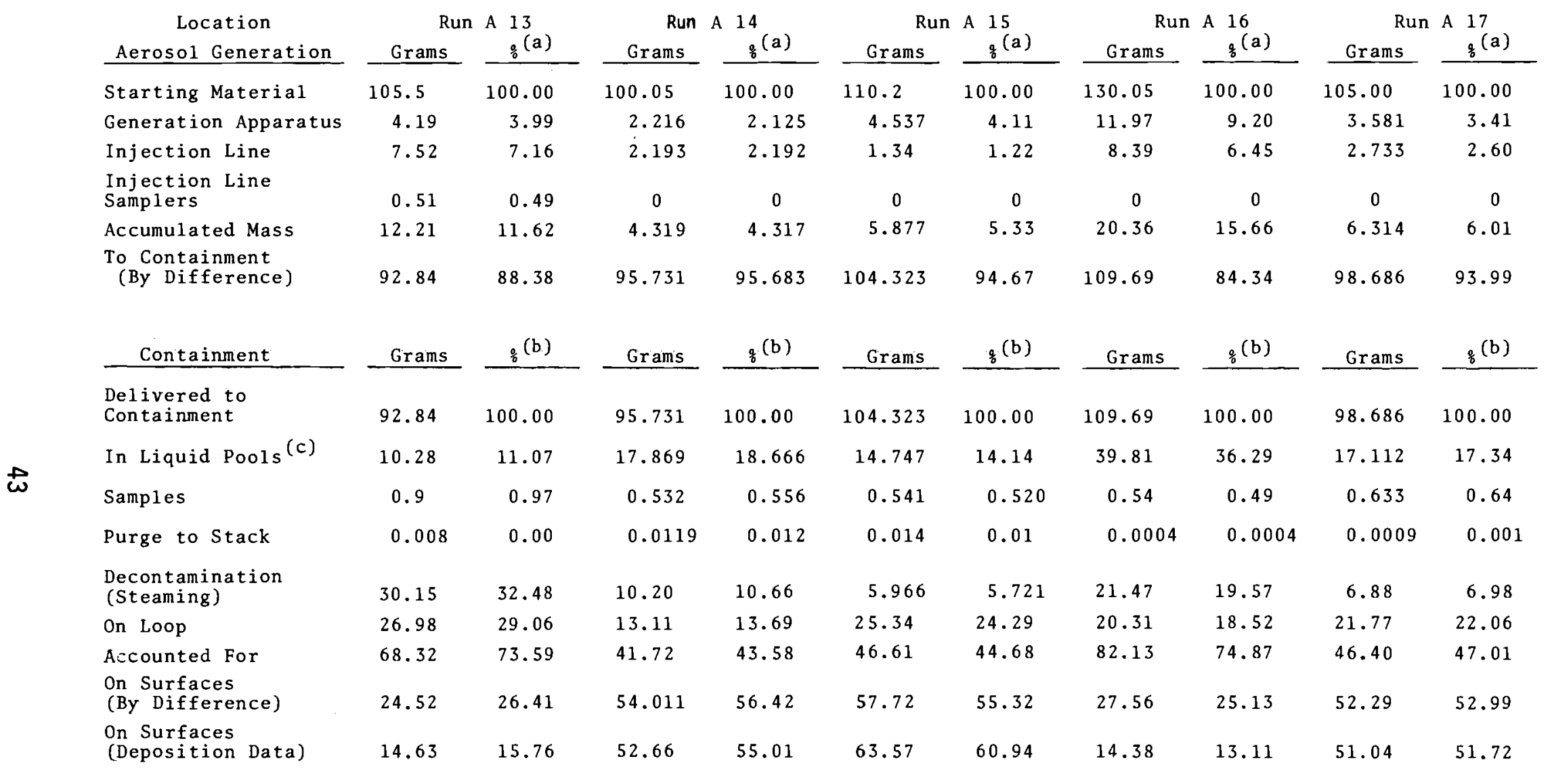

(a) \% of starting mass

(b) \% of delivered mass

(c) Includes spray solutions and steam condensate 
TABLE 10. Cesium Material Balances

\begin{tabular}{|c|c|c|c|c|c|c|c|c|c|c|c|}
\hline & \multirow{2}{*}{$\begin{array}{c}\text { Location } \\
\text { Aeroso1 Generation }\end{array}$} & \multicolumn{2}{|c|}{ Run A 13} & \multicolumn{2}{|c|}{ Run A 14} & \multicolumn{2}{|c|}{ Run A 15} & \multicolumn{2}{|c|}{ Run A 16} & \multicolumn{2}{|c|}{ Run A 17} \\
\hline & & Grams & $\underset{0}{0}(a)$ & Grams & $\frac{\circ}{0}(a)$ & Grams & $\frac{\circ}{6}(a)$ & Grams & $\frac{\circ}{6}(a)$ & Grams & $\%(a)$ \\
\hline & Starting Material & 11.54 & 100.00 & 11.228 & 100.00 & 10.989 & 100.00 & 445.40 & 100.00 & 11.222 & 100.00 \\
\hline & Generation Material & 4.04 & 35.01 & 1.428 & 12.718 & 6.873 & 62.54 & $209 \cdot 30$ & 46.99 & 7.450 & 66.39 \\
\hline & Injection Line & 0.50 & 4.33 & 2.058 & 18.329 & 1.530 & 13.92 & 20.81 & 4.67 & 1.287 & 11.47 \\
\hline & $\begin{array}{l}\text { Injection Line } \\
\text { Samplers }\end{array}$ & 0.07 & 0.61 & 0 & 0 & 0 & 0 & 0 & 0 & 0 & 0 \\
\hline & Accumulated Mass & 4.61 & 39.91 & 3.486 & 31.047 & 8.403 & 76.46 & 230.11 & 51.66 & 8.737 & 77.86 \\
\hline & $\begin{array}{l}\text { To Containment } \\
\text { (By Difference) }\end{array}$ & 6.93 & 60.05 & 7.742 & 68.953 & 2.585 & 23.54 & 215.29 & 48.34 & 2.485 & 22.14 \\
\hline & Containment & Grams & $\frac{9}{0}(b)$ & Grams & $\%(b)$ & Grams & $\frac{0}{6}(b)$ & Grams & $\frac{0}{\circ}(b)$ & Grams & $\frac{\mathrm{g}}{8}(\mathrm{~b})$ \\
\hline & $\begin{array}{l}\text { Delivered to } \\
\text { Containment }\end{array}$ & 6.93 & 100.00 & 7.742 & 100.00 & 2.585 & 100.00 & 215.29 & 100.00 & 2.485 & 100.00 \\
\hline & In Liquid Pools (c) & 1.226 & 17.69 & 2.992 & 38.646 & 0.685 & 26.50 & 85.85 & 39.88 & 1.227 & 49.38 \\
\hline & Samples & 0.032 & 0.46 & 0.039 & 0.504 & 0.016 & 0.62 & 0.80 & 0.37 & 0.0146 & 0.59 \\
\hline & Purge to Stack & 0.00005 & 0.00 & 0.00002 & 0.0003 & 0.000004 & 0.00 & 0.002 & 0.0009 & 0.0001 & 0.003 \\
\hline & $\begin{array}{l}\text { Decontamination } \\
\text { (Steaming) }\end{array}$ & 1.027 & 14.82 & 1.248 & 16.12 & 0.512 & 19.81 & 40.23 & 18.69 & 0.5218 & 21.00 \\
\hline & Loop Components & 2.92 & 42.12 & 1.209 & 15.616 & 0.746 & 28.86 & 16.77 & 7.79 & 0.9032 & 36.35 \\
\hline & Accounted For & 5.205 & 75.11 & 5.488 & 70.886 & 1.959 & 75.78 & 143.65 & 66.72 & 2.667 & 107.31 \\
\hline & $\begin{array}{l}\text { On Surfaces } \\
\text { (By Difference) }\end{array}$ & 1.725 & 24.89 & 2.254 & 29.114 & 0.626 & 24.22 & 71.64 & 33.28 & -0.182 & -7.31 \\
\hline & $\begin{array}{l}\text { On Surfaces } \\
\text { (Deposition Data) }\end{array}$ & 0.074 & 1.07 & 0.058 & 0.75 & 0.032 & 1.24 & 0.353 & 0.16 & 0.0211 & 0.85 \\
\hline
\end{tabular}

(a) \% of starting mass

(b) \% of delivered mass

(c) Includes spray solution and steam condensate 


\section{REMOVAL EFFICIENCIES FOR FILTER LOOP COMPONENTS}

Interstage samples were taken to provide a direct measurement of removal efficiency for individual loop components. Six individual Maypack samplers were installed to withdraw samples between the several components. One of these was used as a blank. The other 5 samplers were operated at 5 discrete time step during the run. The decontamination factors measured from these samples are summarized in Table 11 for Run A-17.

TABLE 11. Measured Loop Decontamination Factors For Run A-17

Decontamination Factor at Stated Time

\begin{tabular}{|c|c|c|c|c|c|c|c|c|c|}
\hline \multirow[b]{2}{*}{ Component } & \multicolumn{3}{|c|}{35 minutes } & \multicolumn{3}{|c|}{60 minutes } & \multicolumn{3}{|c|}{80 minutes } \\
\hline & $\underline{\underline{C S}}$ & $\underline{I}$ & $\underline{\mathrm{CH}_{3} \mathrm{I}}$ & $\overline{c s}$ & I & $\mathrm{CH}_{3} \mathrm{I}$ & $\overline{c s}$ & I & $\mathrm{CH}_{3} \mathrm{I}$ \\
\hline Heat Exchanger & 1.2 & 1.3 & - & 1.2 & 1.6 & - & 1.2 & 1.4 & - \\
\hline Demister & 6.2 & 1.3 & - & 3.7 & 1.1 & - & 2.4 & 2.5 & - \\
\hline HEPA Filter & 44 & 1.6 & - & 40 & 85 & - & - & $>13$ & - \\
\hline 1st Charcoal Bed & - & 470 & 1.7 & - & - & 1.7 & - & - & 1.7 \\
\hline 2nd Charcoal Bed & - & $>7$ & - & - & - & - & - & - & - \\
\hline 3rd Charcoal Bed & - & - & - & - & - & - & - & - & - \\
\hline Overall & 27,00 & $>8000$ & 12 & 1900 & $>120$ & 10 & 520 & $>180$ & 7.5 \\
\hline
\end{tabular}

Aerosol particles and elemental iodine are removed with very high efficiencies early in the run. Methyl iodide is removed with lower efficiency, but still is effectively removed. The removal efficiency for cesium, elemental iodine, and methyl iodide decreases with time, though from a practical standpoint, this decrease is negligible until the concentration decreases to very low levels. The overall decontamination factor listed in Table 11 is the experimentally measured value taken from samples of the air entering and leaving the loop. The overall decontamination factor must equal to the product of the decontamination factors for the individual components. The analytical sensitivity limits prevented measurement of the decontamination factor for each loop component so it is not possible to compare the overall loop efficiency with that predicted for the components in series. 
BNWL-1587

Although one would like to know the removal efficiency for each component at long times (24-48 hours), the very low airborne concentration which existed at these times effectively prevented their reliable detection. Much more sophisticated sampling and and analytical techniques would be required to do this.

The measured loop component efficiencies for the five filter loop tests are summarized in Tables A-1 through A-5 in the Appendix. PARTICLE SIZE MEASUREMENTS

Aerosol particle size measurements were made during the experiments using a round jet cascade impactor.* Use of a cascade impactor to sample saturated steam-air mixtures is less than ideal, because of thermodynamic changes which occur within the impactor. In order to avoid water condensation on the impactor stages, the impactor was preheated to about $300^{\circ} \mathrm{F}$ prior to use. Warming of the saturated steam-air gas stream may be expected to cause evaporation of water associated with aerosol particles. This evaporation would cause a decrease in the particle size compared to that in the containment atmosphere. Postma (4) has discussed evaporation of "wet" particles within a cascade impactor.

The particle sizes measured by the impactor are listed in Table 12. These particle diameters are similar for the ambient temperature run, $A-13$, TABLE 12. Cesium Particle Size in Filter Loop Tests

$\begin{array}{ccc}\text { Run No. } & \begin{array}{c}\text { Mass Median Aerodynamic Diamet } \\ \text { 10-20 min }\end{array} & \frac{100 \mathrm{~min}}{0.9} \\ \text { A-13 } & \frac{0.9}{2} & 0.6 \\ \text { A-14 } & 0.9 & 0.3 \\ \text { A-15 } & 0.5 & 0.5 \\ \text { A-16 } & 1.0 & 0.5 \\ \text { A-17 } & 0.5 & <0.4\end{array}$

and the other tests made at $250^{\circ} \mathrm{F}$. For Run $\mathrm{A}-13$ the impactor was not heated prior to use, hence the uniformity of the results leads to the *Model CI-S-8, Scientific Advances Inc., Columbus, Ohio. 
conclusion that use of a heated impactor did not change the indicated particle sizes. The particle sizes shown in Table 12 are in agreement with those obtained in previous CSE experiments. $(1,2,3,4)$ VISUAL OBSERVATIONS OF CONTAINMENT ATMOSPHERE

The CSE vessel is equipped with a 6 " diameter window and interior lights so that the containment atmosphere can be observed visually. The time sequence of observations in a typical run is briefly as follows. When steam is introduced into the cold vessel, a dense fog is formed. Mixing of the steam with the cool air initially present leads to supersaturation and condensation within the gas phase. The fog clears when the temperature approaches equilibrium. Uranium oxide aerosol is then injected into the vessel, and this results in a very slight fog, barely visible in the $25 \mathrm{ft}$ diameter vesse 1 . When cesium and iodine are injected, a very dense fog forms, reducing the visibility to a few feet. This fog clears gradually by natural processes before the loop fan is started.

Within a few minutes after the loop flow was started, the fog disappeared completely. Two factors explain this. First, iodine and particles were removed from the atmosphere which would clean the atmosphere directly. Second, the charcoal beds adsorbed significant amounts of water vapor, which caused slight superheating of the vessel atmosphere. This caused fog drops to evaporate. The vessel atmosphere remained clear for the remainder of the test period. MECHANICAL ASPECTS OF LOOP OPERATION Operational Tests

Several operational tests were made on the loop before and after each test to verify that the loop components were undamaged and that leakage past seals was within expected tolerance. Prior to each run, the HEPA filters were tested for penetration using a standard DOP aerosol test. This was done after assembly of the loop. Also, the charcoal beds were tested for penetration using methyl iodide. The methyl iodide pretest was of short duration and showed: (1) that direct leakage of air through the bed was within tolerance limits, and (2) that the charcoal installed 
possessed a high degree of retentivity toward methyl iodide, and by implication toward elemental iodine.

The loop operated at a slight negative pressure compared to its environment so that in-leakage between stages was a potential problem. Before each run the ductwork was tested at the operating differential pressure for inleakage. This was done by sealing the inlet and outlet openings, and evacuating the duct to the operating pressure differential. The in-leakage rate was calculated from the rate of pressure buildup within the duct.

Following each test, the DOP penetration test was applied to the HEPA filter. In one experiment, Run A-14, the methyl iodide penetration test was carried out after the run.

Results of the operational tests are summarized in Table 13. The HEPA filter was not degraded by the containment test. The charcoal beds

TABLE 13. Operational Tests on Loop and Components

\begin{tabular}{|c|c|c|c|c|c|}
\hline & $\begin{array}{c}\text { Run No. } \\
\text { A-13 }\end{array}$ & $\begin{array}{l}\text { Run No. } \\
\mathrm{A}-14\end{array}$ & $\begin{array}{l}\text { Run No. } \\
\text { A-15 } \\
\end{array}$ & $\begin{array}{c}\text { Run No. } \\
\text { A-16 }\end{array}$ & $\begin{array}{c}\text { Run No. } \\
\mathrm{A}-17 \\
\end{array}$ \\
\hline \multicolumn{6}{|l|}{ Pre Run } \\
\hline Duct Leakage, $\%(a)$ & 0.01 & 0.01 & 0.02 & 0.02 & 0.002 \\
\hline DOP Penetration, $\%$ & $<0.03$ & $<0.03$ & $<0.03$ & 0.01 & $<0.03$ \\
\hline $\mathrm{CH}_{3} \mathrm{I}$ Penetration, $\%$ (b) & $<0.002$ & 0.02 & 0.001 & 0.0003 & $0.03^{(c)}$ \\
\hline \multicolumn{6}{|l|}{ Post Run } \\
\hline DOP Penetration, \% & $<0.03$ & $<0.03$ & $<0.03$ & $<0.03$ & $<0.03$ \\
\hline $\mathrm{CH}_{3} \mathrm{I}$ Penetration, $\%$ & & $\sim 0.2$ & & & \\
\hline
\end{tabular}

(a) As \% of loop flow at estimated operating $\Delta P$

(b) Penetration in 3 min at ambient temp and humidity, $1000 \mathrm{cfm}$

(c) Same as (b) except $1800 \mathrm{cfm}$.

were somewhat less effective for methyl iodide after the containment test, but were still within an acceptable range. 
BNWL-1587

Loop Flow and Pressure Drop

The temperature and pressure of the vessel atmosphere was measured for the entire test, along with the loop flow rate. Typical results are shown in Figure 16. The atmosphere temperature and pressure were essentially constant until steam flow was halted, and then decayed over the next 24 hours. The loop flow rate was adjusted using a damper to maintain it constant. In Run A-17, the increase in pressure drop caused the loop flow to decrease with the damper completely open. This was expected because the flow rate for this run was $1800 \mathrm{cfm}$ or about double the design capacity of the system.

The pressure drops across loop components for Run A-17 are shown in Figure 17. The most notable feature of the data shown is that the pressure drop across the HEPA filter increased from about 2" to $4.5^{\prime \prime}$ some 15 hours after the loop flow was started. For times from $15 \mathrm{hr}$ to $24 \mathrm{hr}$, the pressure drop limited the loop flow rate, which fell to $1600 \mathrm{cfm}$ from $1800 \mathrm{cfm}$. The HEPA filter returned to the pre-run flow resistance soon after steam injection was terminated.

Data on loop flow rate, thermodynamic conditions, and pressure drop for a11 5 filter loop tests are given in Figures $A-35$ to $A-44$ in the Appendix.

Heat Removal By Finned Tubes

Although the primary objective of the filter loop tests was to assess the removal of airborne fission products, the loop instrumentation allowed the heat transfer coefficient to the finned tubes to be evaluated. The heat transfer coefficient was found to be sensitively dependent on the air/steam ratio. Results for Run A-16 are shown in Figure 18. The outside heat transfer coefficient, based on total outside area, is shown as a function of the steam/air ratio of the inlet gas. During the steady state temperature period of Run A-16, the heat exchanger removed 44,000 BTU/min, including both sensible and latent heat. 


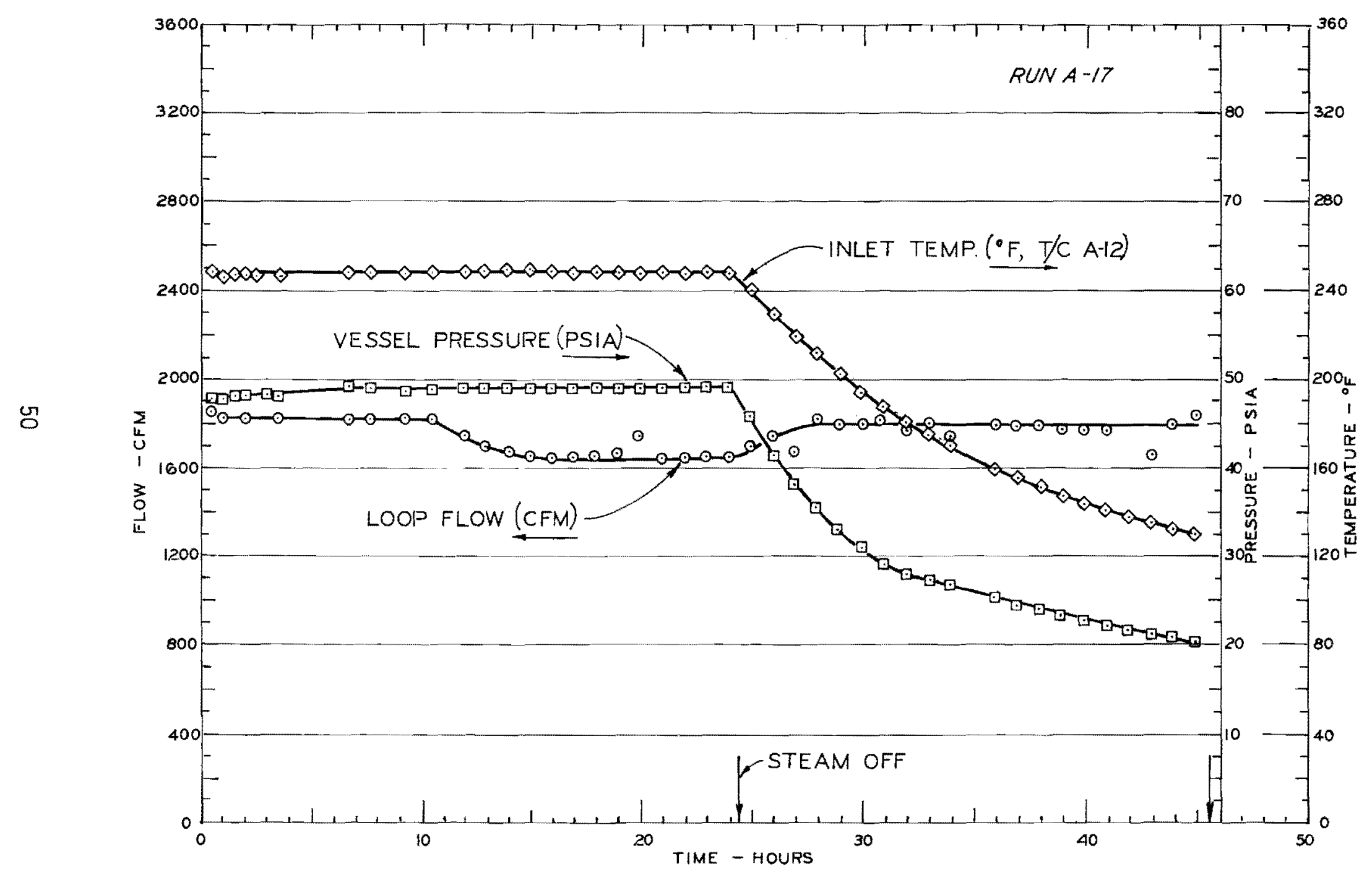

FIGURE 16. Thermodynamic Conditions and Loop Flow for CSE Run A-17 


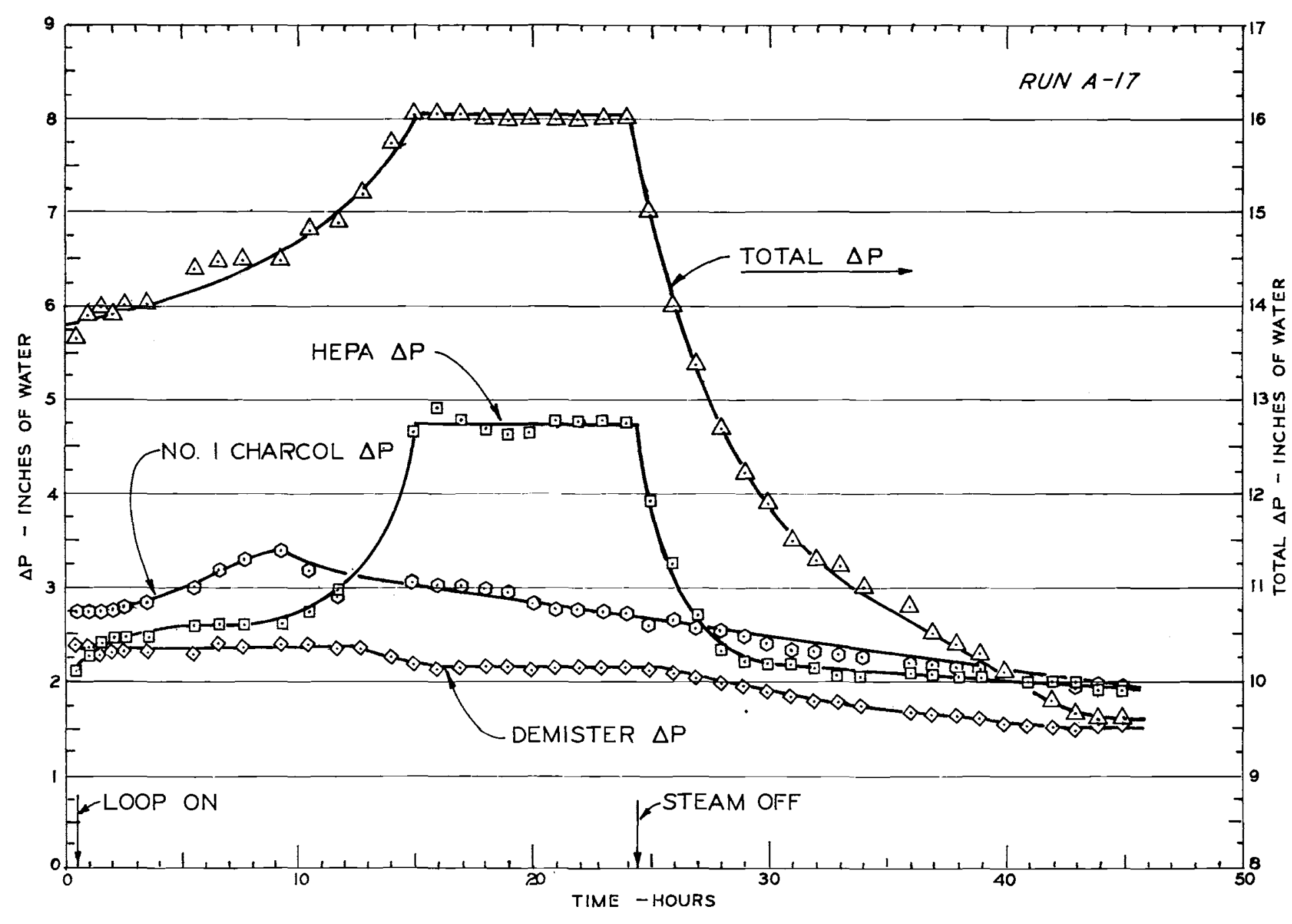

FIGURE 17. Pressure Drop Across Loop Components in CSE Run A-17 


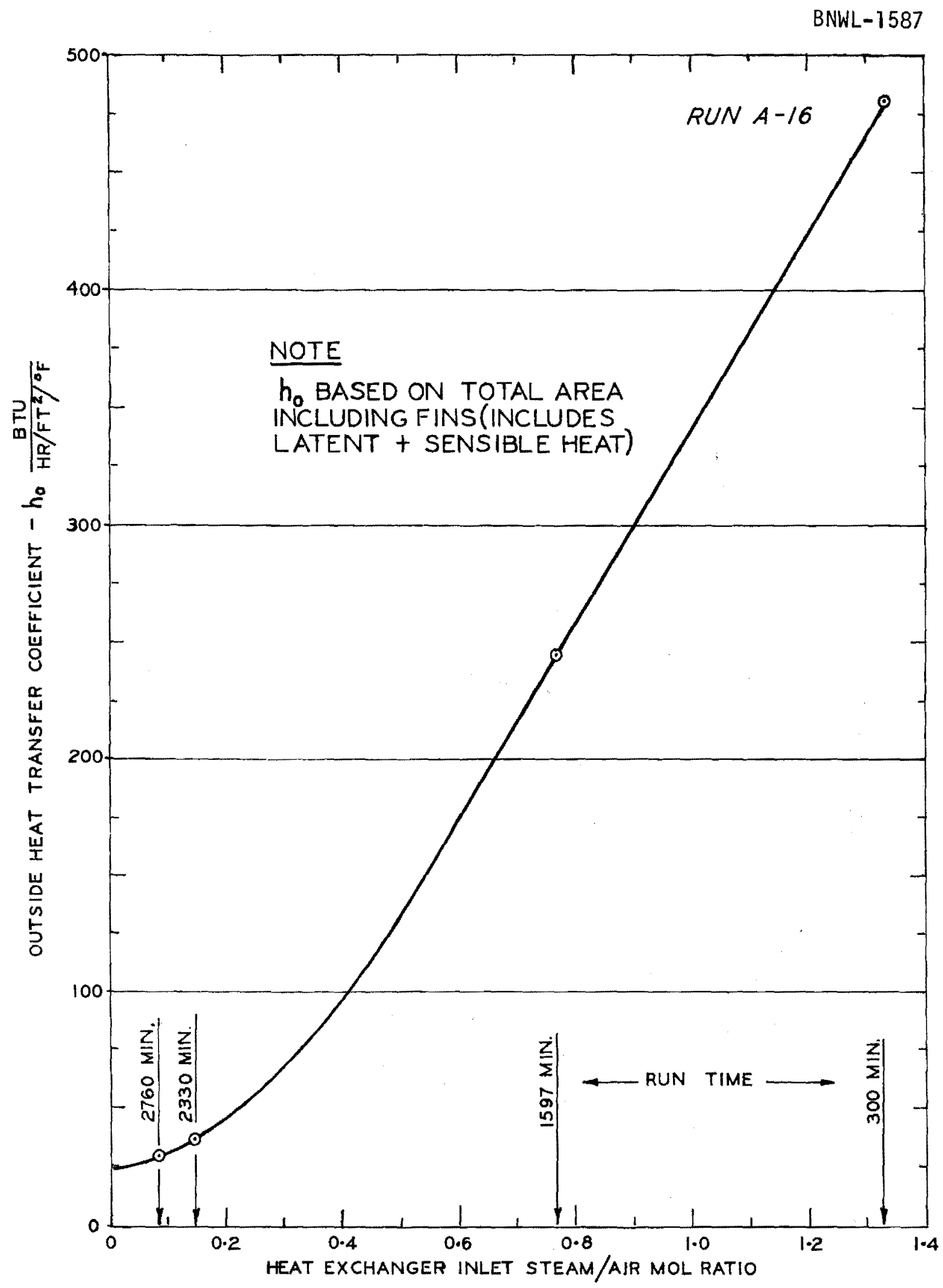

FIGURE 18. Heat Transfer Coefficient to Finned Tubes For CSE Run A-16 
Iodine and Steam Adsorption by Charcoal Beds

After each experiment the charcoal beds were reweighed to measure moisture pickup and charcoal samples were analyzed for total iodine, to look for any losses of iodine impregnant. Table 14 gives the amount of stable iodine found.

TABLE 14. Stable Iodine on Charcoal Beds After Use, wt \%

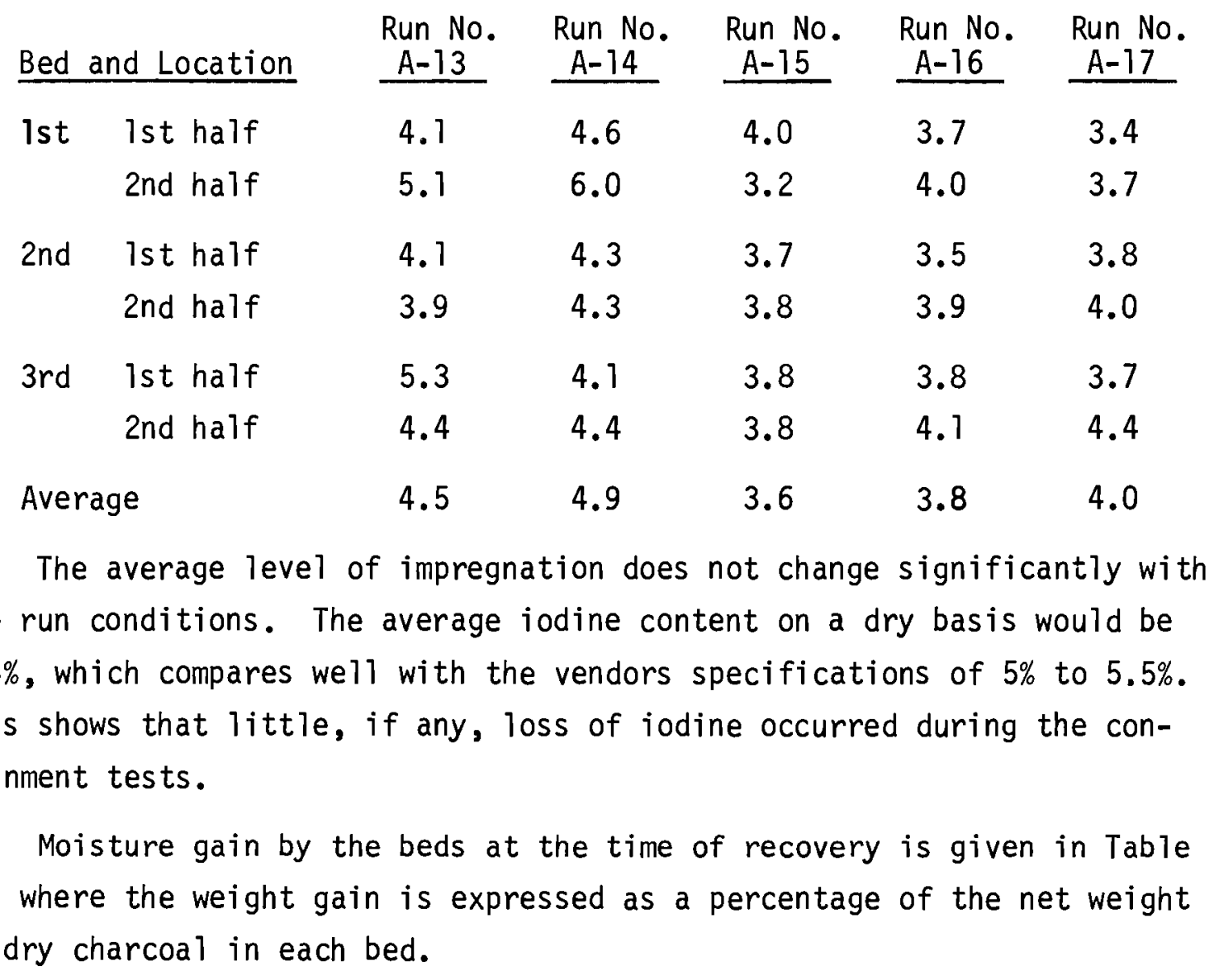


TABLE 15. Moisture Pickup by Charcoal at End of Run, ${ }^{(a)}$ wt\%

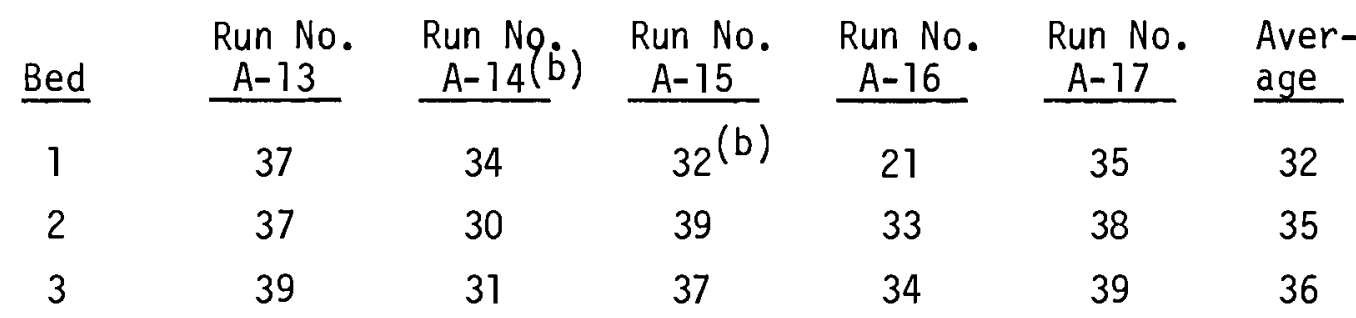

(a) Based on vendors net wt when filled

(b) Net wt. not recorded. Assumed 50.5 1b.

The average $34 \%$ weight gain measured at the end of the run is lower than would be expected for charcoal saturated with moisture at 100\% relative humidity. A charcoal with $1400 \mathrm{~m}^{2} / \mathrm{g}$ area would be expected to pick up about $50 \mathrm{wt} \%$ moisture ${ }^{(15)}$ if at equilibrium. These beds have had many hours to re-equilibrate with the lower humidity air used to purge the vessel before sample recovery. This likely accounts for the lower than expected moisture content.

Mechanical Reliability of Loop

In a design basis accident, the filter loop is required to run for weeks in the humid hot containment atmosphere. Each CSE run involved about 150 hours of operation including the vessel warmup and steam decontamination after each run. The total exposure to elevated temperature and humidity amounted to about 30 days. The motor, fan, and sample inlet valves were exposed to the containment atmosphere for this total time. The filter loop components, however, were changed after each experiment.

The motor was a 10 horsepower, encapsulated winding, totally-enclosed, fan-cooled unit with class $\mathrm{H}$ insulation. It was completely trouble free. A11 bearings on the fan and motor were regreased with a high temperature lithium-silicone grease before the series of loop tests. Bearing performance was adequate. except that grease washed out of one fan bearing, possibly as a result of a damaged seal. No serious deterioration of other 
loop components was noted. The galvanized protective screen at the face of the HEPA filter showed loss of zinc due to oxidation and flaking.

The loop sections were assembled with asbestos gaskets. Components were installed using neoprene sponge gaskets and no problems were experienced with either type.

The fan was driven by three V-belts. The flow in Run A-14 was stopped early because of belt slippage. Type L light duty belts had been unknowingly used and these stretched beyond use in the steam air environment. All subsequent runs used premium grade $B$ section V-belts without problems.

EFFECT OF HUMIDITY ON METHYL IODIDE REMOVAL BY CHARCOAL BEDS

The temperature of air exiting from the charcoal beds was measured during the runs. Significant heating of the air was recorded when the beds were adsorbing moisture. This heating is due to heat of adsorption as the water vapor condenses in the charcoal pores. Temperature increases up to $35^{\circ} \mathrm{F}$ were recorded. Figure 19 is typical, and similar heating was measured in all runs. The net effect is that the air flowing through the charcoal bed is dehumidified, both by heating and by transfer of moisture to the charcoal. The relative humidity due to heating only is shown in Figure 18. If allowance is made for moisture removal, the humidity would be a few percent lower. This is a transient effect. After a few hours, the bed is saturated and the exit air is also saturated.

It is well documented that the ability of charcoal to remove methyl iodide from air is dependent on the humidity of the air. $(12,13,14,15,21)$ To measure this humidity effect, Runs A-13 and A-14 were made with "dry" (no previous exposure to steam) charcoal and in Runs A-16 and A-17 the charcoal beds were pre-equilibrated with the saturated steam/air atmosphere. Run A-15 involved two methyl iodide releases, one before saturation of the beds and one $22 \mathrm{hr}$ later. Figure 20 gives the main room methy 1 iodide concentrations measured in Run A-15. The dry charcoal removed the methy 1 iodide at nearly $100 \%$ efficiency until the concentration was reduced to about 0.002 of that at the start. The saturated charcoal beds following 


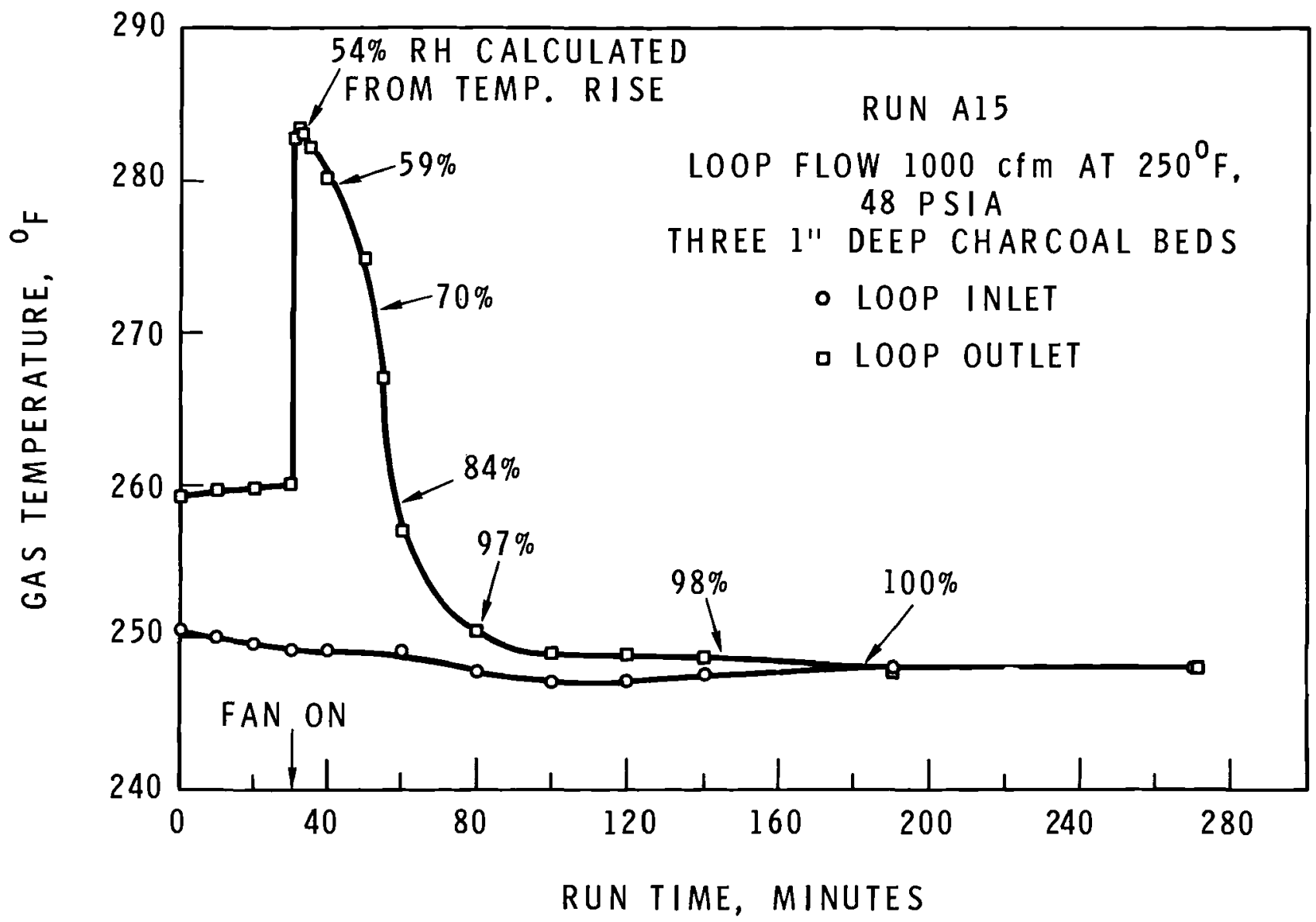




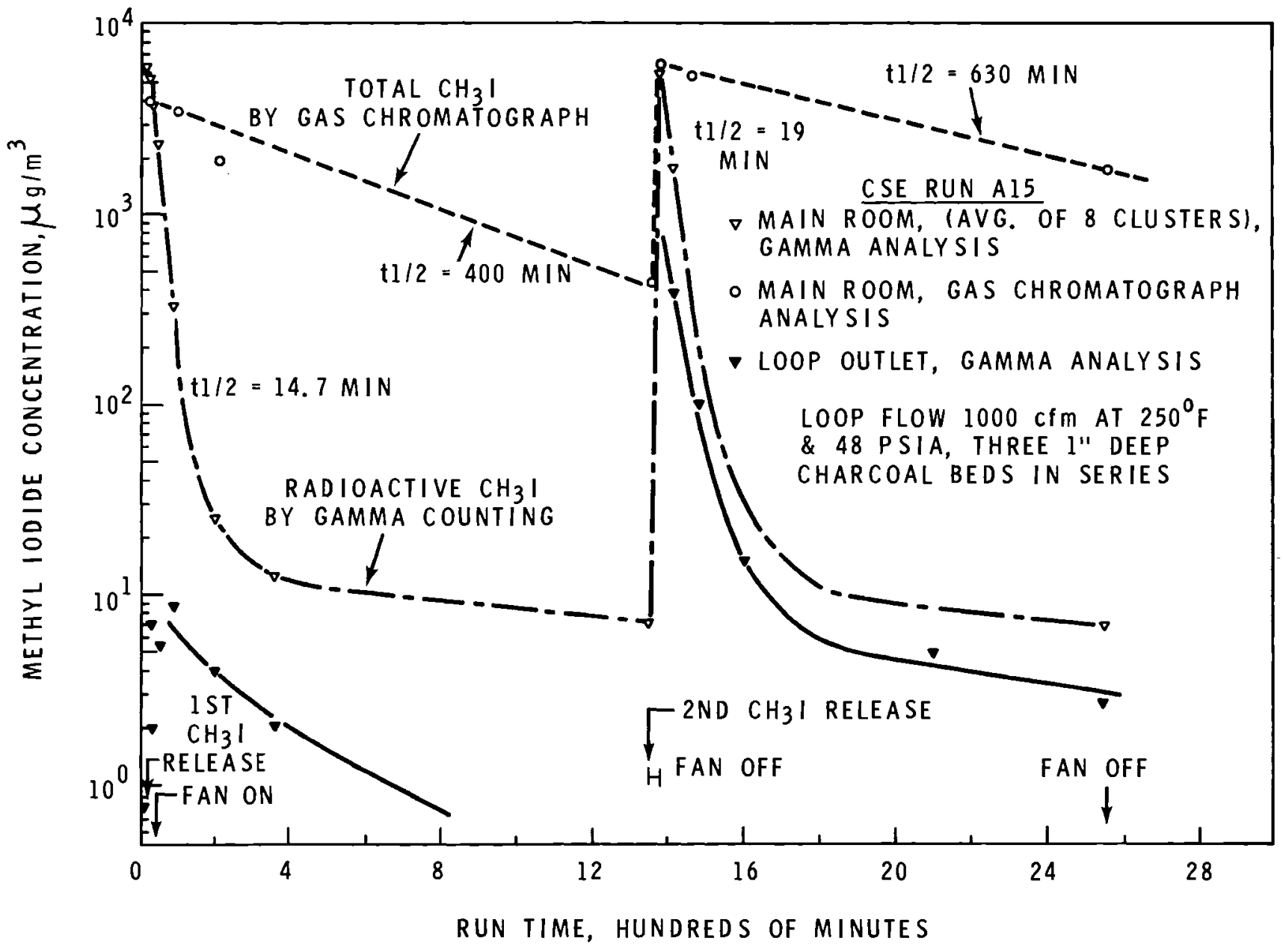

$\frac{\sum_{i}^{\infty}}{1}$

FIGURE 20. Methyl Iodide Removal by Impregnated Charcoal in CSE Run A-15 
the second release, removed methy 1 iodide at a reduced efficiency of about $78 \%$. The final concentration of methy 1 was about the same as achieved by the "dry" beds. This is a graphic demonstration of the behavior of a recirculating system, wherein good cleanup is accomplished even though operating at less than $100 \%$ efficiency.

The primary removal of methyl iodide was by isotopic dilution of the radioactive iodine with the stable iodine on the impregnated charcoal. This was borne out by analyses of the airborne methyl iodide concentration using a gas chromatograph. The total concentration of airborne methyl iodide (radioactive and non-radioactive) decreased only about a factor of ten whereas the radioactive methy 1 iodide was reduced in concentration by more than three orders of magnitude. DEPOSITION OF FISSION PRODUCTS ON EXPOSED SURFACES

Deposition coupons were attached to the Maypack sample clusters housing to evaluate the sorption of fission products by several surfaces. The coupons were 2-1/2 inches in diameter, 1/16 inch thick, and had a $17 / 32$ center hole. Both sides were exposed to the atmosphere. Thus heat would transfer to the specimens only during temperature transients.

Results for iodine are summarized in Table 16. It is obvious that stainless steel picks up much less iodine than the other surfaces.

Results for cesium are presented in Table 17. Cesium retention is essentially the same for all of the surfaces tested. 
TABLE 16. Iodine Deposition on Various Noncondensing Surfaces

\begin{tabular}{|c|c|c|c|c|c|}
\hline \multirow[b]{2}{*}{ Surface Material $(a)$} & \multirow[b]{2}{*}{$\begin{array}{l}\text { Run } \\
\mathrm{A}-13\end{array}$} & \multicolumn{3}{|c|}{$\begin{array}{l}\text { Deposition at end of Experiment } \\
\mu / \mathrm{G} / \mathrm{cm}^{2} \text { and } \pm 10(\%)\end{array}$} & \multirow[b]{2}{*}{$\begin{array}{l}\text { Run } \\
A-17 \\
\end{array}$} \\
\hline & & $\begin{array}{l}\text { Run } \\
\text { A-14 }\end{array}$ & $\begin{array}{l}\text { Run } \\
\text { A-15 } \\
\end{array}$ & $\begin{array}{l}\text { Run } \\
\text { A-16 } \\
\end{array}$ & \\
\hline \multirow[t]{2}{*}{ Silver ${ }^{(b)}$} & 31.9 & 25.2 & 28.4 & 6.60 & 27.1 \\
\hline & $\pm 29 \%$ & $\pm 39 \%$ & $\pm 52 \%$ & $\pm 20 \%$ & $\pm 30 \%$ \\
\hline \multirow[t]{2}{*}{ Carbon Stee ${ }^{(b)}$} & 31.6 & 23.0 & 30.3 & 5.83 & 0.152 \\
\hline & \pm 37 & \pm 54 & \pm 49 & \pm 23.5 & $\pm 100 \%$ \\
\hline Stainless $304^{(b)}$ & 0.588 & 0.317 & 0.184 & 0.690 & 32.3 \\
\hline (ASTM A240-63) & $\pm 80 \%$ & $\pm 23 \%$ & $\pm 53 \%$ & $\pm 43 \%$ & $\pm 36 \%$ \\
\hline \multirow[t]{2}{*}{ Phenoline $302^{(b, c)}$} & 6.31 & 22.7 & 27.4 & 6.20 & 22.0 \\
\hline & $\pm 54 \%$ & $\pm 22 \%$ & $\pm 35.6 \%$ & $\pm 17 \%$ & $\pm 37 \%$ \\
\hline \multirow[t]{2}{*}{ Amercoat $66^{(b, d)}$} & 2.85 & 26.4 & 28.1 & 7.05 & 29.0 \\
\hline & $\pm 52 \%$ & $\pm 32 \%$ & $\pm 49 \%$ & $\pm 22 \%$ & $\pm 36 \%$ \\
\hline
\end{tabular}

(a) $21 / 2$ in. diameter, 1/16 in. thick, 17/32 in. center hole. Total surface $=64 \mathrm{~cm}^{2}$.

(b) Average of 11 locations in main room.

(c) Coating manufactured by Carboline Company, St. Louis, Missouri. Average of 22 locations.

(d) Coating manufactured by Amercoat Corporation, South Gate, California. 
TABLE 17. Cesium Deposition on Various Noncondensing Surfaces

\begin{tabular}{|c|c|c|c|c|c|}
\hline \multirow[b]{2}{*}{ Surface Material (a) } & \multirow{2}{*}{$\begin{array}{l}\text { Run } \\
\text { A-13 } \\
\end{array}$} & \multicolumn{3}{|c|}{$\begin{array}{l}\text { Deposition at end of Experiment } \\
\mu \mathrm{g} / \mathrm{cm}^{2} \text { and } \pm 10 \quad(\%)\end{array}$} & \multirow[b]{2}{*}{$\begin{array}{l}\text { Run } \\
A-17\end{array}$} \\
\hline & & $\begin{array}{l}\text { Run } \\
\mathrm{A}-13 \\
\end{array}$ & $\begin{array}{l}\text { Run } \\
A-15 \\
\end{array}$ & $\begin{array}{l}\text { Run } \\
\text { A-16 } \\
\end{array}$ & \\
\hline \multirow[t]{2}{*}{ Silver $(b)$} & 0.054 & 0.030 & 0.0045 & 0.38 & 0.022 \\
\hline & $\pm 52 \%$ & $\pm 24 \%$ & $\pm 88 \%$ & $\pm 69 \%$ & $\pm 58 \%$ \\
\hline \multirow[t]{2}{*}{ Carbon Steel ${ }^{(b)}$} & 0.049 & 0.047 & 0.023 & 0.027 & 0.012 \\
\hline & $\pm 40 \%$ & $\pm 58 \%$ & $\pm 82 \%$ & $\pm 61 \%$ & $\pm 61 \%$ \\
\hline $\begin{array}{l}\text { Stainless } 304(b) \\
\text { (ASTM A240-63) }\end{array}$ & $\begin{array}{l}0.027 \\
\pm 37 \%\end{array}$ & $\begin{array}{l}0.033 \\
\pm 60 \%\end{array}$ & $\begin{array}{l}0.062 \\
\pm 56 \%\end{array}$ & $\begin{array}{l}0.024 \\
\pm 175 \%\end{array}$ & $\begin{array}{l}0.022 \\
\pm 50 \%\end{array}$ \\
\hline \multirow[t]{2}{*}{ Phenoline $302^{(b, c)}$} & 0.032 & 0.025 & 0.014 & 0.152 & 0.009 \\
\hline & $\pm 37 \%$ & $\pm 38 \%$ & $\pm 37 \%$ & $\pm 24 \%$ & $\pm 37 \%$ \\
\hline \multirow[t]{2}{*}{ Amercoat $66^{(b, d)}$} & 0.031 & 0.021 & 0.007 & 0.206 & 0.013 \\
\hline & $\pm 18 \%$ & $\pm 51 \%$ & $\pm 40 \%$ & $\pm 67 \%$ & $\pm 29 \%$ \\
\hline
\end{tabular}

(a) 2 1/2 in. diameter, 1/16 in. thick, 17/32 in. center hole. Total surface $=64 \mathrm{~cm}^{2}$.

(b) Average of 11 locations in main room.

(c) Coating manufactured by Carboline Company, St. Louis, Missouri. Average 22 locations.

(c) Coating manufactured by Amercoat Corporation, South Gate, California. 


\section{DISCUSSION OF RESULTS}

MIXING OF GAS SPACE

All practical models of fission product transport in containment vessels are based on the assumption that the bulk of the volume within a single room is well mixed. All prior CSE experiments have shown this to be a good assumption, and it was expected that gas phase mixing in the air cleaning runs would be complete. Mixing can be assessed by noting the standard deviation of the measured concentration levels, such as shown in Figure 21. Early in Run A-14, standard deviations are of the order of $20 \%$ of the mean. This degree of variation is about equal to the variation expected as a result of differences in sampled volumes and component analysis. Hence, it is concluded that the gas phase of the main room is well mixed.

At longer times, the concentrations are much lower, and the standard deviations are relatively larger. This larger standard deviation is the result of background contamination which becomes important at the lower concentrations.

Mixing between adjacent rooms is relatively slow, as shown by the gas phase concentration data shown in Figure 10 . The middle room concentration remains below the main room concentration for about 2 hours. These results are similar to earlier spray and natural transport tests in CSE as expected. In all CSE tests, inter-room mixing has been due solely to natural convection.

These observations show that the "well-mixed gas space" assumption would be valid within a single room, but that separate rooms can have different concentrations. COMPARISON OF MEASURED REMOVAL RATE WITH THEORY

A simple model of removal by an air cleaning loop showed that the removal rate was equal to the sum of that due to the loop, and that due to surface deposition: 


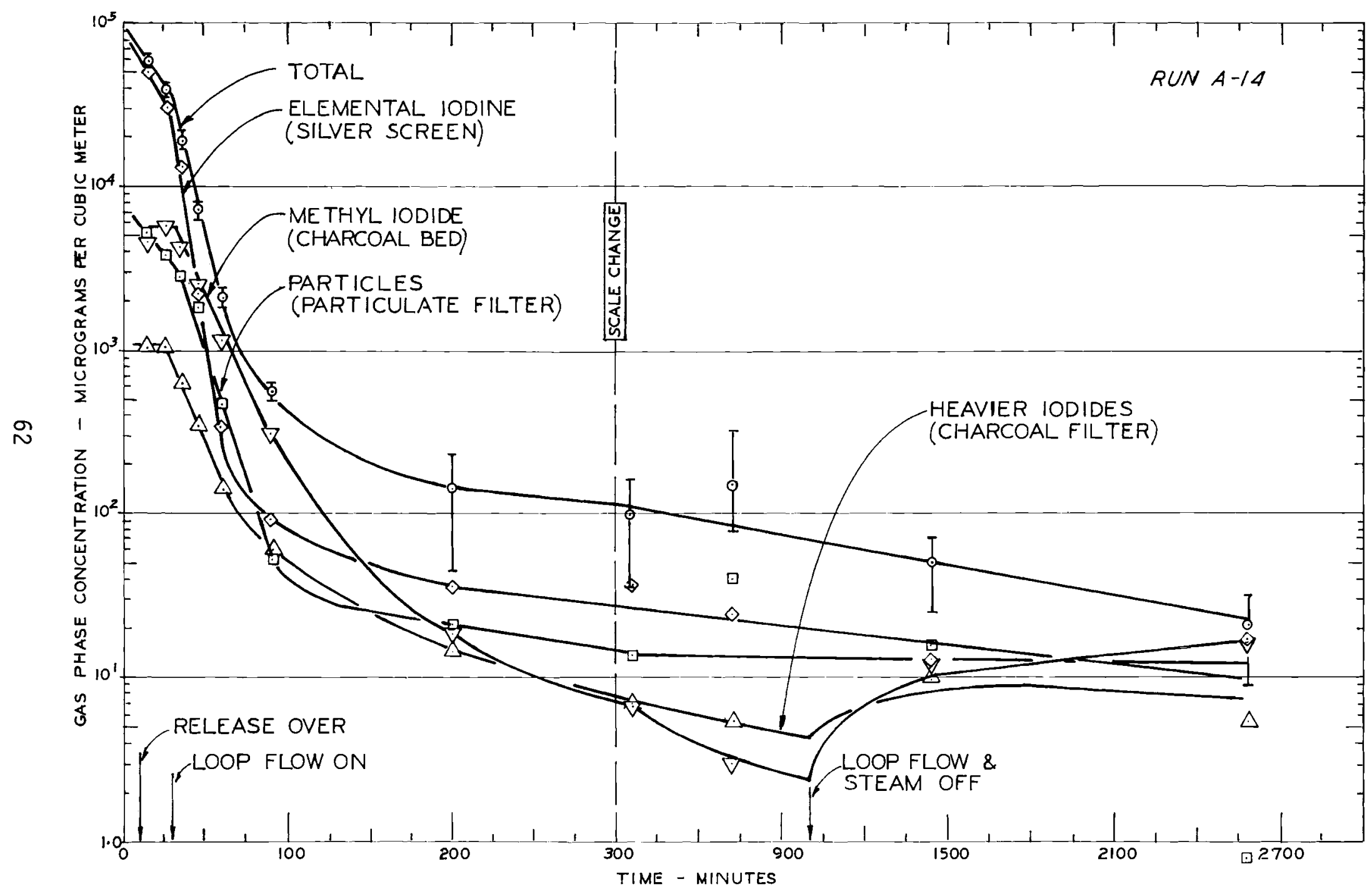

FIGURE 21. Iodine Concentration in the Main Room Gas Space in CSE Run A-14 


$$
-\underbrace{\frac{\mathrm{dC} g}{d t}}_{\text {overa11 }}=\underbrace{\frac{F E}{V} C_{g}}_{\text {loop }}+\underbrace{k_{g} A\left(C_{g}-C_{g i}\right.}_{\text {natural deposition }})
$$

The natural, or surface deposition removal rate, $k_{g} A\left(C_{g}-C_{g i}\right)$ was evaluated by measuring $\frac{d C_{g}}{d t}$ with the loop fan off $(F=0)$. Such a measurement was made at the beginning of four of the five filter loop experiments. From the total observed removal rate, one can obtain that due to the loop:

loop removal rate $=$ overal1 rate - natural deposition rate

In writing Eq (10) it has been assumed that the surface deposition rate is not influenced by the operation of the fan. In reality, the fan operation will agitate the gas phase, causing an increase in the mass transfer coefficient. Initially the loop also dries the air which would reduce the particle size, and potentially reduce the deposition rate of aerosols. Thus Eq (10) will overpredict the loop removal rate by a small increment.

Predicted removal rates are compared to measured rates in Table 18. The removal rates are presented in terms of removal half-times measured early in the run. The measured removal rates are in agreement with predicted in 4 of the 5 runs. This is believed due to enhanced surface deposition of elemental iodine as a result of flow induced mixing.

The removal rate was increased by increasing the flow rate in Run A-17. The increase in removal rate was slightly less than predicted, due apparently to a lowering in removal efficiency for methyl iodide.

Run A-16 used an extended release of fission products, with the loop operating from the beginning. The observed efficiency is some $25 \% 1$ ower than observed in prior runs. This decrease is attributed to drying of the containment atmosphere, which caused a reduced natural deposition rate. Thus it appears that the loop operated at 100\% efficiency, but that our method for correcting for natural transport removal was faulty. 
TABLE 18. Comparison of Observed and Predicted

Fission Product Removal Rates By Filter Loop

Early Concentration Half-Times, $t_{1 / 2}$, minutes

\begin{tabular}{|c|c|c|c|c|c|c|c|c|c|c|c|c|c|c|c|}
\hline \multirow{3}{*}{ CSE Run No. } & \multirow{2}{*}{\multicolumn{3}{|c|}{$A-13$}} & \multirow{2}{*}{\multicolumn{3}{|c|}{$A-14$}} & \multirow{2}{*}{\multicolumn{3}{|c|}{$A-15$}} & \multirow{2}{*}{\multicolumn{3}{|c|}{$A-16$}} & \multirow{2}{*}{\multicolumn{3}{|c|}{ A-17 }} \\
\hline & & & & & & & & & & & & & & & \\
\hline & $\underline{N}$ & $\underline{N+L}$ & $\underline{L}$ & $\underline{N}$ & $\mathrm{N+L}$ & $\underline{\underline{L}}$ & $\underline{N}$ & $\underline{N+L}$ & $\underline{L}$ & $\underline{\underline{N}}$ & $\underline{\mathrm{N}+\mathrm{L}}$ & $\underline{\underline{L}}$ & $\underline{\bar{N}}$ & $\underline{N+L}$ & L \\
\hline Elemental I & 26 & 7.3 & 10.1 & 16 & 4.9 & 7.1 & 27 & 6.0 & 7.7 & 15 & 7.3 & 14.3 & 13 & 3.8 & 5.4 \\
\hline "Particulate" I & 50 & 11 & 14.1 & 27 & 9 & 13.5 & 27 & 10.3 & 16.7 & 36 & 15 & 25.7 & 25 & 6.3 & 8.7 \\
\hline AC Paper & 50 & 16 & 21 & $39(a)$ & 9 & 11.8 & 58 & 10 & $12.5(c)$ & 39 & 13.7 & 14.2 & 20 & 7.7 & 12.5 \\
\hline Char Bed & - & 15 & $15^{(c)}$ & - & 14.3 & $14.3^{(c)}$ & - & 14.7 & 14.7 (c) & - & 16 & ${ }_{16}(\mathrm{~b})$ & - & 11 & ${ }_{11}(\mathrm{~b})$ \\
\hline Cesium & 62 & 11 & 13.7 & 42 & 12.3 & 17.4 & 70 & 13 & 16.0 & 47 & 9.3 & 11.5 & 33 & 7.7 & 10 \\
\hline Uranium & 80 & 14 & 17.0 & 85 & 13 & 15.4 & 70 & 12 & 14.5 & 31 & 16 & 33 & 41 & 8.3 & 10.4 \\
\hline Average & & & 15.15 & & & 13.25 & & & 14.4 & & & 19.1 & & & 9.7 \\
\hline Expected $^{(e)}, \min$ & & & 14.8 & & & 13.5 & & & $14.6^{(d)}$ & & & 14.2 & & & 7.9 \\
\hline Ratio: Exp./Calc & & & .98 & & & 1.02 & & & 1.01 & & & .743 & & & .81 \\
\hline
\end{tabular}

$N=$ Natural $L=$ Loop Only

(a) The natural removal half-time is an average of 8 CSE runs under similar conditions.

(b) Bed moisture equilibrated.

(c) "Dry" Bed.

(d) Excludes (c) above.

(e) $t_{1 / 2}=\frac{0.693 \mathrm{~V}}{\mathrm{~F}}, \mathrm{~F}$ Includes steam condensed. Assumed 10op efficiency $=100 \%$. 
BNWL-1587

APPROACH TO EQUILIBRIUM GAS CONCENTRATION

The initial removal rate continues until several vessel volumes have passed through the loop. The removal rate then decreases and assymptotically approaches zero. The net removal rate does not vanish altogether, however, so that for all CSE loop tests the gas phase concentration was decreasing when the loop flow was terminated.

The change in iodine removal rate with time is depicted in Figure 22, where the normalized removal rate (observed rate/rate for 100\% 10op efficiency) is shown as a function of the number of vessel volumes passed through the loop. The removal rate remains constant at a value $50 \%$ to $110 \%$ higher than the theoretical value until the atmosphere has been turned over 1.5 to 2.5 times. The net removal rate then falls with time. The observed removal rate is equal to the theoretical rate at 2 to 3 turnovers. The removal rate continues to fall with time and is less than $10 \%$ of the theoretical value for times equivalent to more than 10 turnovers.

Similar data for cesium are shown in Figure 23. For cesium, the initial rapid removal rate persists for a longer time. The removal rate does not diminish from the initial value until 3.5 to 5.5 vessel volumes have passed through the air cleaning loop. At long times, the removal rate approaches zero.

The decrease in removal rate may be due to two factors. According to the material balance equation, the net removal is equal to the sum of loop removal and wall absorption:

$$
-\frac{d C_{g}}{d t}=+\underbrace{\frac{F E}{V} C_{g}}_{\begin{array}{c}
\text { loop } \\
\text { removal }
\end{array}}+\underbrace{k_{g} A\left(C_{g}-C_{g i}\right.}_{\begin{array}{c}
\text { wal1 } \\
\text { removal }
\end{array}})
$$

A decrease in net removal rate would be observed if the loop removal efficiency, E, decreased markedly. Also, the net removal rate would decrease if the wall removal term changed sign and became a source term. This would be expected to take place as the gas concentration decreased below the concentration at absorption interfaces: 


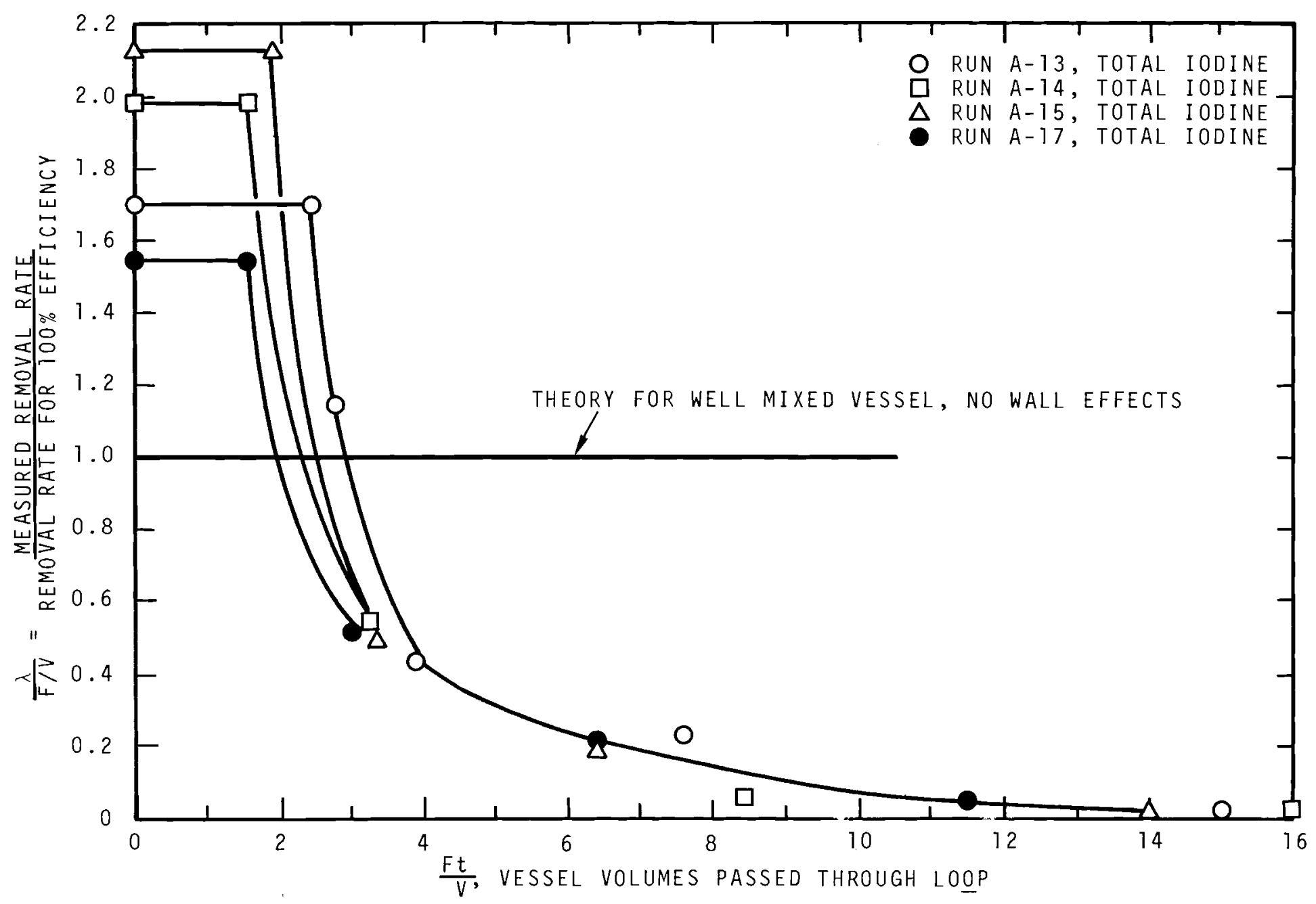

FIGURE 22. Comparison of Iodine Removal Rate With Theory 


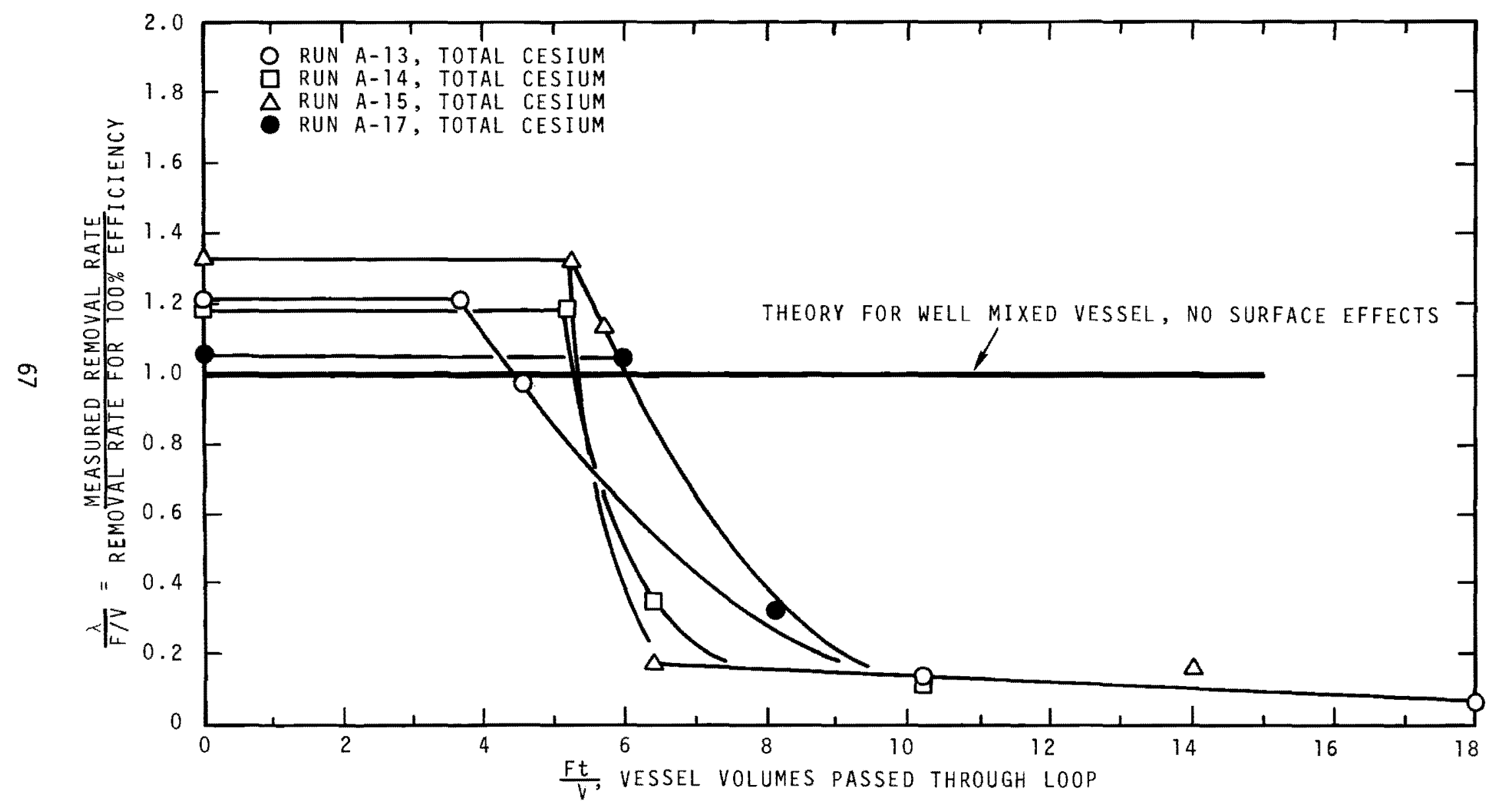

FIGURE 23. Comparison of Cesium Removal Rate With Theory 


$$
C_{g} \leqslant C_{g i}
$$

The loop removal efficiency was measured directly by interstage sampling. The most extensive data were obtained in Run A-16. These are presented in Table 19. The interstage samplers show that the removal efficiencies decrease slightly with time, but the decrease is of a negligible magnitude and could not account for the observed lowering in removal rate. On this basis we must conclude that surface desorption is the controlling factor in causing the removal rate to fall.

An experimental observation which re-enforces the conclusion that surface desorption is the controlling factor, is that in Run A-14, the iodine gas phase concentration appeared to increase when the loop flow was terminated. The airborne iodine concentration for Run $A-14$ is shown in Figure A-2 of the Appendix. An increase in cesium concentration was unobservable, because the concentrations were too close to background level.

The plausibility of release from surfaces was examined by estimating the generation rates which would be needed to maintain a steady state, low level, concentration. For cesium, the concentration at long times was of the order $0.1 \mathrm{~kg} / \mathrm{M}^{3}$. For a loop flow of $1000 \mathrm{cfm}$, the cesium aerosol generation rate needs to be only 3 micrograms per minute. Detachment of drops and bubbles could account for this low generation rate. For iodine, the concentration levels were about 100 times higher, and a generation rate of 300 micrograms per minute would be needed. This, however, amounts to only 3 parts in one million, per minute compared to the amount of iodine injected. This is plausible.

A simple model which accounts for desorption may be constructed as pictured in Figure 24. 
TABLE 19. Measured Loop Decontamination Factors, (a) Run A-16

\begin{tabular}{|c|c|c|c|c|c|c|c|c|c|c|c|c|}
\hline \multirow{2}{*}{ Time, Minutes ${ }^{(d)}$} & \multicolumn{3}{|c|}{30} & \multicolumn{3}{|c|}{85} & \multicolumn{3}{|c|}{110} & \multicolumn{3}{|c|}{180} \\
\hline & $\underline{\mathrm{Cs}}$ & $I$ & $\mathrm{CH}_{3} \mathrm{I}$ & $\underline{\mathrm{Cs}}$ & $\underline{I}$ & $\mathrm{CH}_{3} \mathrm{I}$ & $\underline{\mathrm{Cs}}$ & $\underline{I}$ & $\mathrm{CH}_{3} \mathrm{I}$ & $\underline{\mathrm{Cs}}$ & $\underline{I}$ & $\mathrm{CH}_{3} \mathrm{I}$ \\
\hline$H E X+M E$ & 3 & 1 & 1 & 4 & 1 & 1 & 4 & 1 & 1 & 3 & 1 & 1 \\
\hline Prefilter & 3 & 4 & 1 & 1 & 2 & 1 & 1 & 2 & 1 & 1 & 2 & 1 \\
\hline HEPA & $>200$ & 18 & 1 & 1000 & 3 & 1 & 700 & 2 & 1 & $>15^{(b)}$ & 1 & 1 \\
\hline 1st Char Bed & & 10 & 2 & & 15 & 2 & & 20 & 2 & & 10 & 2 \\
\hline 2nd Char Bed & & 6 & 5 & & 8 & 4 & & 10 & 3 & & $>2^{(b)}$ & 1 \\
\hline $\begin{array}{l}\text { 3rd Char Bed } \\
\text { Overall }(c)\end{array}$ & $>2000^{(b)}$ & 4300 & 53 & 4500 & 1000 & 30 & 2900 & $>1000^{(b)}$ & 20 & $>40^{(b)}$ & $>100^{(b)}$ & 30 \\
\hline $\begin{array}{l}\text { (a) DF = Conc. } \\
\text { (b) Measured d } \\
\text { (c) Best estim } \\
\text { (d) Loop flow }\end{array}$ & $\begin{array}{l}\text { in/Conc. } 0 \\
\text { wnstream c } \\
\text { te of all } \\
\text { tarted at }\end{array}$ & $\begin{array}{l}t ; \text { Eff } \\
\text { nc. wa } \\
\text { ompone } \\
-10)\end{array}$ & $\begin{array}{l}\text { ciency } \\
\text { less } \\
\text { ts. }\end{array}$ & $\begin{array}{l}1-1 / \\
n \text { the }\end{array}$ & $\begin{array}{l}\mathrm{F} . \\
\text { lank. }\end{array}$ & & & & & & & \\
\hline
\end{tabular}


BNWL-1587

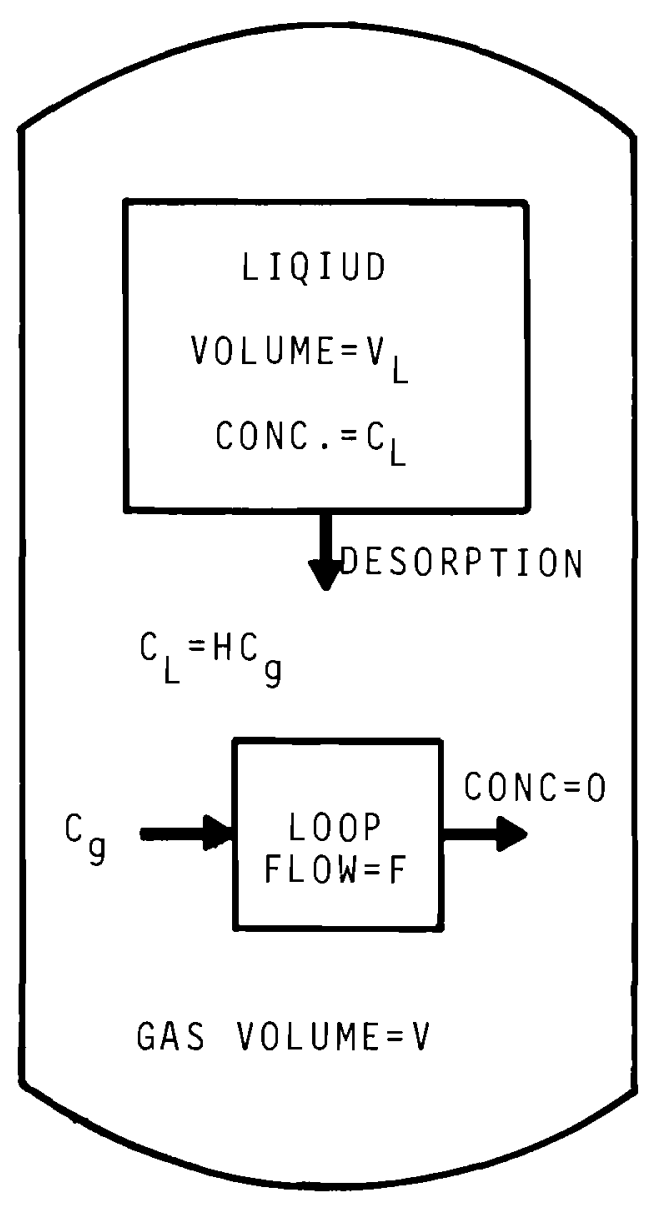

FIGURE 24. Model of Surface Desorption Influence

If equilibrium between the gas and liquid phase is assumed, the input rate to the gas phase

$$
\text { input rate from liquid }=V_{L} \frac{d C_{L}}{d t}
$$

The output rate from the gas phase is

$$
\text { output rate }=\mathrm{FC}_{\mathrm{g}}
$$

and the accumulation rate within the gas phase is

$$
\text { accumulation rate }=\frac{\mathrm{dC}}{\mathrm{dt}}
$$

From a material balance, equations (11), (12), and (13), lead to

$$
V_{L} \frac{d C_{\ell}}{d t}=F C_{g}+V \frac{d C_{g}}{d t}
$$


Using the equilibrium relation, $C_{L}=H C_{g}$ equation (14) may be written as

$$
-\frac{d C_{g}}{d t}=\frac{-F C_{g}}{V\left(1+\frac{V_{L} H}{V}\right)}
$$

Thus the removal rate is diminished from the ideal, non-desorption case by a factor of $\left(1+\frac{V_{L} H}{V}\right)$. For the CSE experiments, $V_{L} / V$ varied with time. For long times, it was about 0.01 . Thus with a partition coefficient of 1000 , the loop removal rate would be reduced to $10 \%$ of the value for no surface effects. This simple model thus appears to reasonably fit the observations.

In summary, surface desorption effects play an important role in describing removal of airborne fission products by filter loops. Neglection of surface effects is conservative for short times. At longer times, the surface desorption represents a source term which appreciably slows the removal rate.

EFFECT OF HEAT EXCHANGER AND MIST ELIMINATOR ON LOOP OPERATION

Deletion of the heat exchanger and mist eliminator from the loop during Run A-15 did not significantly reduce the loop effectiveness, but stressed the system in two ways. First, the HEPA pressure difference increased more during this run than in the runs which used the omitted components. The observed pressure drops for Run $A-15$ are shown in Figure 25. The total loop $\Delta \mathrm{P}$ decreased to nearly normal values during the DOP test performed after the run.

Moisture may have carried over to the first charcoal bed, as an increase in $\Delta \mathrm{P}$ was noted there also. Both iodine and cesium removal efficiencies remained high for the loop which did not incorporate the heat exchanger and mist eliminator.

The second effect of deleting the mist eliminator is to increase the fission product loading on the HEPA filter and charcoal. The moisture eliminator is an effective prefilter, and together with the heat exchanger 


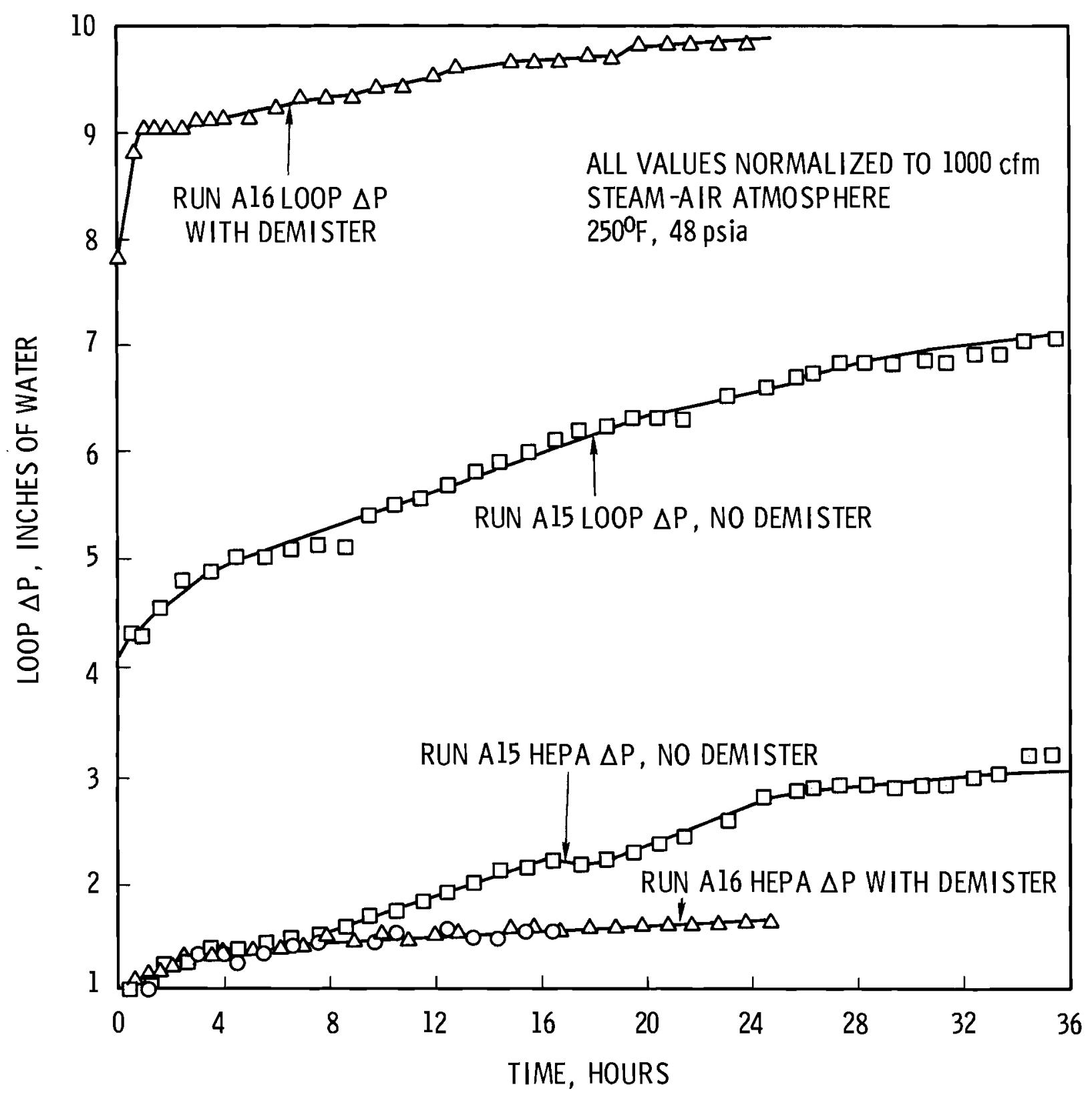

FIGURE 25. Effect of Heat Exchanger and Mist Eliminator on Loop Pressure Drop 
can remove $50 \%$ to $70 \%$ of the cesium from the inlet gas. For iodine, this effect is smaller. Only $3 \%$ to $4 \%$ of the iodine is removed by these two components. The efficiency of the moisture separated or for cesium particles is somewhat less than expected, however. Hilliard ${ }^{(2)}$ estimates the $C s$ to be present as droplets about 10 microns in diameter, and Peters ${ }^{(22)}$ calculates the separator to be $98 \%$ efficient for 10 micron particles. We measure about 50 to $70 \%$, which is significantly less than estimated from Peters ${ }^{(22)}$ work. Although we can postulate no reason for it, it is possible that drops may evaporate during passage through the mist eliminator and the measured efficiency would then be explained by the smaller particle sizes. Cascade impactor sampling during the runs indicated that the cesium particles were only 0.5 to $1 \mu$, which is more consistent with the low removal efficiency for the mist eliminator. INFLUENCE OF RELATIVE HUMIDITY ON METHYL IODIDE ADSORPTION

The efficiency of charcoal for removal of methyl iodide from humid containment atmospheres is important in determining the overal1 removal of iodine. The CSE tests were al1 made under conditions of $100 \%$ relative humidity. The atmospheric conditions were established by addition of saturated steam. All vessel heat loss was at the outer surfaces and no significant sources of internal heat (except the fan motor and lamps which amounted to about $10 \mathrm{KW}$ maximum compared to $\sim 100 \mathrm{KW}$ of external losses) existed, hence it may be expected that the vessel atmosphere was saturated with water.

As noted in an earlier section, charcoal heating due to moisture adsorption had been measured. Two types of charcoal tests were made. In one type of test the charcoal was exposed to steam and methyl iodide simultaneously. In the second the charcoal was exposed to the steam air atmosphere first, allowing the bed to become saturated with water vapor at the test conditions prior to exposure to the methyl iodide. Good removal of methyl iodide by the iodine impregnated charcoal was observed in both cases. Table 20 gives the charcoal efficiencies as determined by the observed main room half times. 
TABLE 20. Methy1 Iodide Removal By Charcoal

\begin{tabular}{|c|c|c|c|c|c|c|}
\hline \multirow[b]{2}{*}{ Run } & \multirow{2}{*}{$\begin{array}{l}\operatorname{Calc}^{(b)} \\
t_{1 / 2} \\
\underline{\min } \\
\end{array}$} & \multicolumn{2}{|c|}{ Dry (Self-Heated) } & \multicolumn{2}{|c|}{ Saturated } & \multirow[b]{2}{*}{$\begin{array}{l}\text { Integrated (c) } \\
\text { Efficiency, } \%\end{array}$} \\
\hline & & $\begin{array}{l}\mathrm{t}_{1 / 2}, \\
\min \end{array}$ & $\underline{\operatorname{Eff}}(a)_{\%}$ & $\begin{array}{l}t 1 / 2 \\
\min \end{array}$ & $E f f(a)_{\%}$ & \\
\hline$A-13$ & 14.8 & 15 & 99 & & & 99.2 \\
\hline$A-14$ & 13.5 & 14.3 & 94 & & & 99.98 \\
\hline$A-15$ & 14.6 & 14.7 & 99 & 19 & 77 & 99.96 \\
\hline A-16 & 14.2 & & & 16 & 89 & 99.992 \\
\hline$A-17$ & 7.9 & & & 11 & 72 & 99.993 \\
\hline Averas & & & $97.3 \%$ & & $79.3 \%$ & \\
\hline (a) & Efficiency = & $\frac{t_{1 / 2}}{t_{1 / 2}}$ & $\frac{\text { culated }}{\text { erved }}$ & & & \\
\hline (b) & $t_{1 / 2}$ calcula & ed $=0.6$ & $3 \mathrm{~V} / \mathrm{F}$ & & & \\
\hline (c) & Integr & & $\%=\frac{\mathrm{CH}}{\mathrm{CH}}$. & $\frac{\text { Remove }}{\text { ReTeas }}$ & 100 & \\
\hline
\end{tabular}

In the tests where fission products and steam were exposed simultaneously, the self-heating of the charcoal prevents condensation in the bed. However, use of beds which had been previously saturated with water vapor also show good removal. The integrated removal of methyl iodide as shown in Table 20 is essentially the same for both types of experiments.

Normal applications of charcoal beds for $\mathrm{CH}_{3}$ I removal use 2 " of charcoal at a face velocity of about 45 feet per minute. The residence time in the bed is thus about 0.22 seconds. Matching of the flow of the HEPA filter and a single $2 \times 2$ face area charcoal unit in the CSE loop required use of three 1" deep beds in series. The residence time at 1000 cfm was about $0.21 \mathrm{sec}$, which is nearly equal to the recommended practice. Thus the charcoal performance should be equivalent to a 2 " deep bed operated at $45 \mathrm{fpm}$. In addition the three individual layers provide a better opportunity to examine the iodine loading vs depth. The measurements made indicate that most of the iodine is trapped on the first $1 / 2^{\text {" }}$ of the first bed. Only small amounts of iodine were found in the downstream charcoal, as shown in Table 7. 


\section{FILTER LOOP CLEANUP IN PWR CONTAINMENT VESSELS}

PWR containment vessels are much larger than the CSE vessel, hence the removal rate data obtained in the CSE tests do not apply directly. Following are general recommendations for analyzing fission product removal by filter loops.

First, the removal efficiency for all fission product species except methy 1 iodide may be taken as $100 \%$. For methy 1 iodide the removal efficiency depends on the relative humidity. The lowest efficiency observed in CSE tests with 100\% relative humidity was $77 \%$ at $1000 \mathrm{cfm}$, for three beds in series (residence time of $0.21 \mathrm{sec}$ ). Thus for methyl iodide a loop removal efficiency of $75 \%$ is justified for containment vesse 1 usage.

Initially, the gas phase removal rate will be equal to the loop removal rate and surface deposition term as described in equation (6). The surface deposition rates may be estimated from data presented by Knudsen ${ }^{(1)}$ and Hilliard ${ }^{(2)}$.

After two volumes have been turned over by the loop, surface deposition of iodine should be ignored, and a reversible source, such as described by Eq (15) should be factored in. Generally, the partition coefficient must be predicted. For this we recommend CSE data be used. Selection of CSE data must be based on a particular solution type. For example, the partition coefficient of a liquid pool containing only boric acid would be much lower than a solution of $\mathrm{NaOH}$ having a much higher $\mathrm{pH}$. The higher pH solutions will minimize the iodine desorption as the airborne concentrations decrease. For particulate materials, the $100 \%$ removal rate will persist until four containment volumes have passed through the loop. For longer times a source term should again be factored in. The source strength may be estimated from conservative use of data shown in Figure 23.

If reactive sprays are used in conjunction with a filter 10op, one would conclude that elemental iodine removal will be governed almost entirely by spray washout. Methyl iodide will, on the other hand, be 
BNWL- 1587

removed only by the filter loop. Particulate materials will fall between, being removed by both the sprays and filter loop.

\section{ACKNOWLEDGEMENTS}

These experiments required the efforts of many persons and would not have been successful without their full cooperation. We are pleased to acknowledge the help of the entire CSE staff. In addition, we wish to recognize the contributions of G. J. Rogers, Manager of Reactor Safeguards Experiment Section, B. M. Johnson, Manager of Fluids and Energy Systems Section, L. F. Coleman, and C. E. Linderoth of the RSE staff, in the completion of this work. 


\section{NOMENCLATURE}

a = effective surface of adsorbent per unit volume of bed

$A=$ interfacial area for mass transfer

$\mathrm{B}_{1}=$ inter-room transport coefficient

$\mathrm{C}_{\mathrm{g}}=$ mass concentration in gas of main room

$C_{g i}=$ solute concentration at interface

$C_{\text {go }}=$ mass concentration in gas at $t=0$

$C_{g i}=$ concentration in gas of adjacent room

$c_{1}=$ concentration in inlet gas

$C_{2}=$ concentration in effluent gas

$c_{L}=$ concentration of solute in liquid phase

$d_{p}=$ average carbon particle diameter

$D_{v}=$ gas phase diffusivity

$\mathrm{E}=$ fraction of airborne species removed by filter in a single pass

$\mathrm{F}=$ flow rate through filter loop

$G \quad=$ fission product mass injection rate

$\mathrm{H}=$ iodine gas-liquid partition coefficient

$k=$ thermal conductivity

$\mathrm{k}_{\mathrm{g}} \quad=$ interfacial mass transfer coefficient

$\mathrm{R}=$ rate of production of a species by a vapor phase reaction

$\operatorname{Re}_{p}=$ Reynolds number for a granule $=\rho d_{p} U / \mu$

Sc $=$ Schmidt number $=\mu / \rho D_{v}$

$t=$ time

$U \quad=$ superficial gas velocity

$\mathrm{V}=$ main gas volume

$V_{L} \quad=$ liquid volume

$x_{0}=$ depth of charcoal bed

Greek Symbols

$\rho \quad=$ density of gas

$\mu=$ absolute viscosity of gas 
BNWL-1587

\section{REFERENCES}

1. J. G. Knudsen and R. K. Hilliard. "Fission Product Transport By Natural Processes in Containment Vesse1s", BNWL-943, BattelleNorthwest, Richland, Washington, January 1969.

2. R. K. Hilliard and L. F. Coleman. "Natural Transport Effects on Fission Product Behavior in the Containment Systems Experiment", BNWL-1457, Battel1e-Northwest, Richland, Washington, December 1970.

3. R. K. Hilliard, L. F. Coleman, C. E. Linderoth, J. D. McCormack, and A. K. Postma. "Removal of Iodine and Particles From Containment Atmospheres By Sprays -- Containment Systems Experiment Interim Report", BNWL-1244, Battelle-Northwest, Richland, Washington, February 1970.

4. A. K. Postma and L. F. Coleman. "Effect of Continuous Spray Operation on the Removal of Aerosols and Gases In The Containment Systems Experiment", BNWL-1485, Batte1le-Northwest, Richland, Washington, December 1970.

5. A. K. Postma and R. K. Hilliard. "Effect of Spray Flow Rate on Washout of Gases and Particles In The Containment Systems Experiment", BNWL-1591, Battelle-Northwest, Richland, Washington, June 1971.

6. H. N. Culver. "Effect of Engineered Safeguards on Reactor Siting", Nuclear Safety, Vol. 7, No. 3, p. 324, Spring, 1966.

7. Code of Federal Regulations, Title 10, Part 100, Reactor Site Criteria. Federal Register, Vol. 26, No. 28, p. 1224.

8. C. A. Burchsted and A. B. Fuller. "Design, Construction, and Testing of High Efficiency Air Filtration Systems for Nuclear Application", ORNL-NSIC-65, Oak Ridge National Laboratory, Oak Ridge, Tennessee, 1970.

9. M. Dale and I. M. Klotz. "Sorption of Cloropicrin Phosgene on Charcoal from a Flowing Gas Stream", Ind. Engr. Chem., Vol. 38, No. 12, pp 1289-1297 (1964).

10. G. H. Prigge. "Application of Activated Carbon in Reactor Containment", DP-778, Savannah River Laboratory, Aiken, South Carolina, 1962.

11. R. C. Milham. "Desorption of Iodine From Activated Carbon," DP-MS-69-62, Savannah River Laboratory, Aiken, South Carolina, November, 1969. 
12. R. E. Adams and W. E. Browning, Jr., "Removal of Radioiodine From Air Streams by Activated Charcoa1", ORNL-2872, Oak Ridge, Tennessee, March 1960.

13. R. E. Adams, et a1. "Removal of Radioactive Methyl Iodide From SteamAir Sys tems", ORNL-4040, Oak Ridge National Laboratory, Oak Ridge, Tennessee, 1967.

14. R. D. Ackley and R. E. Adams. "Removal of Radioactive Methyl Iodide From Steam-Air Sys tems (Test Series II)", ORNL-4180, Oak Ridge National Laboratory, Oak Ridge, Tennessee, 1967.

15. J. L. Kovach. "Review of Methyl Iodide Isotopic Exchange Under Accident Conditions", NACAR 010003, North American Carbon, Inc., Columbus, Ohio, 1970.

16. C. E. Linderoth. "Containment Systems Experiment, Part I, Description of Experimental Facilities", BNWL-456, Battelle-Northwest, Richland, Washington, March 1970.

17. J. D. McCormack. "Maypack Behavior In the Containment Systems Experiment -- A Penetrating Analysis", BNWL-1145, Battelle-Northwest, Richland, Washington, August 1969.

18. L. F. Coleman. "Preparation, Generation, and Analysis of Gases and Aerosols for the Containment Sys tems Experiment", BNWL-1001, BattelleNorthwest, Richland, Washington, Apri 11969.

19. R. K. Hilliard, L. F. Coleman and J. D. McCormack. "Comparisons of the Containment Behavior of a Simulant with Fission Products Released From Irradiated $\mathrm{UO}_{2} "$, BNWL-581, Battelle-Northwest, Richland, Washington, March 1968.

20. B. F. Roberts, S. H. Freid, G. W. Parker, L. F. Parsly, and T. H. Row. "Evaluation of Various Methods of Fission Product Aerosol Simulation", ORNL-TM-2628, Oak Ridge National Laboratory, Oak Ridge, Tennessee, September 1969.

21. J. Mishima. "Methyl Iodide Behavior in Systems Containing Airborne Radioiodine", Nuclear Safety, Vol. 9, pp 35-42 (1968).

22. A. H. Peters. "Application of Demisters and Particulate Filters in Reactor Containment, UP-812, Savannah River Laboratory, Aiken, South Caroline, 1962.

23. L. F. Coleman. "Iodine Gas-Liquid Partition", Nuclear Safety Quarterly Report, February, March, Apri1 1970, BNWL-1315-2. Batte11e-Northwest, Richland, Washington, May 1970, pp 2.12-2.19. 


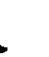


BNWL-1587

\section{APPENDIX}

Tables and Figures of data from the five air cleaning runs are attached. Adequate information is given to support the conclusions drawn in the report and to present detailed information for the use of other workers. 


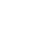


TABLE A-1. Measured Loop Decontamination Factors, Run A-13

\begin{tabular}{|c|c|c|c|c|c|c|}
\hline & & $60 \mathrm{Min}$. & & & 00 Min & \\
\hline & $\underline{\mathrm{Cs}}$ & $\underline{I}$ & $\mathrm{CH}_{3} \mathrm{I}$ & $\underline{\mathrm{Cs}}$ & $I$ & $\mathrm{CH}_{3} \mathrm{I}$ \\
\hline Prefilter & 2 & - & 1 & 1 & - & 1 \\
\hline HEPA & $>5000$ & - & 1 & $>2000$ & - & 1 \\
\hline 1st CB & - & 270,000 & 4 & - & 170 & 4 \\
\hline 2nd $C B$ & - & - & 16 & - & - & 1.5 \\
\hline 3rd $C B$ & - & - & 28 & - & - & 2.7 \\
\hline Overall & $>10,000$ & $>270,000$ & 1800 & $>2000$ & $>170$ & 17 \\
\hline
\end{tabular}


BNWL-1587

TABLE A-2. Measured Loop Decontamination Factors, Run A-14

\begin{tabular}{|c|c|c|c|c|c|c|}
\hline & & 35 Min. & & & 90 Min & \\
\hline & $\underline{C s}$ & $\underline{I}$ & $\mathrm{CH}_{3} \mathrm{I}$ & $\underline{\mathrm{Cs}}$ & I & $\mathrm{CH}_{3}$ \\
\hline Hex + Dem. & 3.5 & 1.4 & - & 3 & 2.2 & - \\
\hline Prefilter & 1.7 & 1.6 & - & 1 & 1 & - \\
\hline HEPA & 6800 & 1.7 & 1 & 2500 & 1 & 1 \\
\hline lst CB & - & $>1500$ & 4.2 & - & $>70$ & 2 \\
\hline 2nd $C B$ & - & 210 & 120 & - & $\sim 3$ & 4 \\
\hline $3 r d C B$ & - & - & & - & - & 4 \\
\hline Overall & 41,000 & $>55,000$ & 420 & 7700 & $>176$ & 32 \\
\hline
\end{tabular}


BNWL-1587

TABLE A-3. Measured Loop Decontamination Factors, Run A-15

\begin{tabular}{|c|c|c|c|c|c|c|}
\hline & \multicolumn{3}{|c|}{$35 \mathrm{Min}$} & \multicolumn{3}{|c|}{$90 \mathrm{Min}$} \\
\hline & $\underline{\mathrm{Cs}}$ & $\underline{I}$ & $\mathrm{CH}_{3} \mathrm{I}$ & $\underline{\mathrm{Cs}}$ & I & $\mathrm{CH}_{3}$ \\
\hline Prefilter & 1 & 1 & - & - & 1 & - \\
\hline HEPA & - & 1.6 & 1 & - & 2 & 1 \\
\hline 1st CB & - & 1400 & 2.5 & - & $>60$ & 1.7 \\
\hline 2nd $C B$ & - & - & 80 & - & - & 4.6 \\
\hline 3rd $C B$ & - & - & 10 & - & - & 4 \\
\hline Overall & 6000 & $>250,000$ & 2000 & 2000 & $>1000$ & 34 \\
\hline
\end{tabular}


TABLE A-4. Measured Loop Decontamination Factors, (a) Run A-16

\begin{tabular}{|c|c|c|c|c|c|c|c|c|c|c|c|c|}
\hline \multirow[t]{2}{*}{ Time, Minutes (d) } & \multicolumn{3}{|c|}{30} & \multicolumn{3}{|c|}{85} & \multicolumn{3}{|c|}{110} & \multicolumn{3}{|c|}{180} \\
\hline & $\underline{\mathrm{Cs}}$ & $\underline{I}$ & $\mathrm{CH}_{3} \mathrm{I}$ & $\underline{C s}$ & $\underline{I}$ & $\mathrm{CH}_{3} \mathrm{I}$ & $\underline{\text { Cs }}$ & $\underline{I}$ & $\mathrm{CH}_{3} \mathrm{I}$ & $\underline{\mathrm{Cs}}$ & $\underline{I}$ & $\mathrm{CH}_{3} \mathrm{I}$ \\
\hline HEX + Dem & 3 & 1 & 1 & 4 & 1 & 1 & 4 & 1 & 1 & 3 & 1 & 1 \\
\hline Prefilter & 3 & 4 & 1 & 1 & 2 & 1 & 1 & 2 & 1 & 1 & 2 & 1 \\
\hline HEPA & $>200$ & 18 & 1 & 1000 & 3 & 1 & 700 & 2 & 1 & $>15^{(b)}$ & 1 & 1 \\
\hline 1st Char Bed & & 10 & 2 & & 15 & 2 & & 20 & 2 & & 10 & 2 \\
\hline 2nd Char Bed & & 6 & 5 & & 8 & 4 & & 10 & 3 & & $>2^{(b)}$ & 1 \\
\hline \multicolumn{13}{|l|}{ 3rd Char Bed } \\
\hline Overal1 ${ }^{(c)}$ & $>2000^{(b)}$ & 4300 & 53 & 4500 & 1000 & 30 & 2900 & $>1000^{(b)}$ & 20 & $>40^{(b)}$ & $>100^{(b)}$ & 30 \\
\hline \multirow{4}{*}{\multicolumn{13}{|c|}{$\begin{array}{l}\text { (a) } D F=\text { Conc. in/Conc. out; Efficiency }=1-1 / D F \text {. } \\
\text { (b) Measured downstream conc. was less than the blank. } \\
\text { (c) Best estimate of all components. }\end{array}$}} \\
\hline & & & & & & & & & & & & \\
\hline & & & & & & & & & & & & \\
\hline (d) Loop flow st & ed at $(-10$ & $\min$. & $a^{2}$ & elease & starte & at $(1$ & in. & & & & & \\
\hline
\end{tabular}




\section{TABLE A-5. Measured Loop Decontamination Factors, (a) Run A-17}

Time, minutes $(b)$

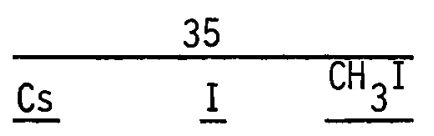

HEX

Dem

HEPA

lst Char Bed

2nd Char Bed

3rd Char Bed

Overall $(c)$

$\begin{array}{crr}1.2 & 1.3 & \\ 6.2 & 1.3 & \\ 44 & 1.6 & \\ & 470 & 1.7 \\ & >7 & \end{array}$

$27,000>8000 \quad 12$

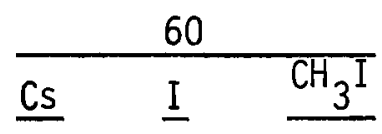

$1.2 \quad 1.6$

$3.7 \quad 1.1$

40

85

1.7

$1900>120 \quad 10$

$\frac{80}{\underline{\mathrm{Cs}} \quad \underline{\mathrm{I}} \underline{\mathrm{CH}_{3} \mathrm{I}}}$

$1.2 \quad 1.4$

$2.4 \quad 2.5$

$>13$

1.7

(a) $\quad D F=$ Conc. in/Conc. out; Efficiency $=1=1 / D F$

(b) Loop flow started at $t=30 \mathrm{~min}$.

(c) Best estimate of al1 components. 


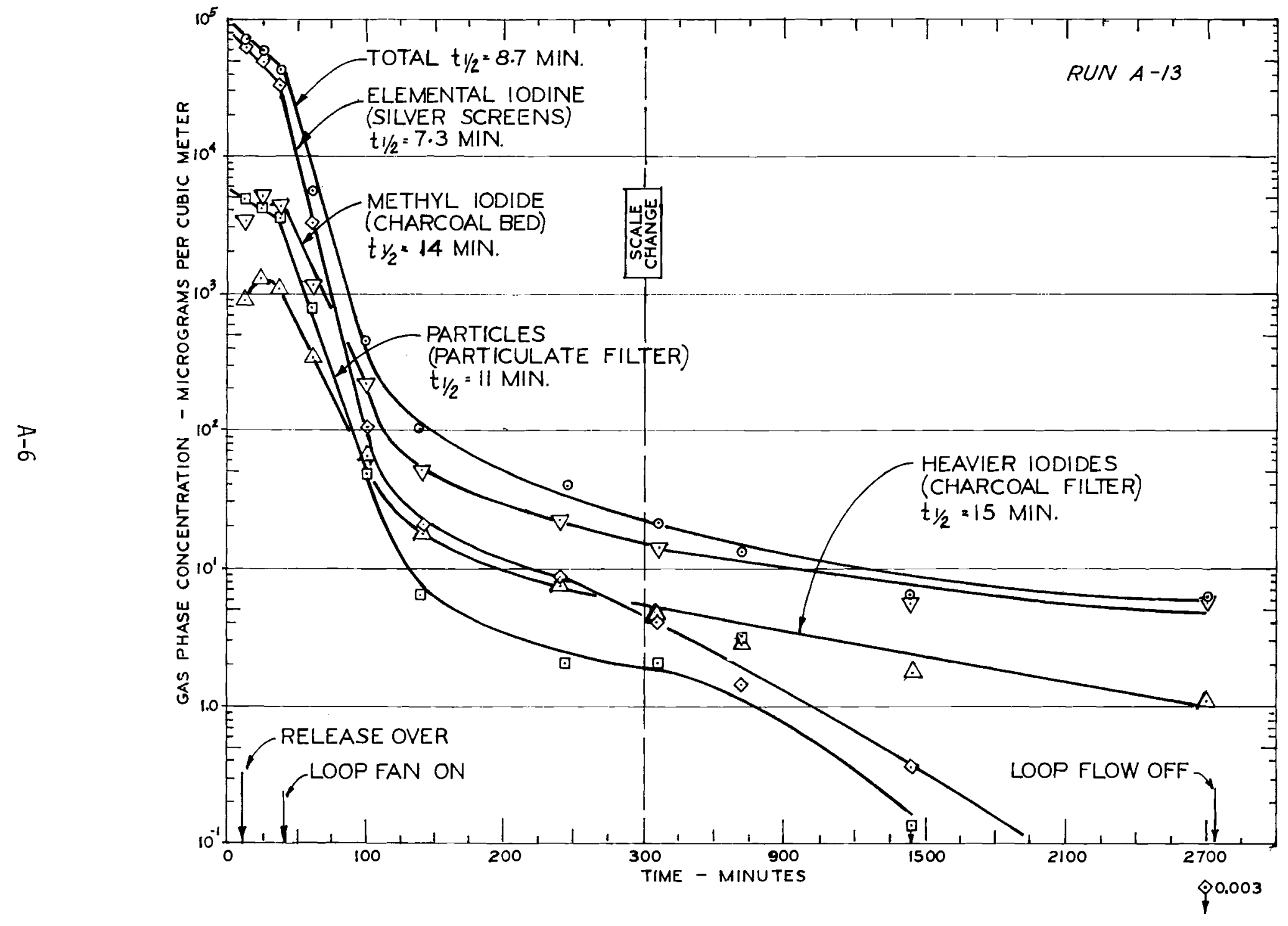

FIGURE A-1. Iodine Concentration in the Main Room Gas Space in CSE Run A-13 


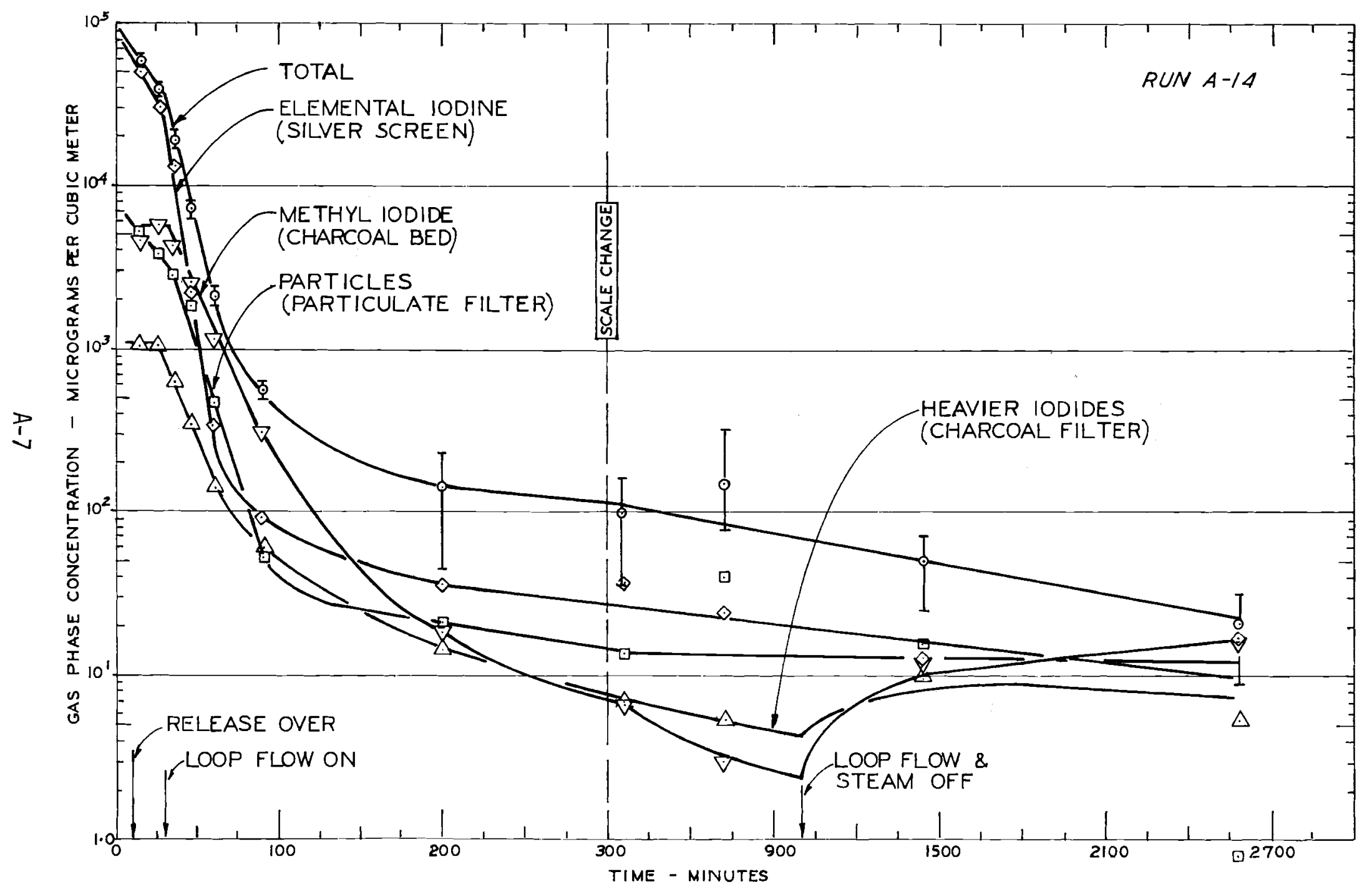

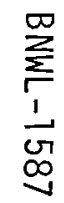

FIGURE A-2. Iodine Concentration in the Main Room Gas Space in CSE Run A-14 


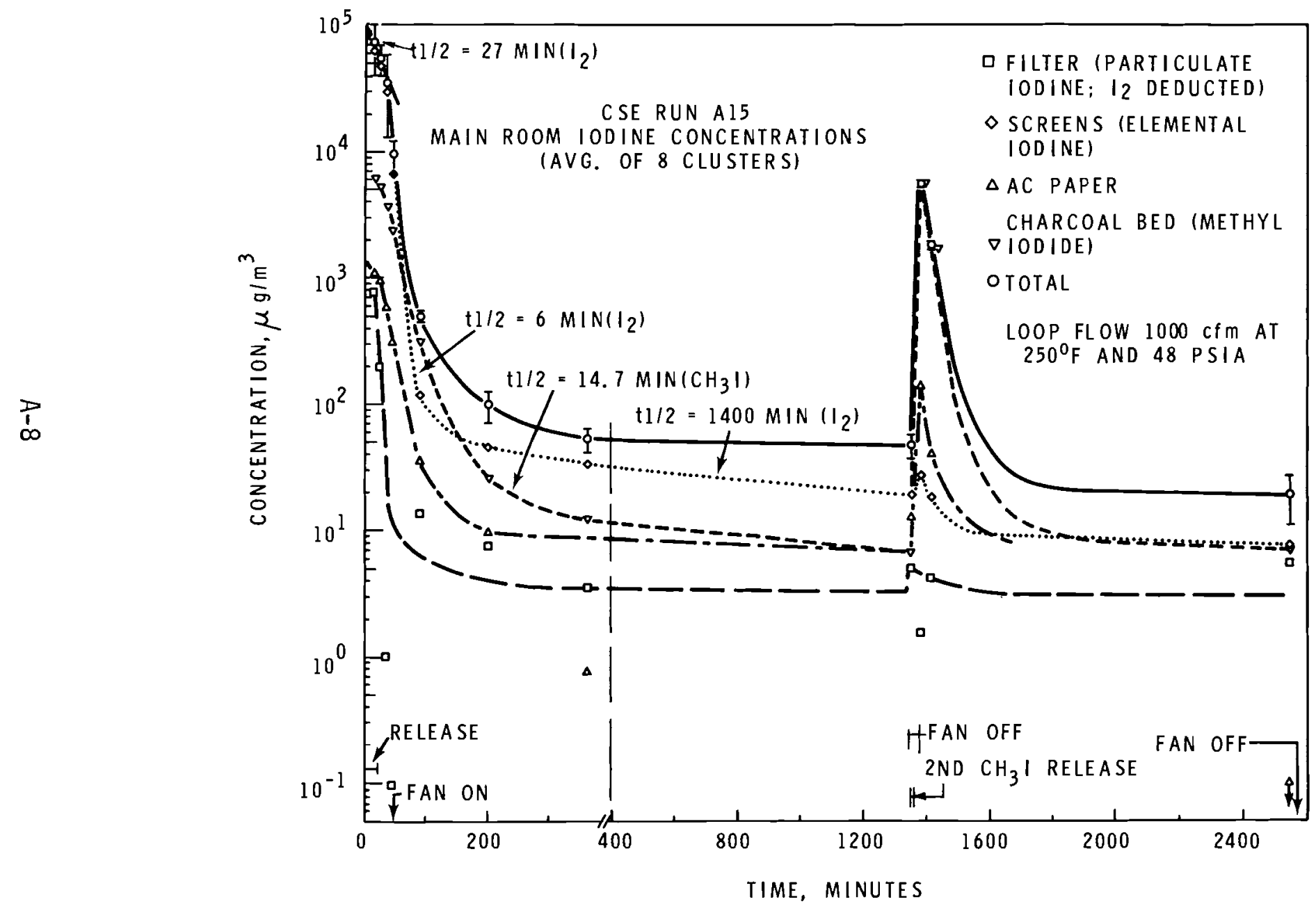

Neg. No. 700315-4 FIGURE A-3. Iodine Concentration in the Main Room Gas Space in CSE Run A-15 


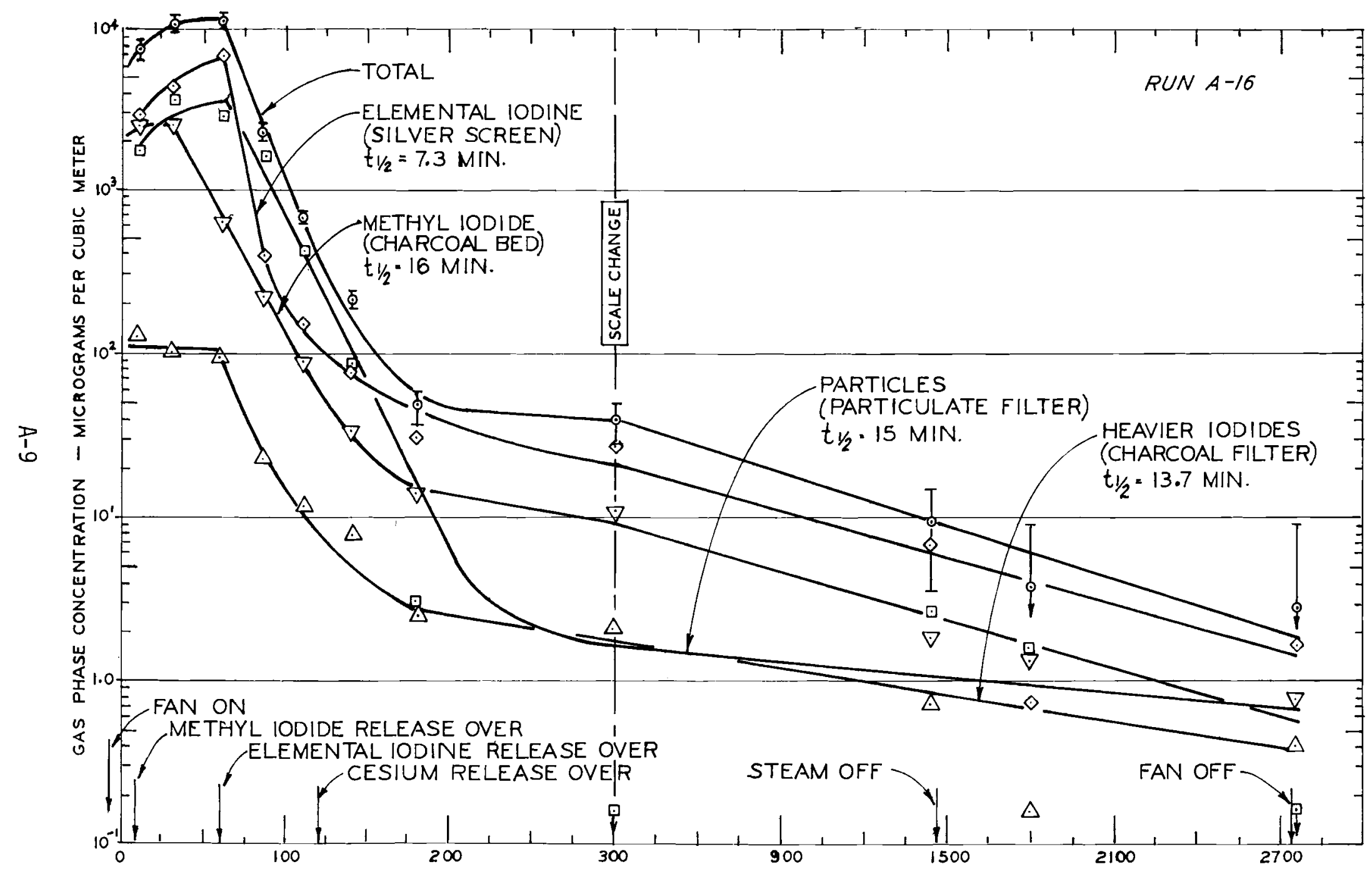

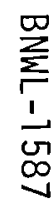

FIGURE A-4. Iodine Concentration in the Main Room Gas Space in CSE Run A-16 
BNWL-1587

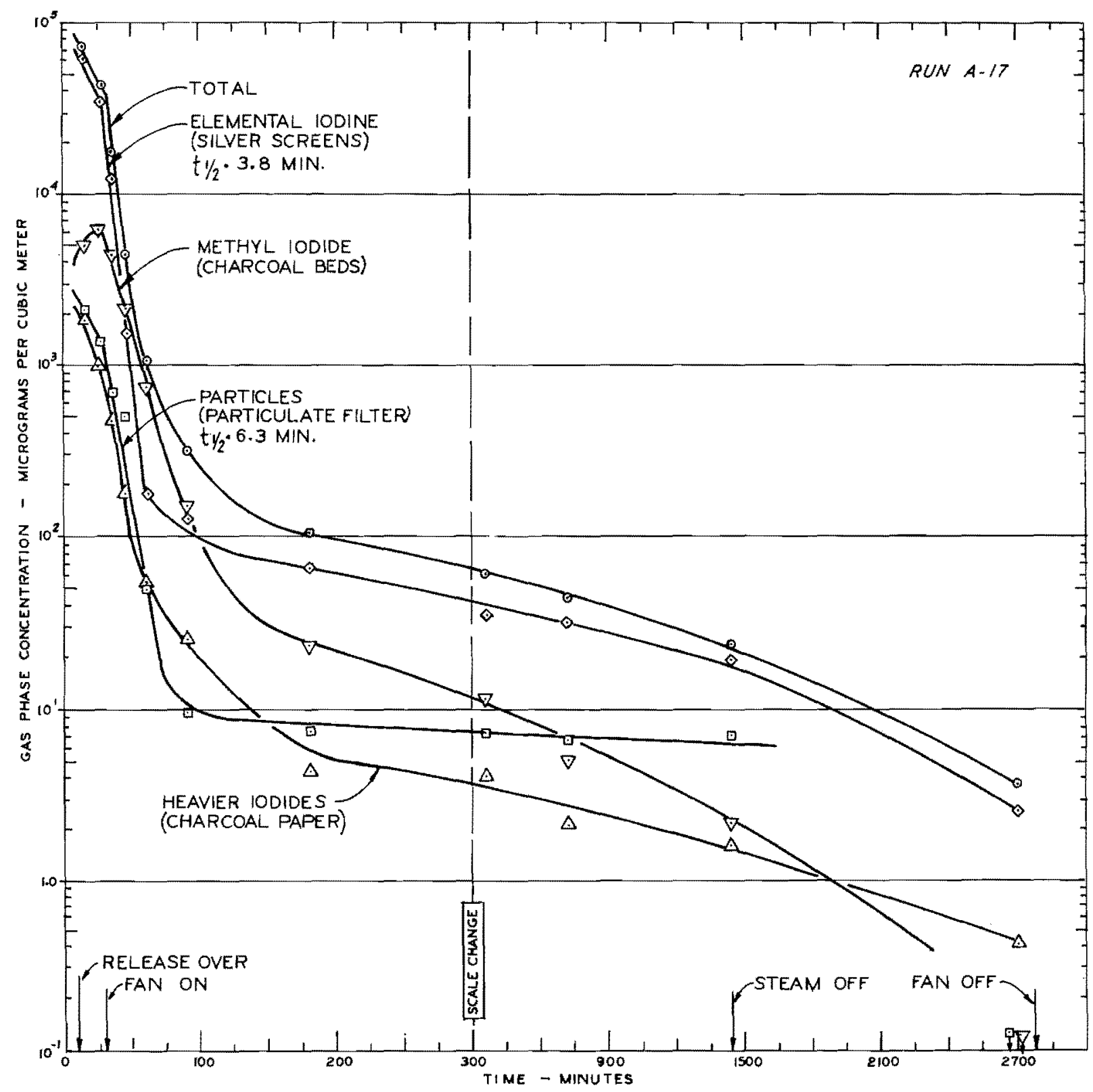

FIGURE A-5. Iodine Concentration in the Main Room Gas Space in CSE Run A-17 


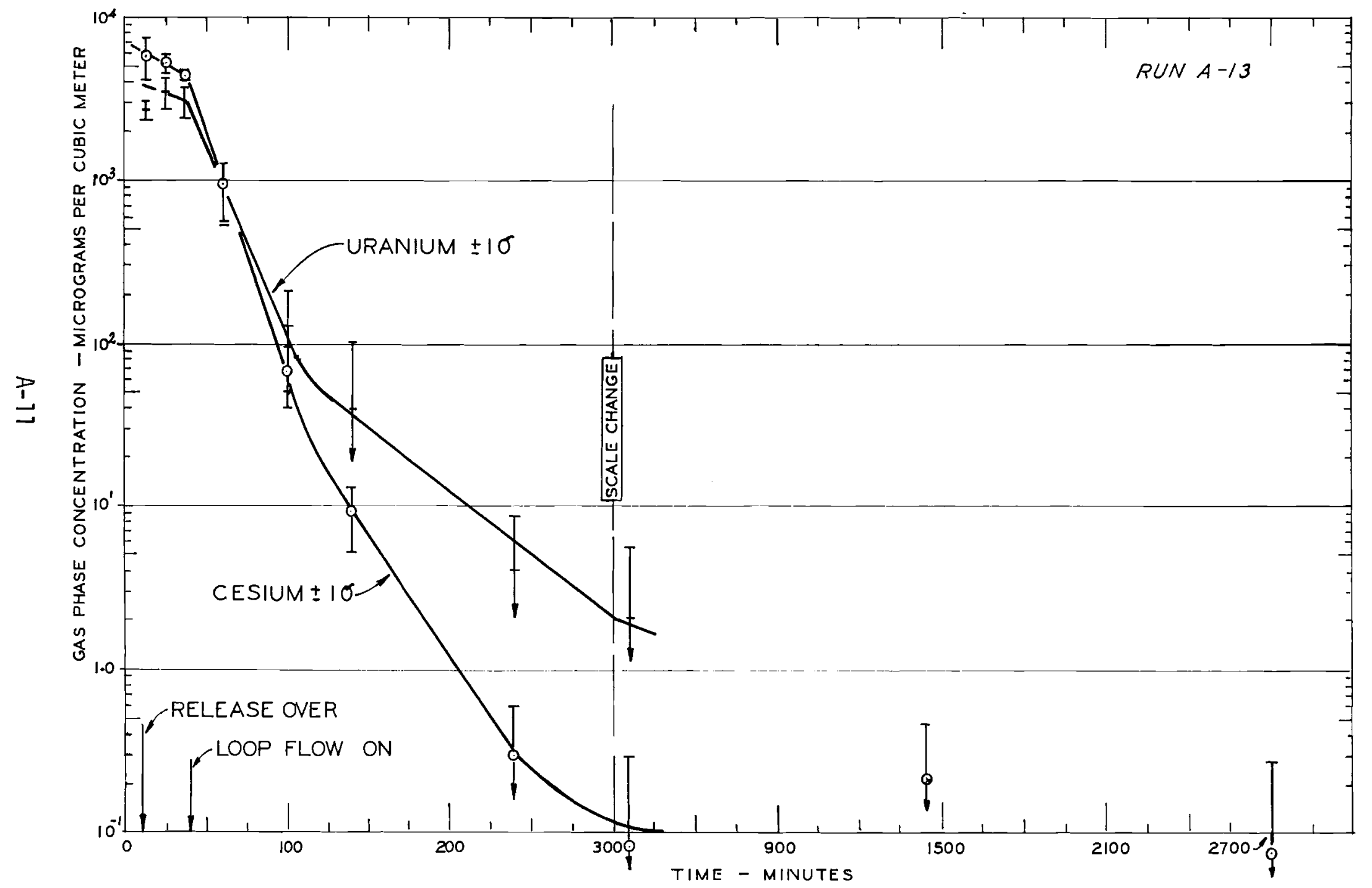

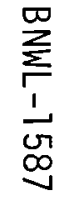

FIGURE A-6. Cesium and Uranium Concentrations in the Main Room Gas Space in CSE Run A-13 


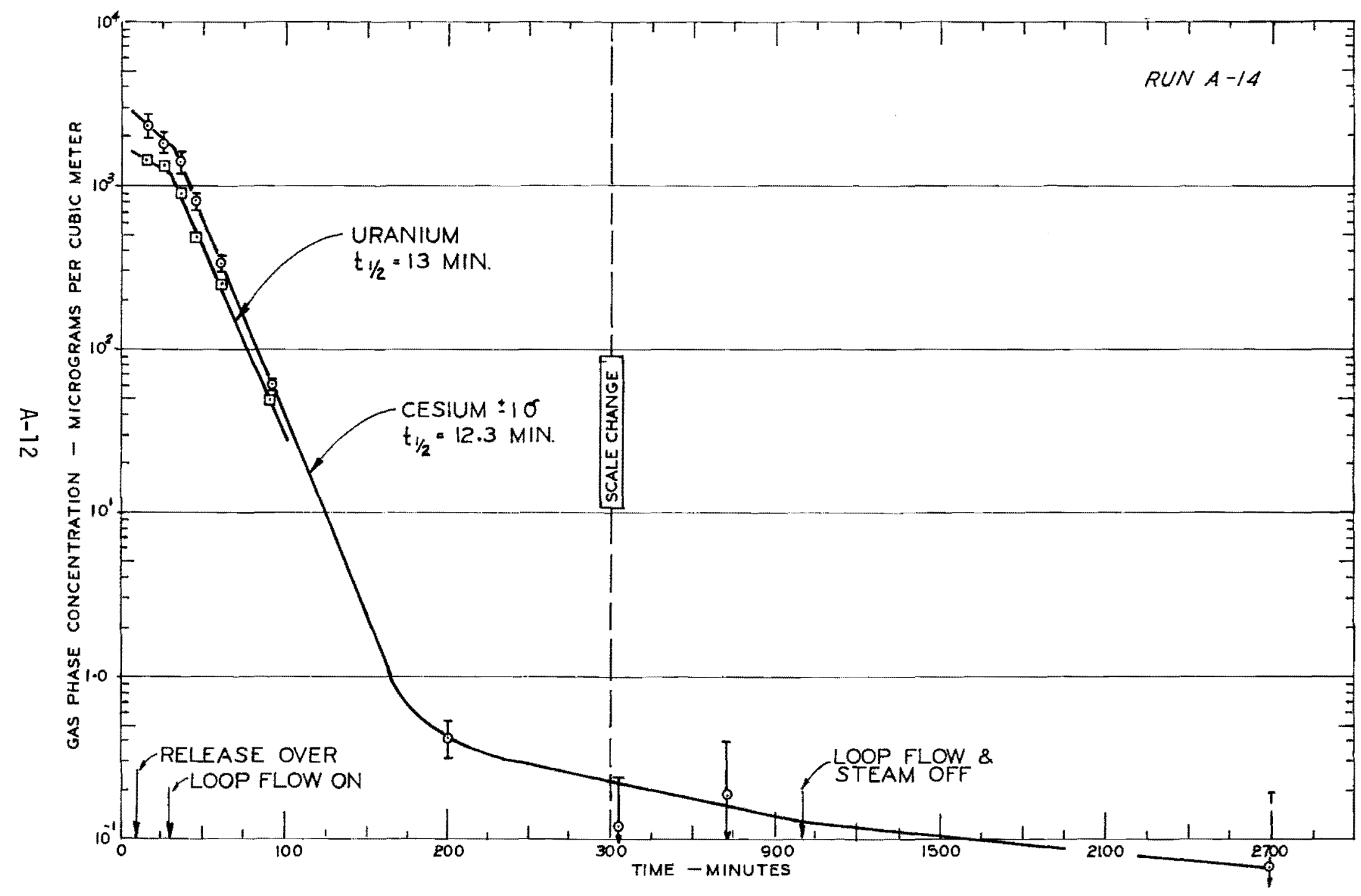

FIGURE A-7. Cesium and Uranium Concentrations in the Main Room Gas Space in CSE Run A-14 


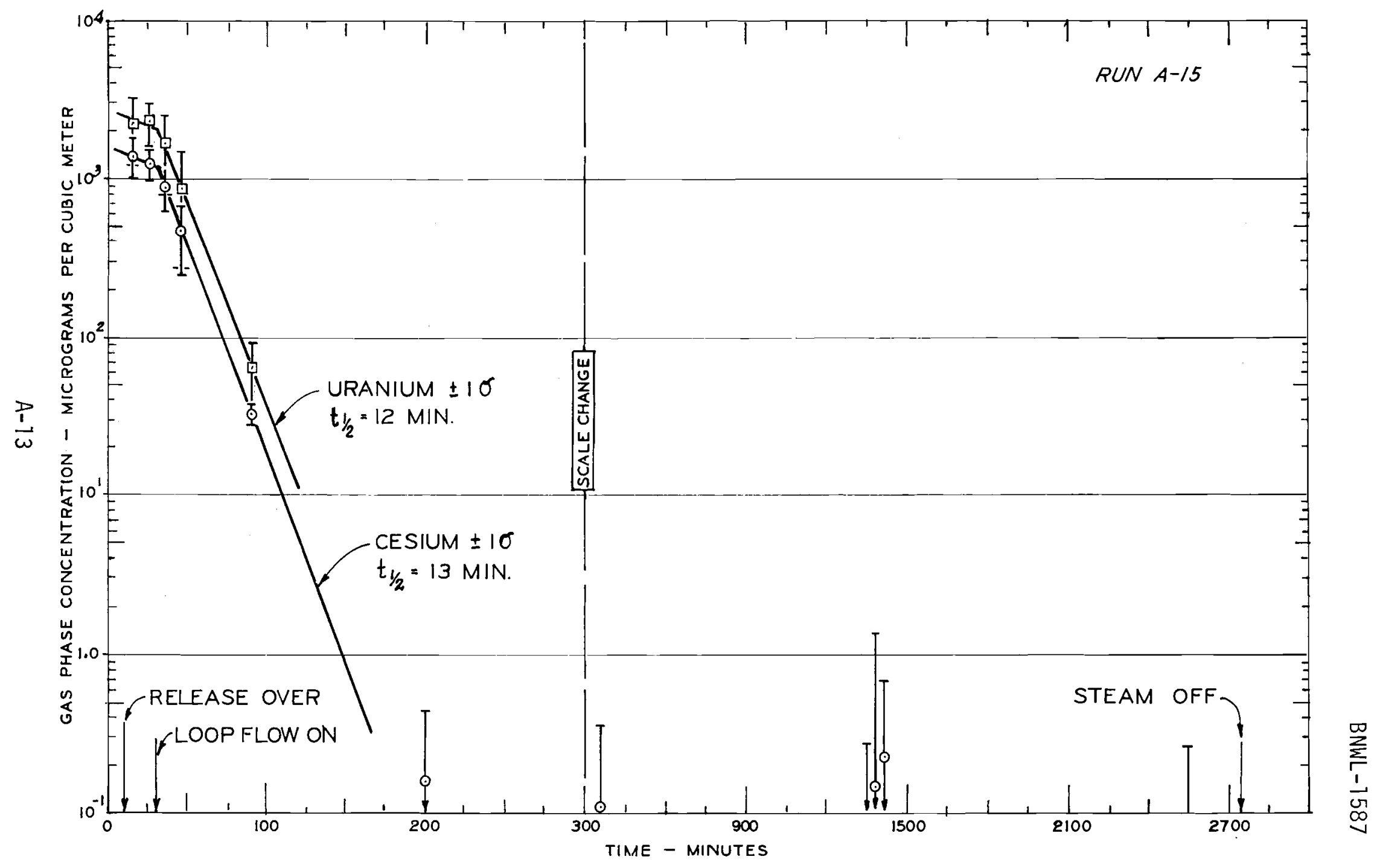

FIGURE A-8. Cesium and Uranium Concentrations in the Main Room Gas Space in CSE Run A-15 


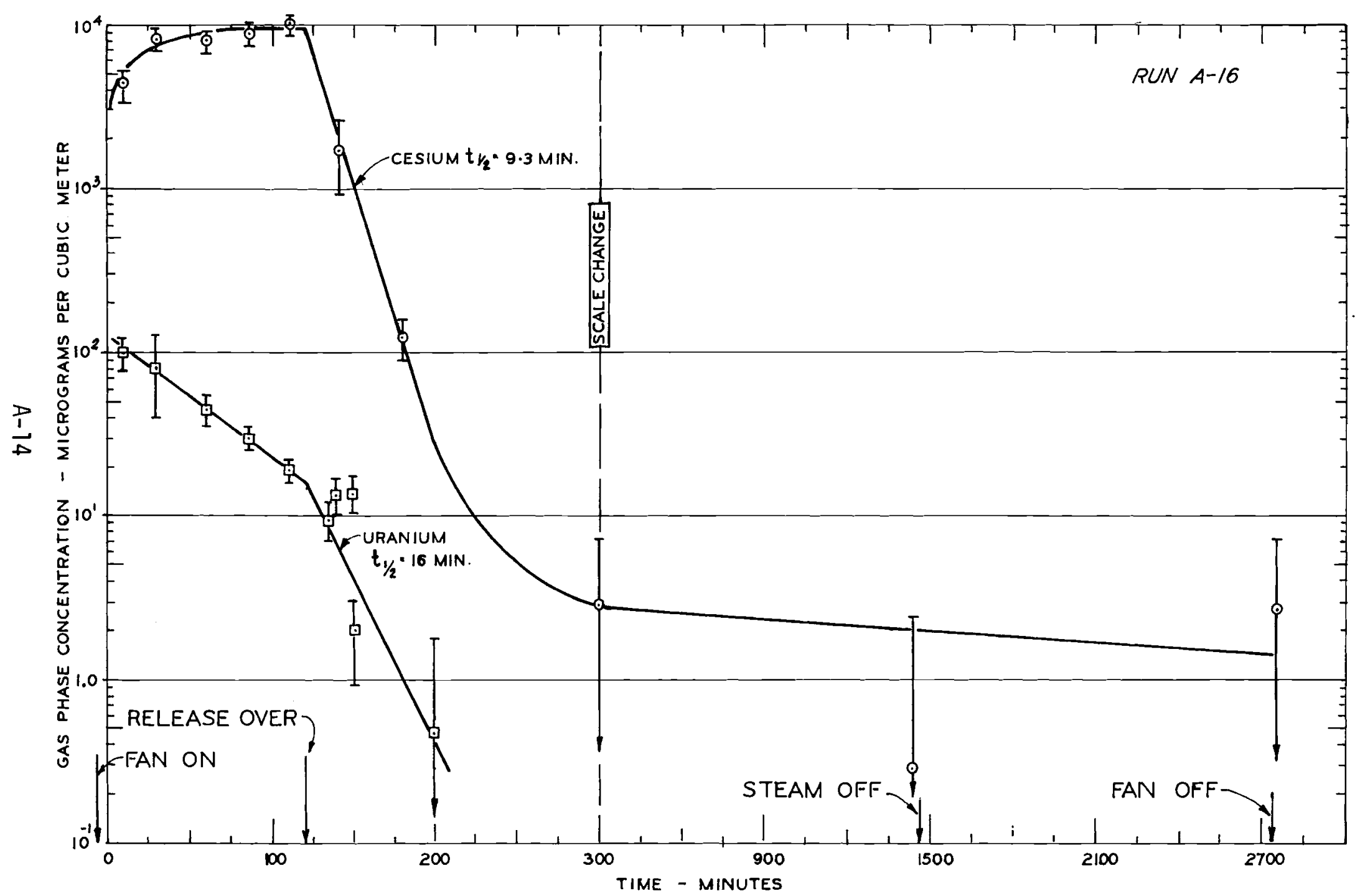

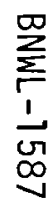

FIGURE A-9. Cesium and Uranium Concentrations in the Main Room Gas Space in CSE Run A-16 
BNWL-1587

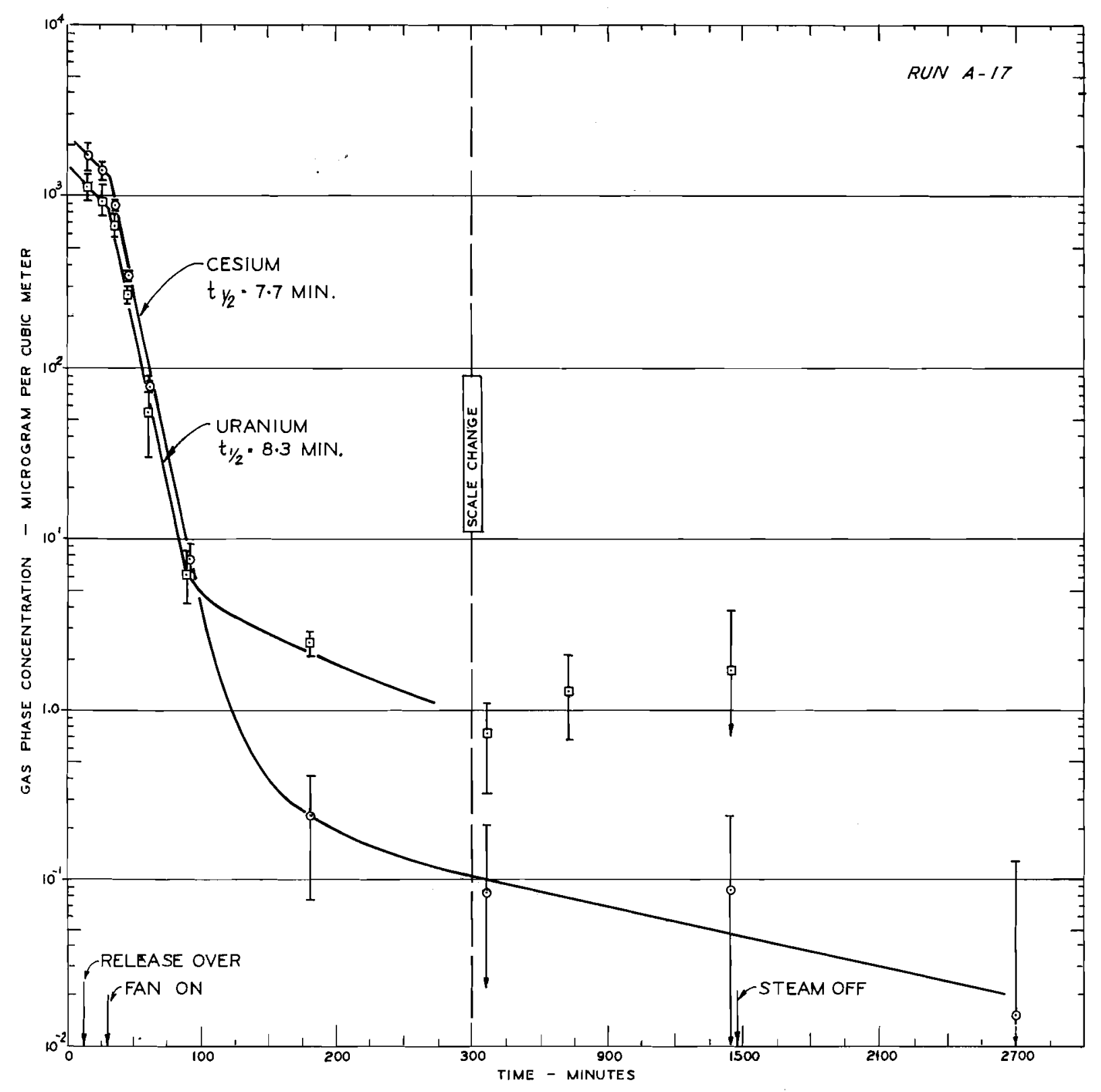

FIGURE A-10. Cesium and Uranium Concentrations in the Main Room Gas Space in CSE Run A-17 
BNWL-1587

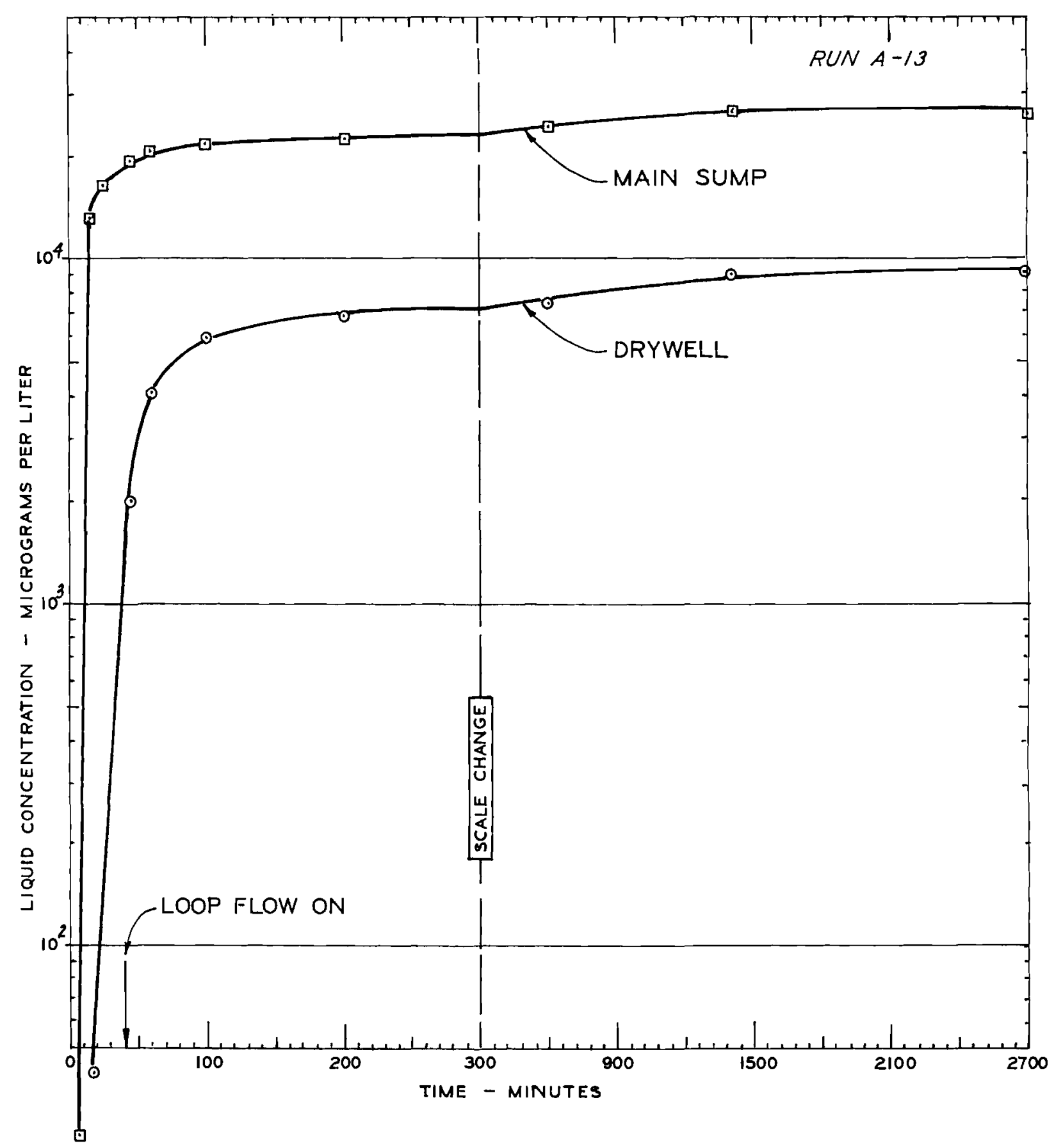

FIGURE A-11. Iodine Concentration in Liquid Sumps in CSE Run A-13 


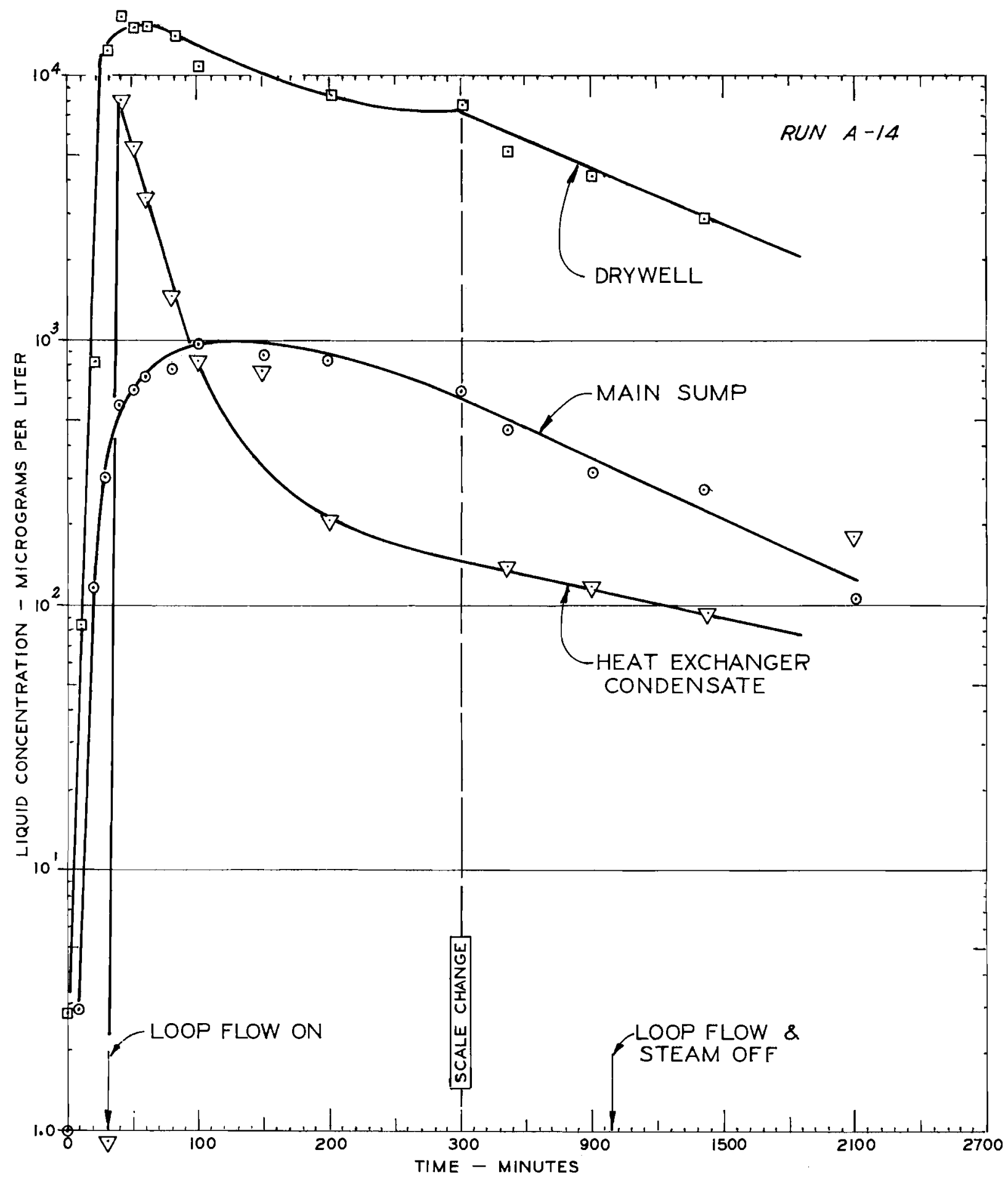

FIGURE A-12. Iodine Concentration in Liquid Sumps in CSE Run A-14 


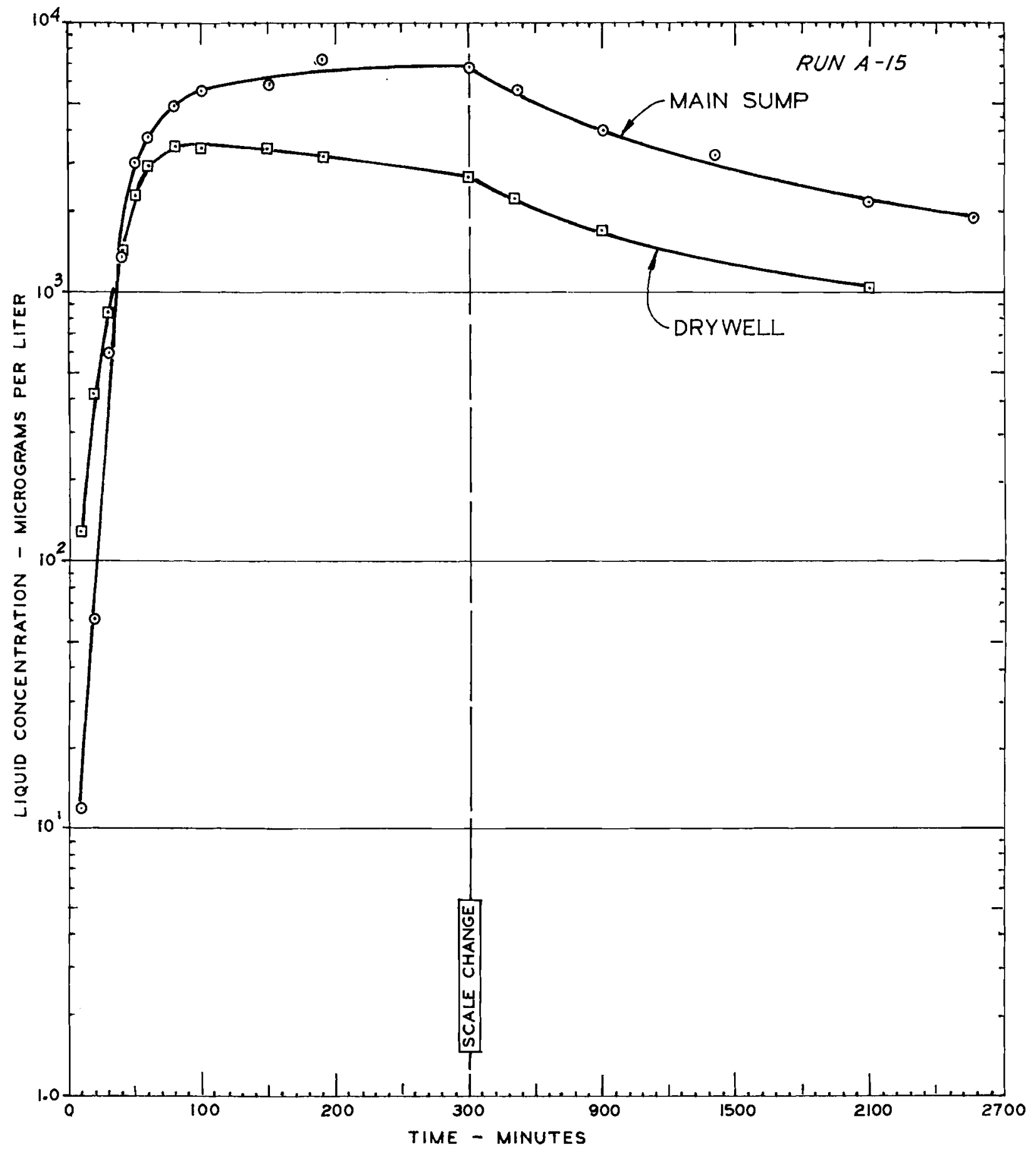

FIGURE A-13. Iodine Concentration in Liquid Sumps in CSE Run A-15 
BNWL-1587

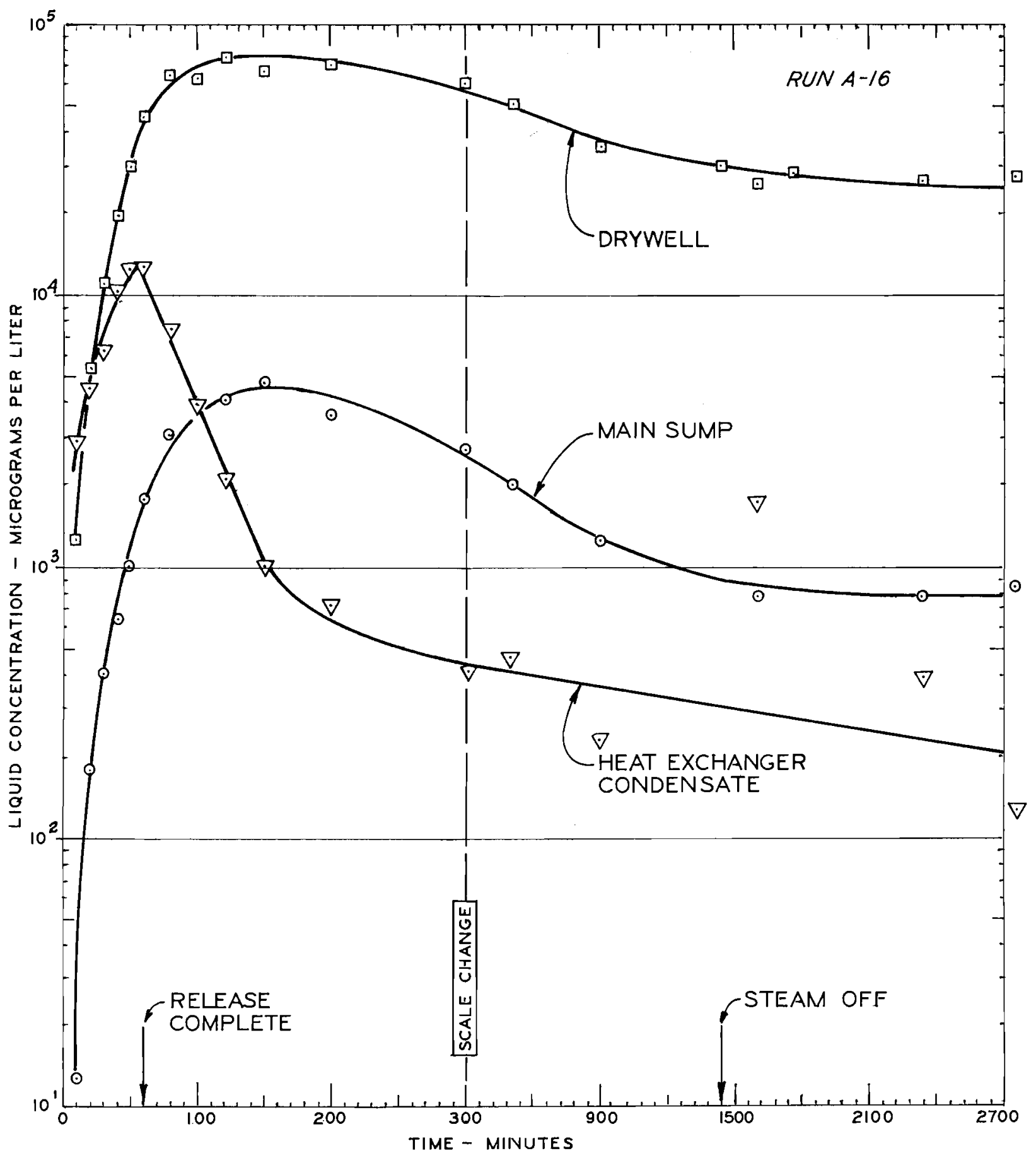

FIGURE A-14. Iodine Concentration in Liquid Sumps in CSE Run A-16 


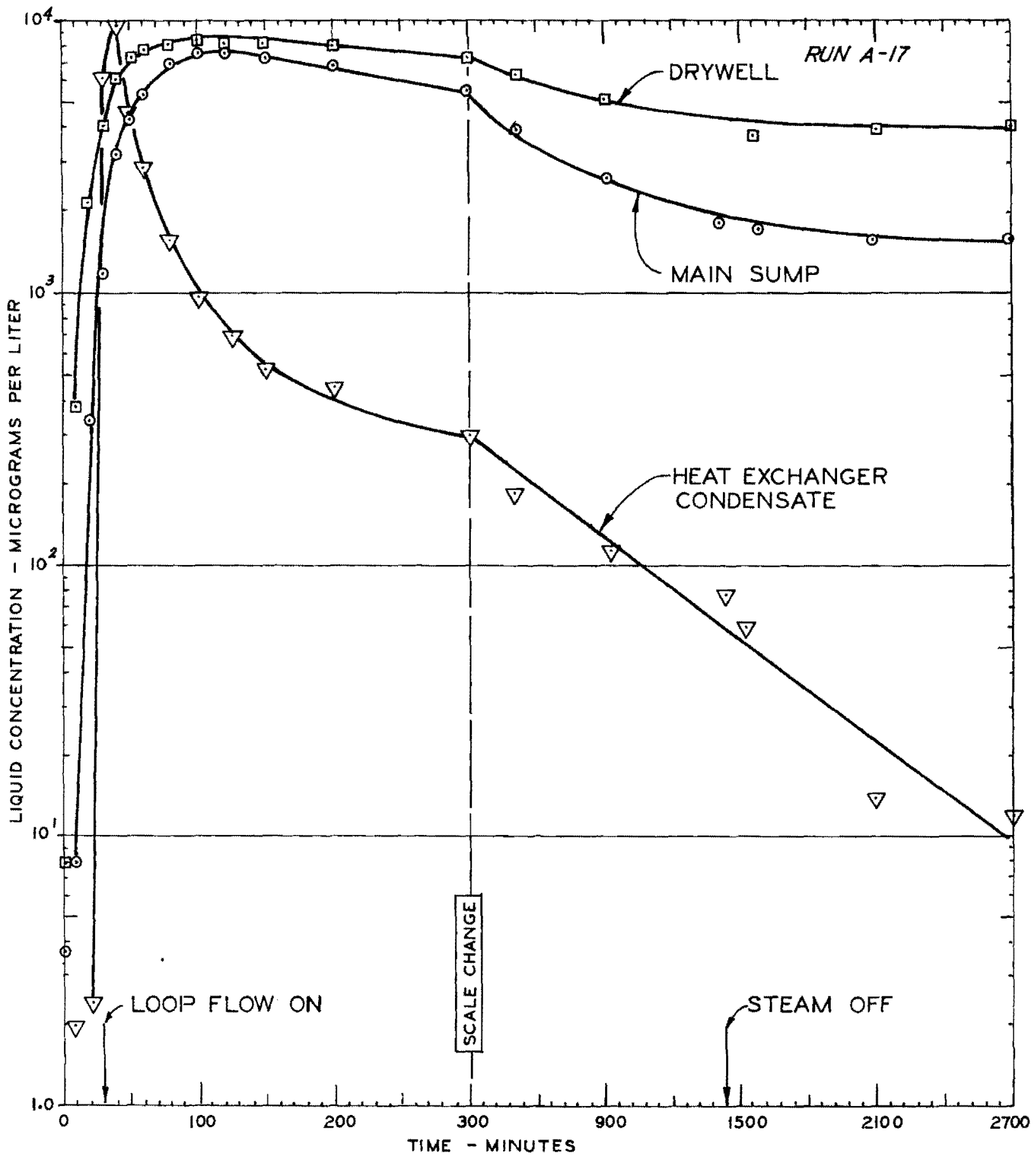

FIGURE A-15. Iodine Concentration in Liquid Sumps in CSE Run A-17 


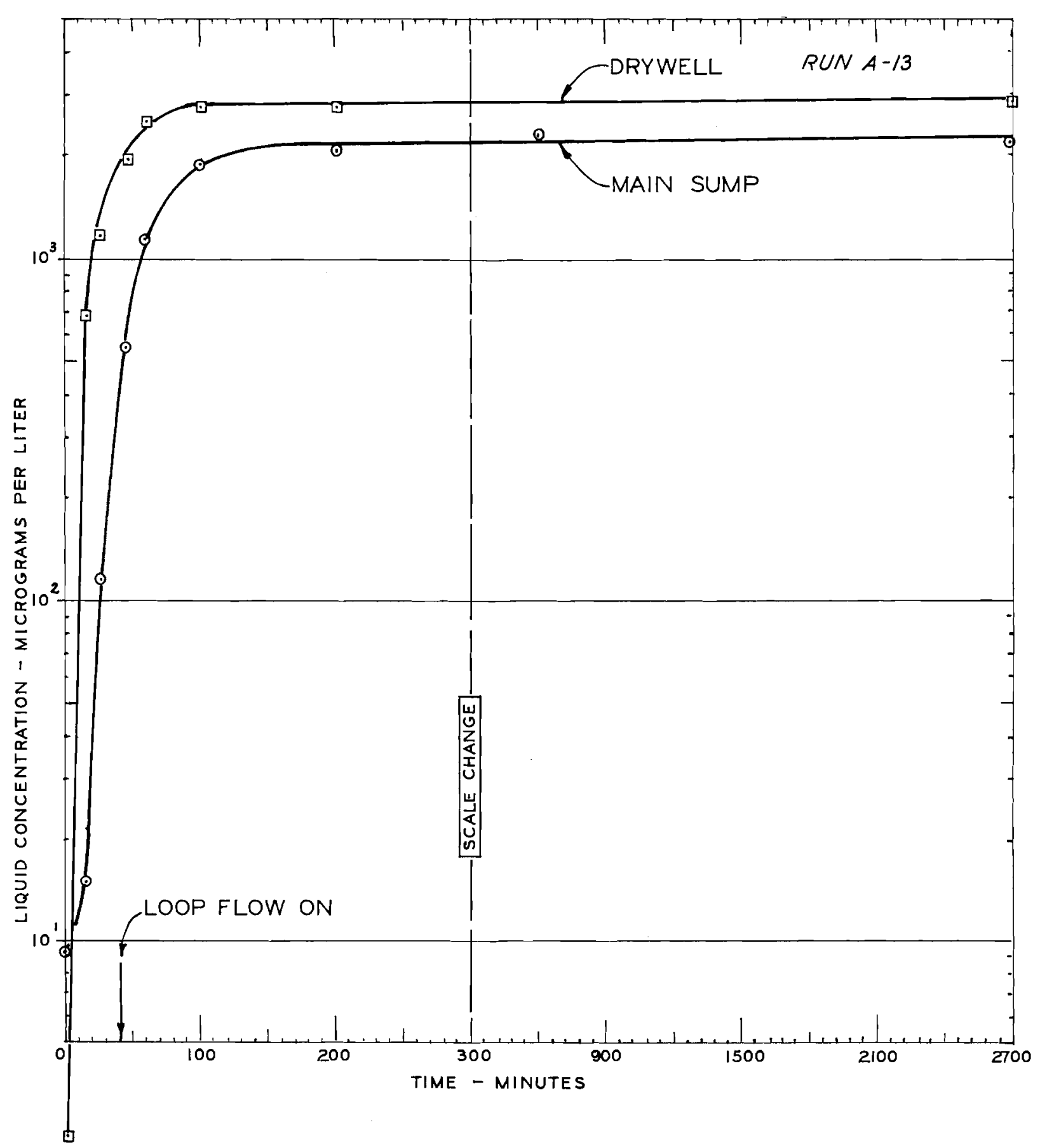

FIGURE A-16. Cesium Concentration in Liquid Sumps in CSE Run A-13 
BNWL-1587

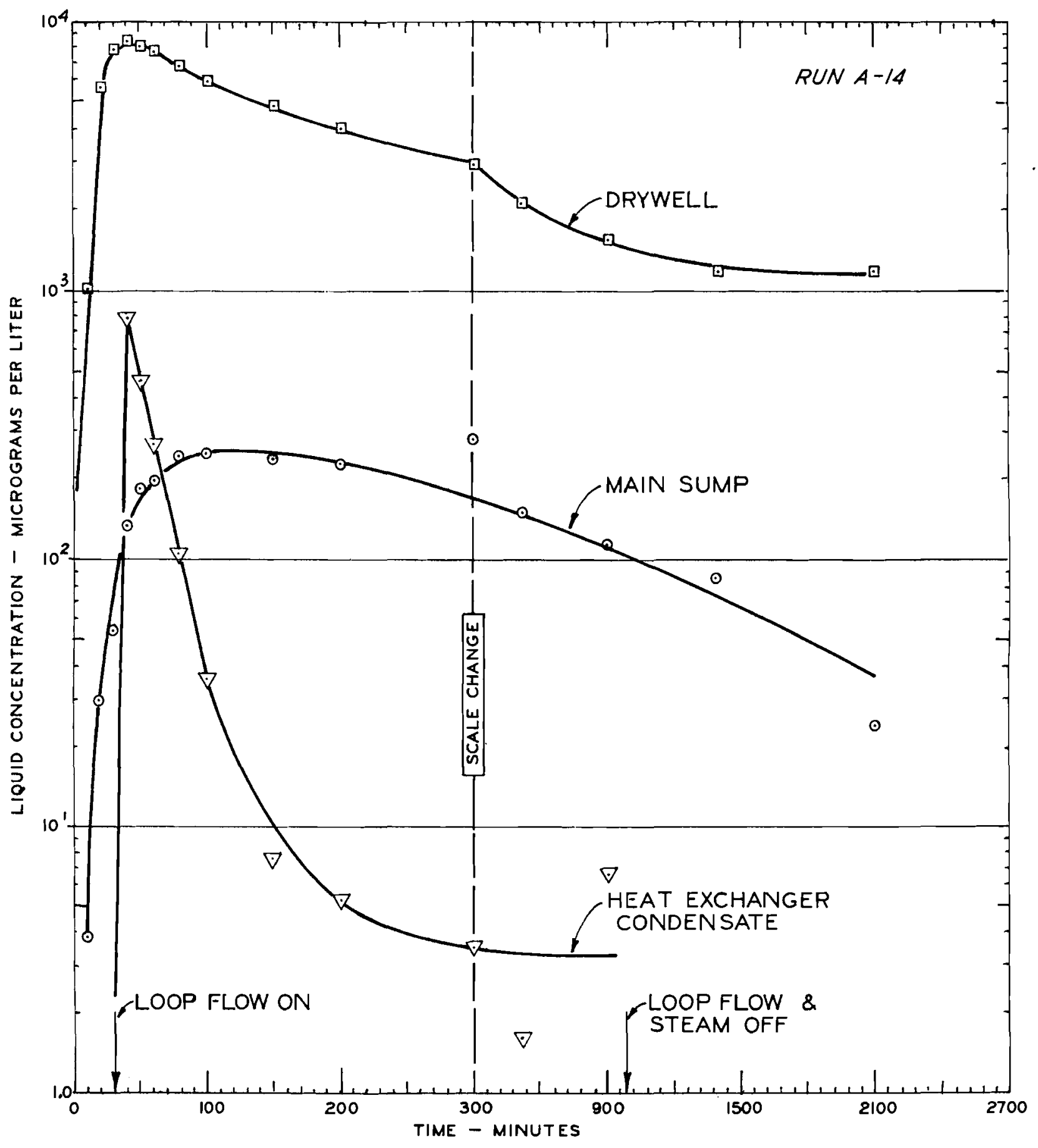

FIGURE A-17. Cesium Concentration in Liquid Sumps in CSE Run A-14 


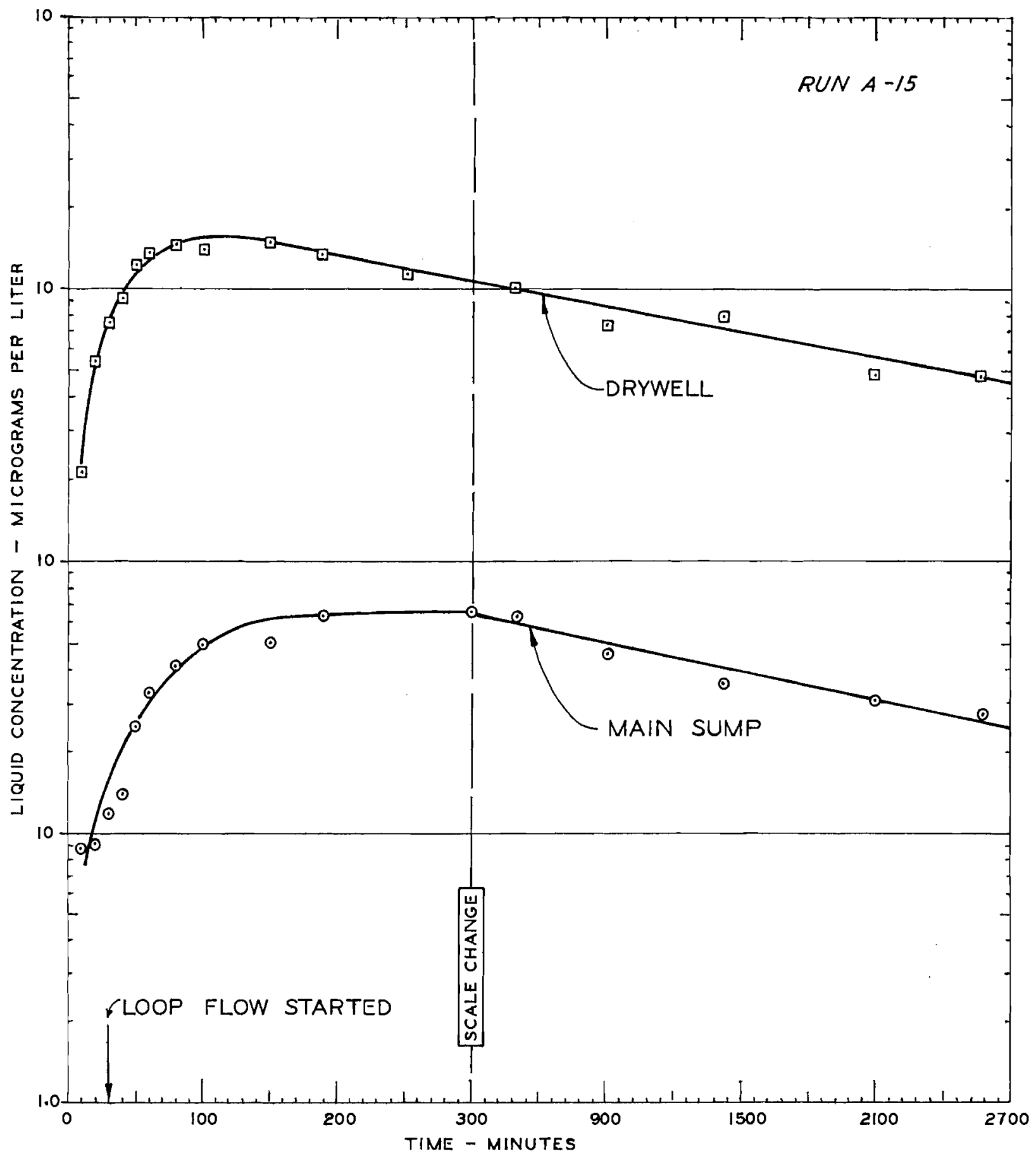

FIGURE A-18. Cesium Concentration in Liquid Sumps in CSE Run A-15 


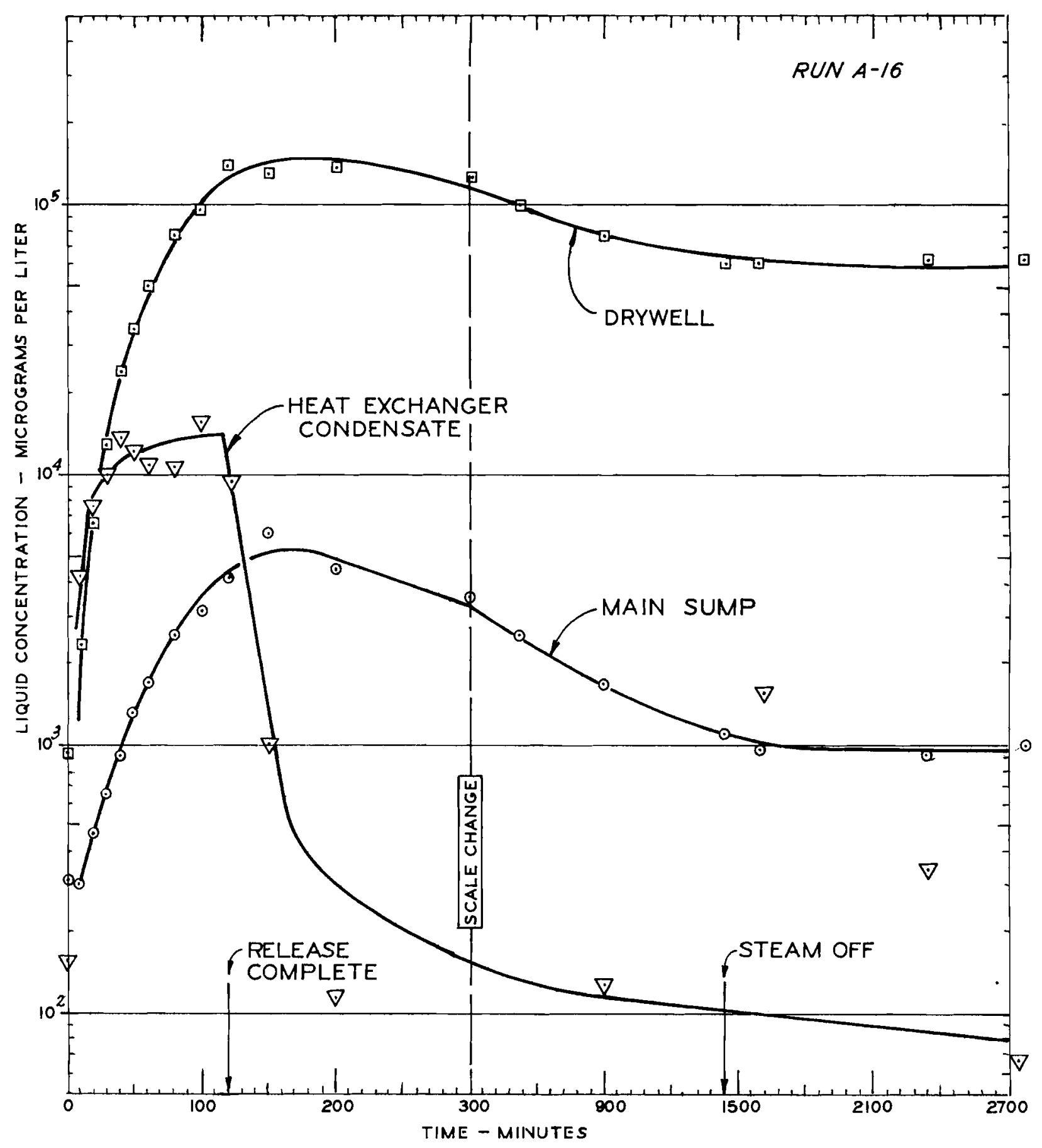

FIGURE A-19. Cesium Concentration in Liquid Sumps in CSE Run A-16 
BNWL-1587

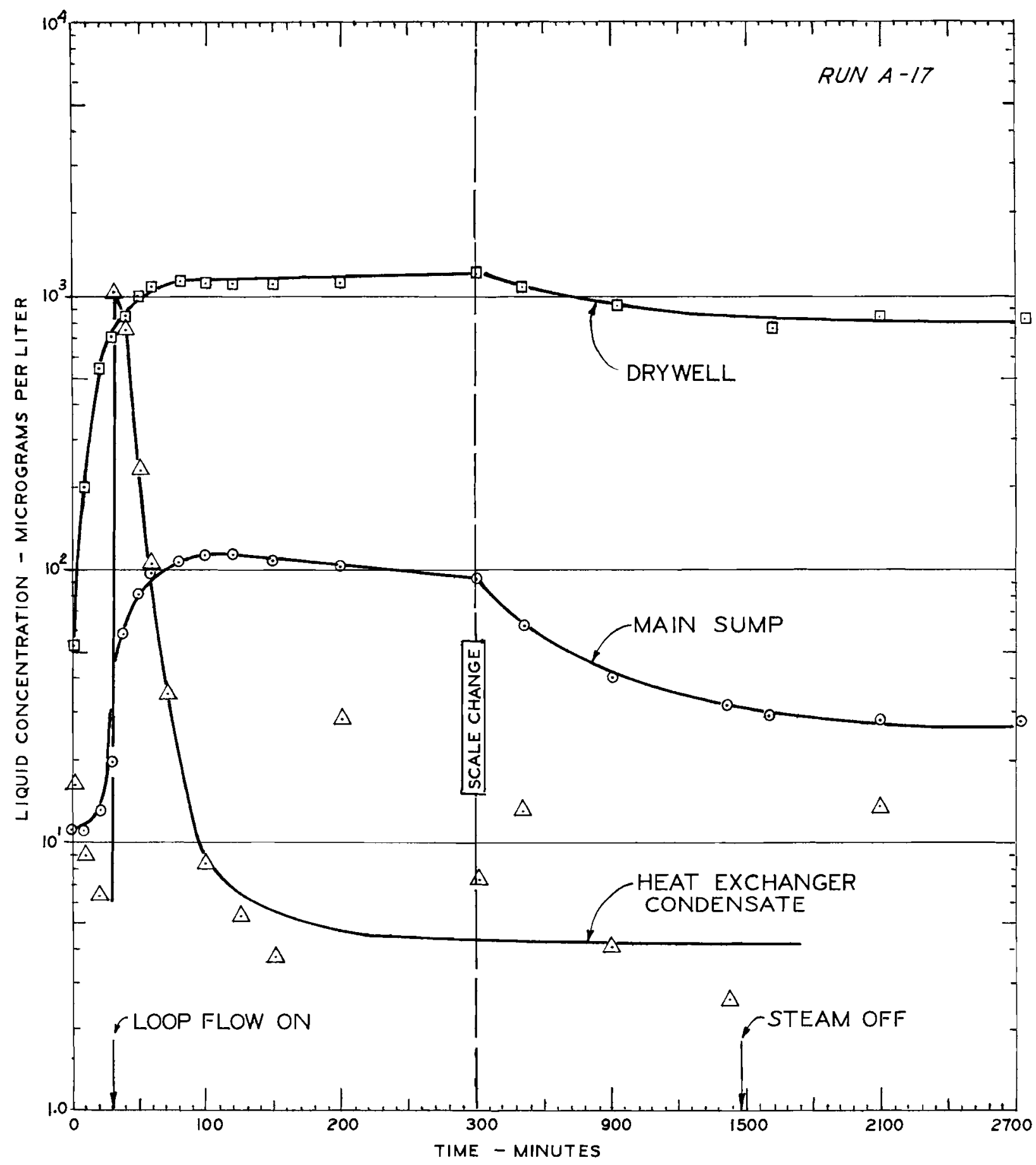

FIGURE A-20. Cesium Concentration in Liquid Sumps in CSE Run A-17 


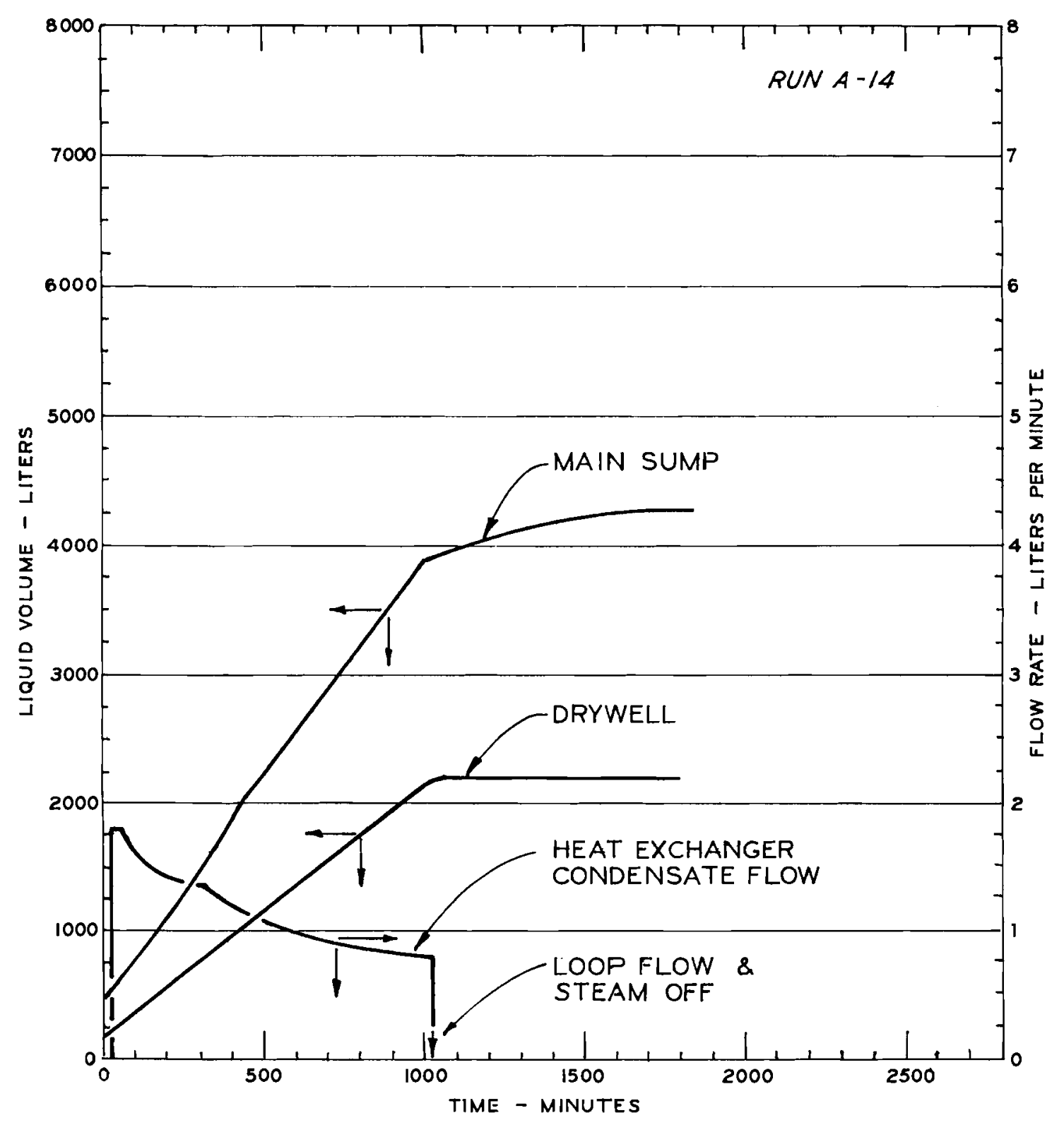

FIGURE A-21. Water Volumes Accumulated in CSE Run A-14 


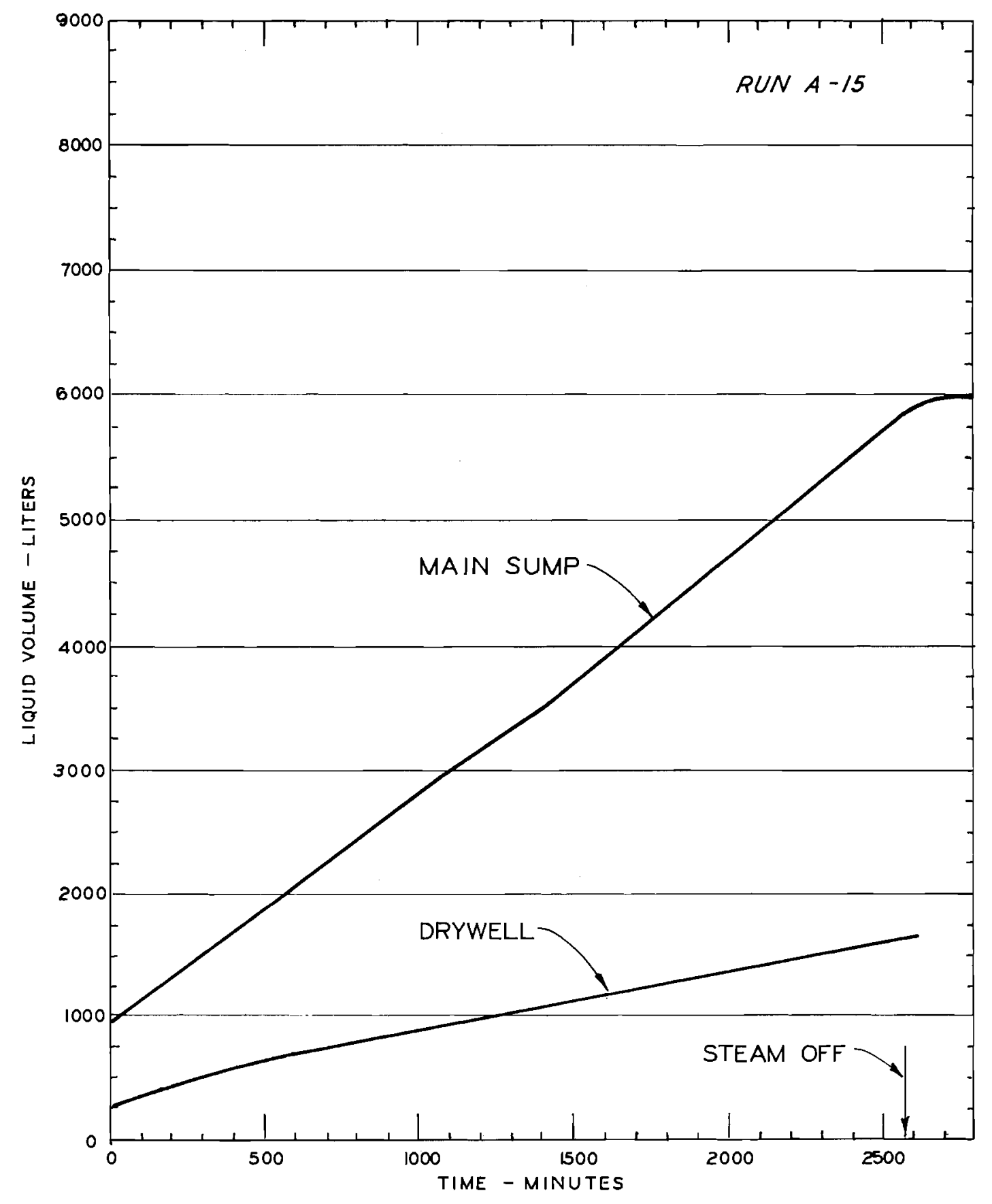

FIGURE A-22. Water Volumes Accumulated in CSE Run A-15 
BNWL-1587

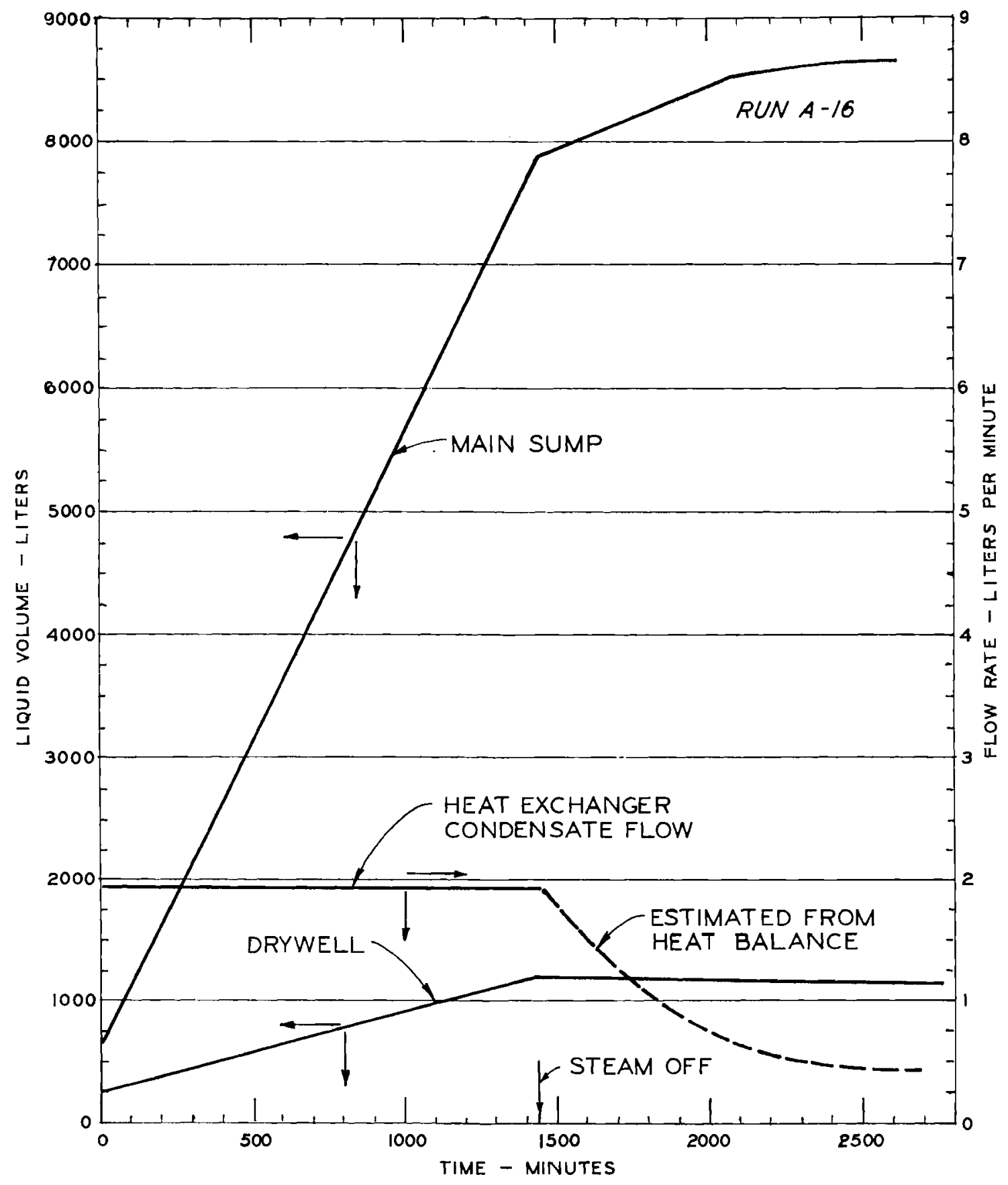

FIGURE A-23. Water Volumes Accumulated in CSE Run A-16 


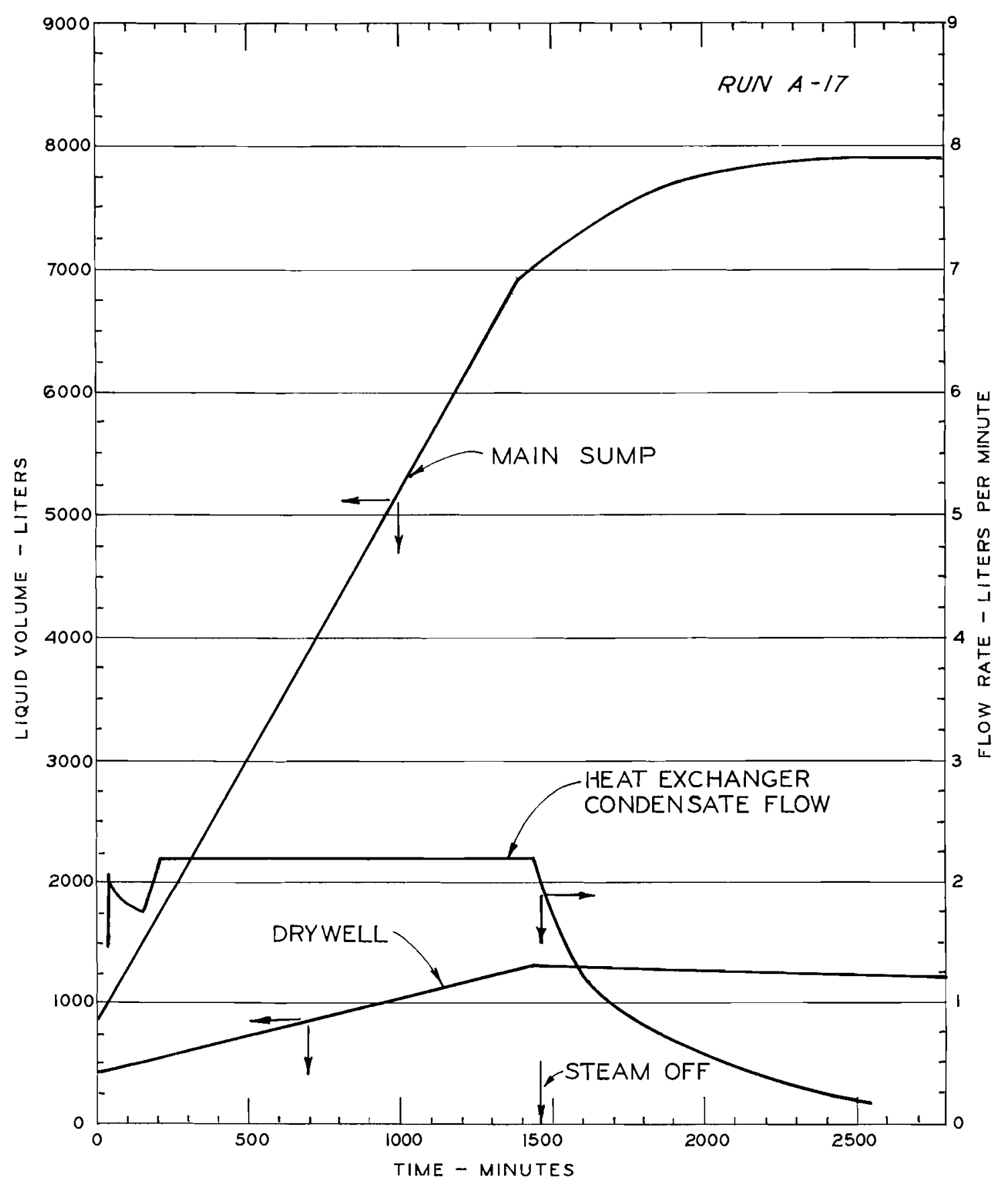

FIGURE A-24. Water Volumes Accumulated in CSE Run A-17 


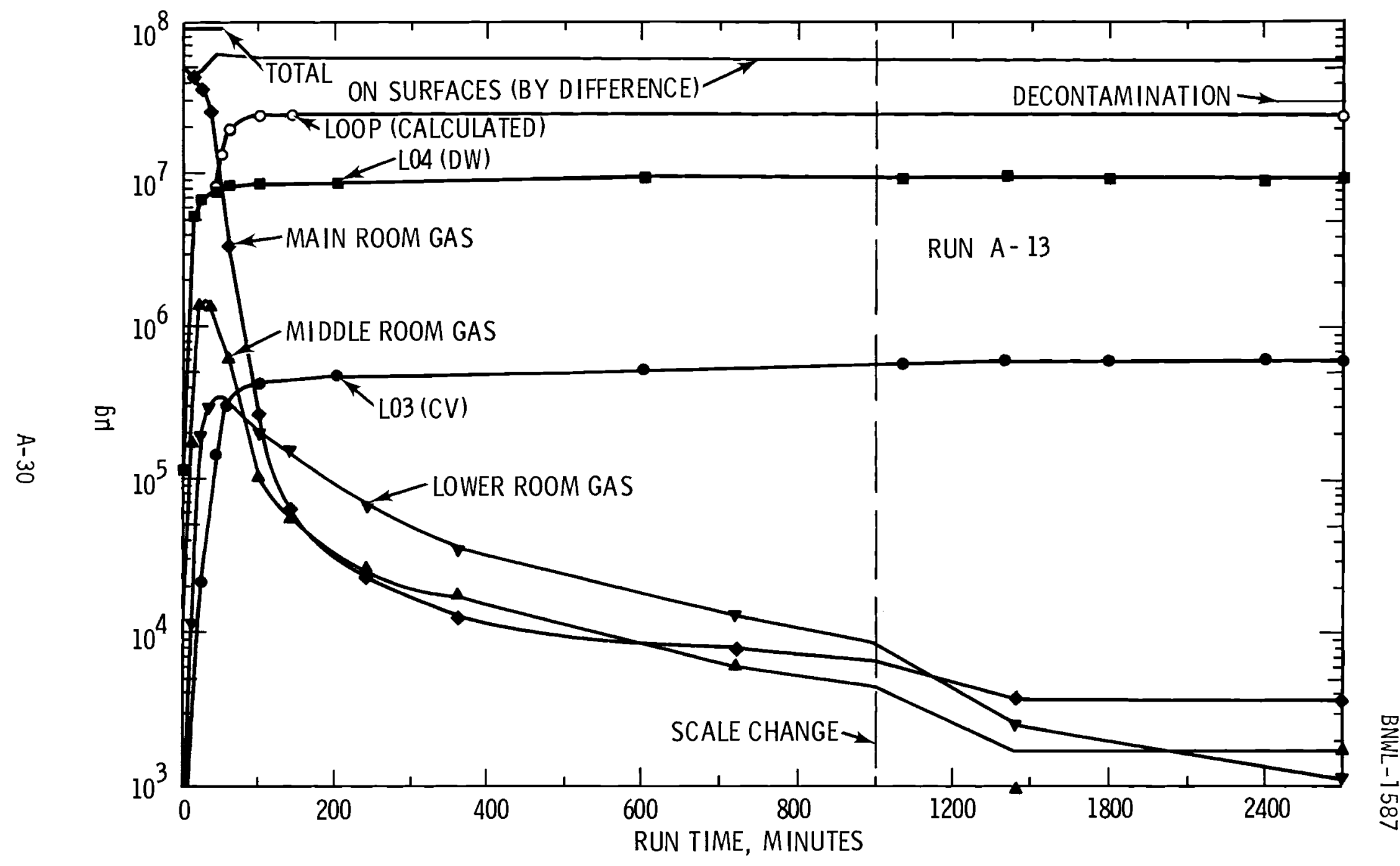

FIGURE A-25. Iodine Material Balance Versus Time for CSE Run A-13 


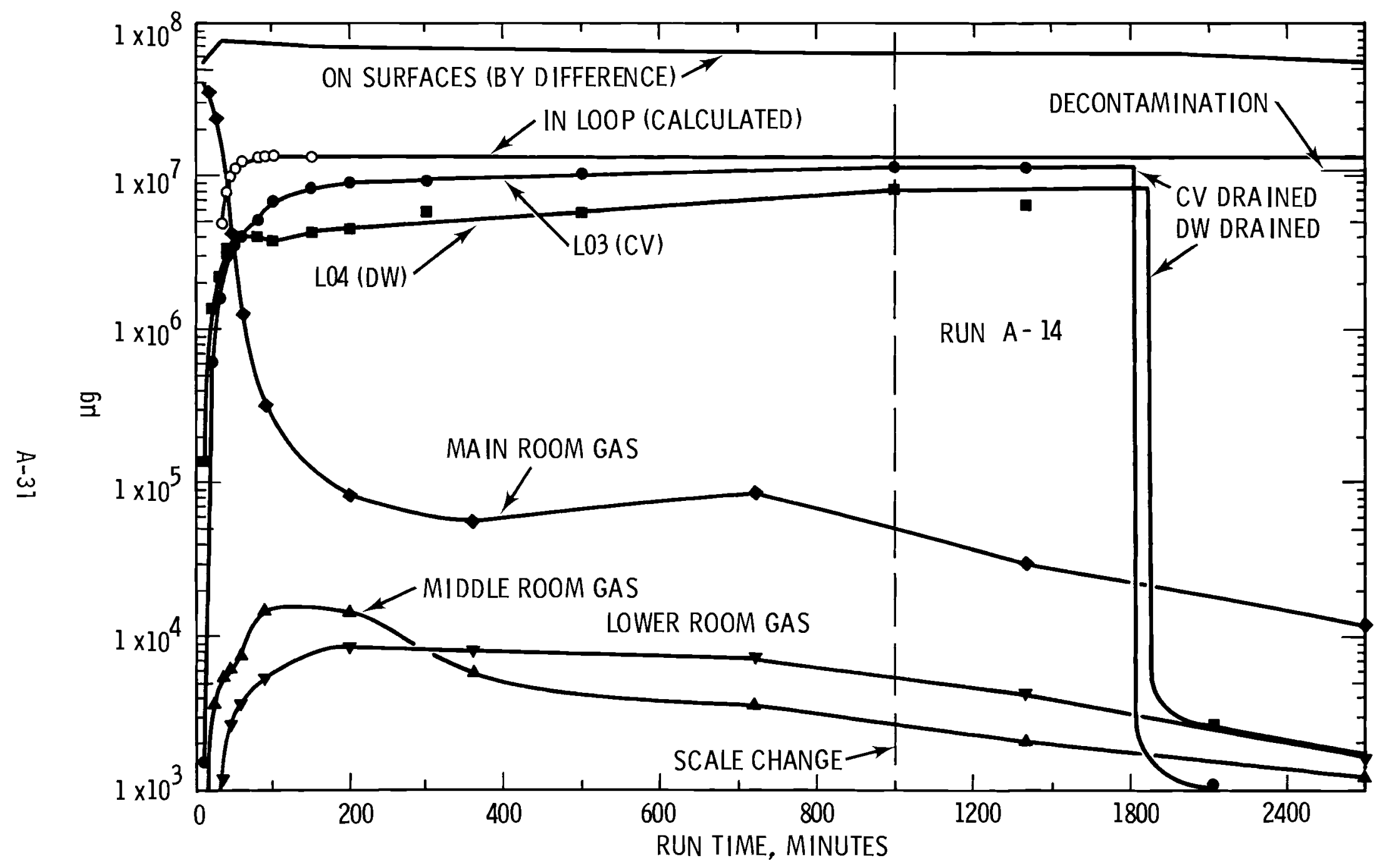

FIGURE A-26. Iodine Material Balance Versus Time for CSE Run A-14 


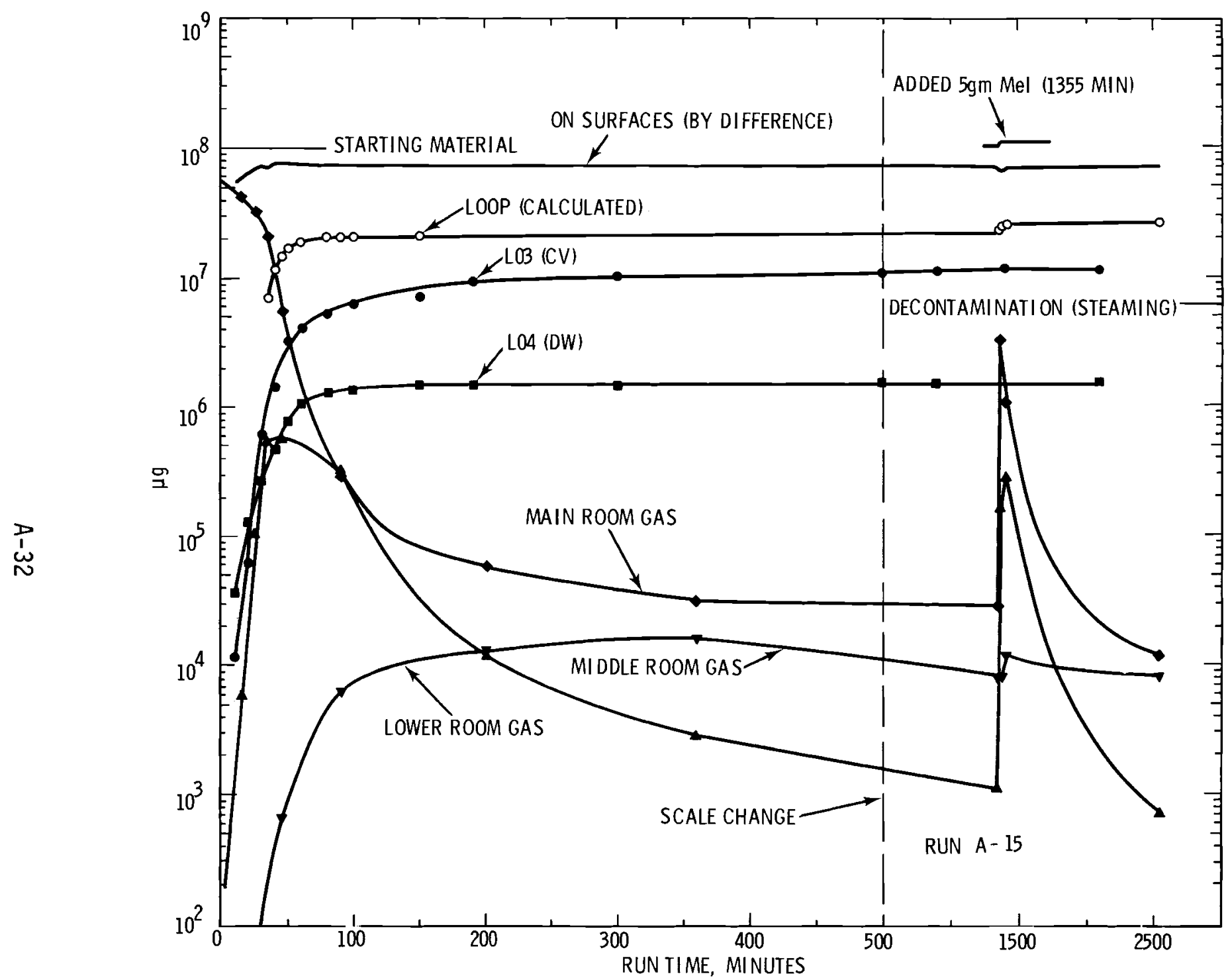

FIGURE A-27. Iodine Material Balance Versus Time for CSE Run A-15 


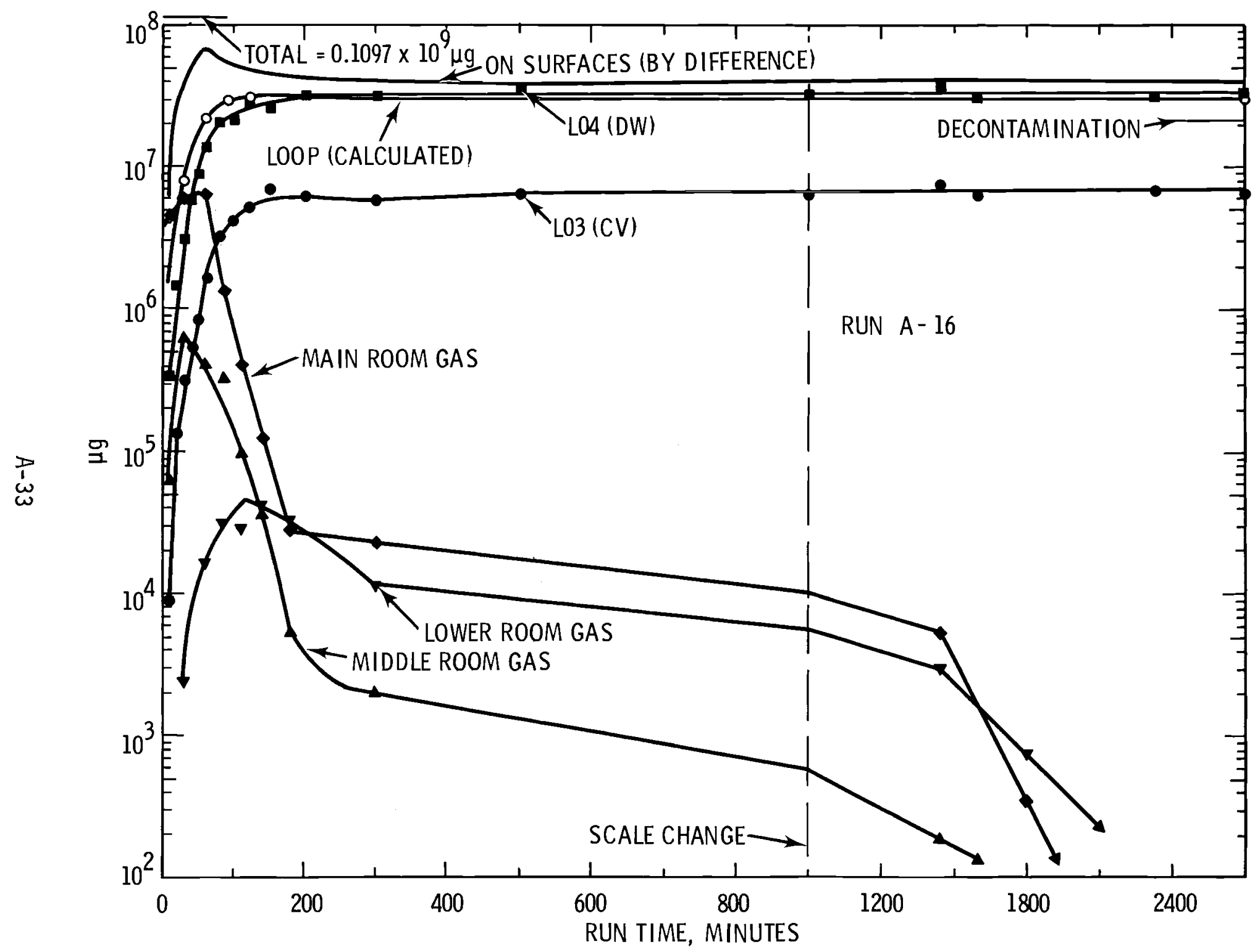

FIGURE A-28. Iodine Material Balance Versus Time for CSE Run A-16 


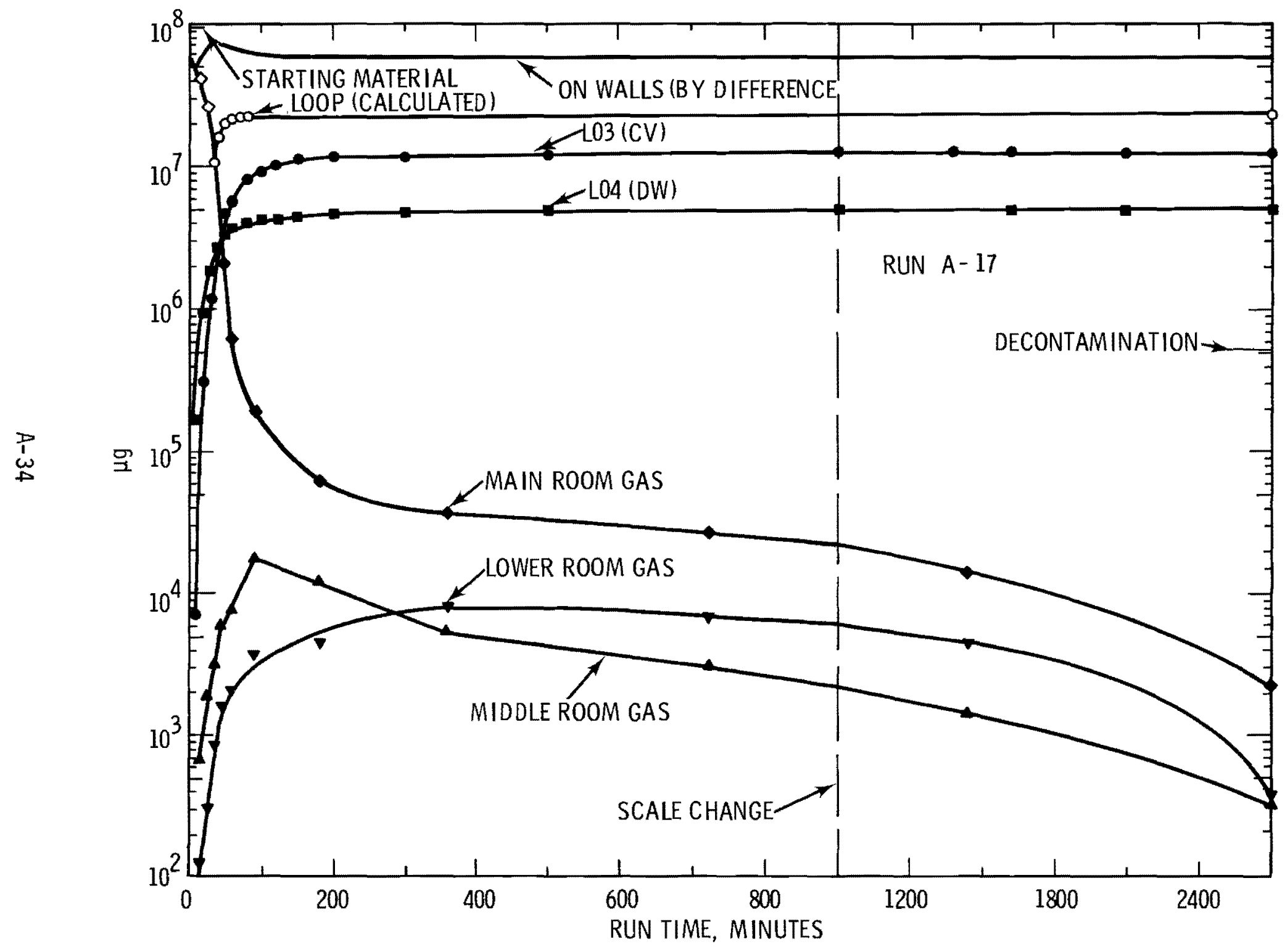

FIGURE A-29. Total Iodine Material Balance vs. Time for CSE Run A-17 


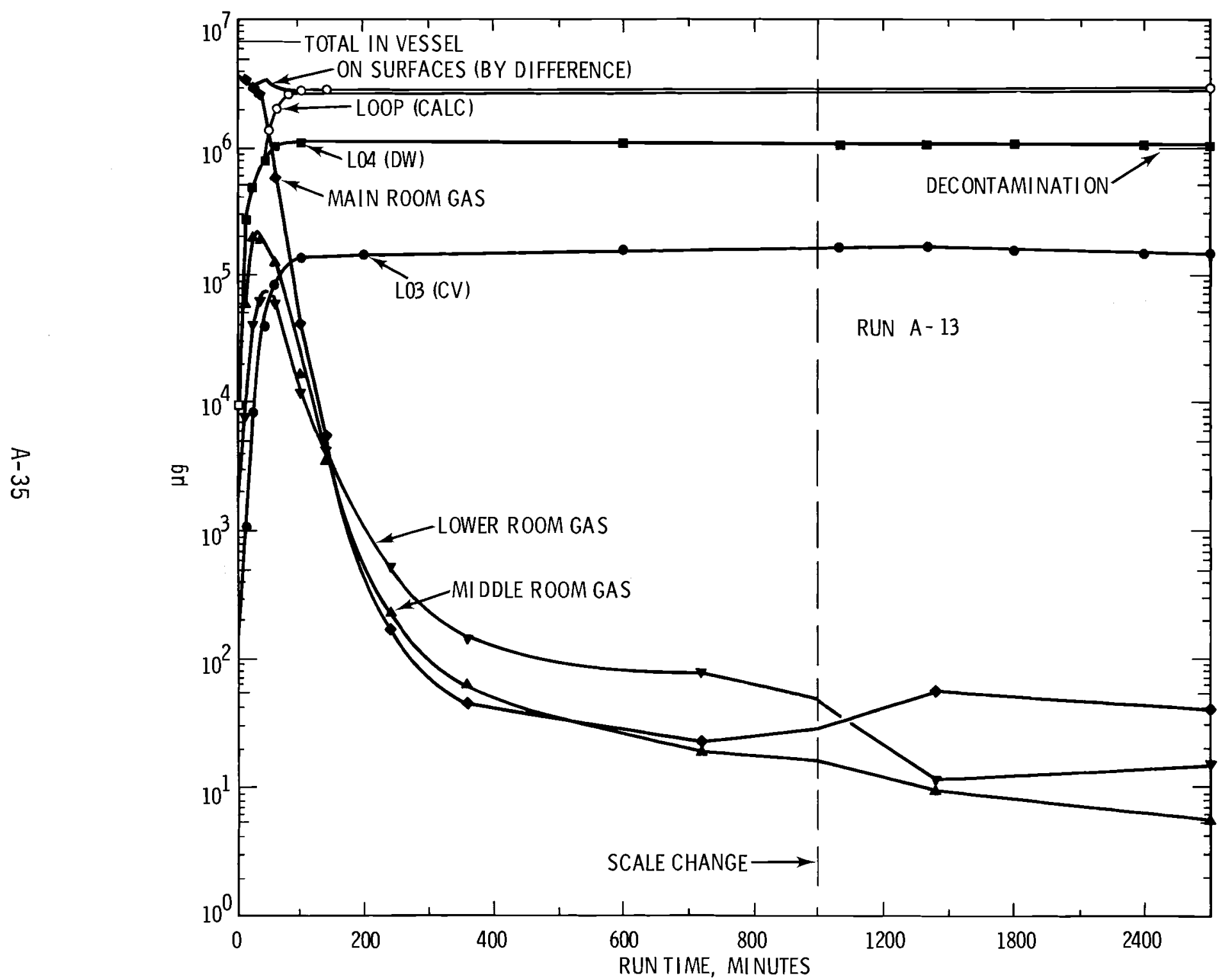

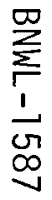

FIGURE A-30. Cesium Material Balance Versus Time for CSE Run A-13 


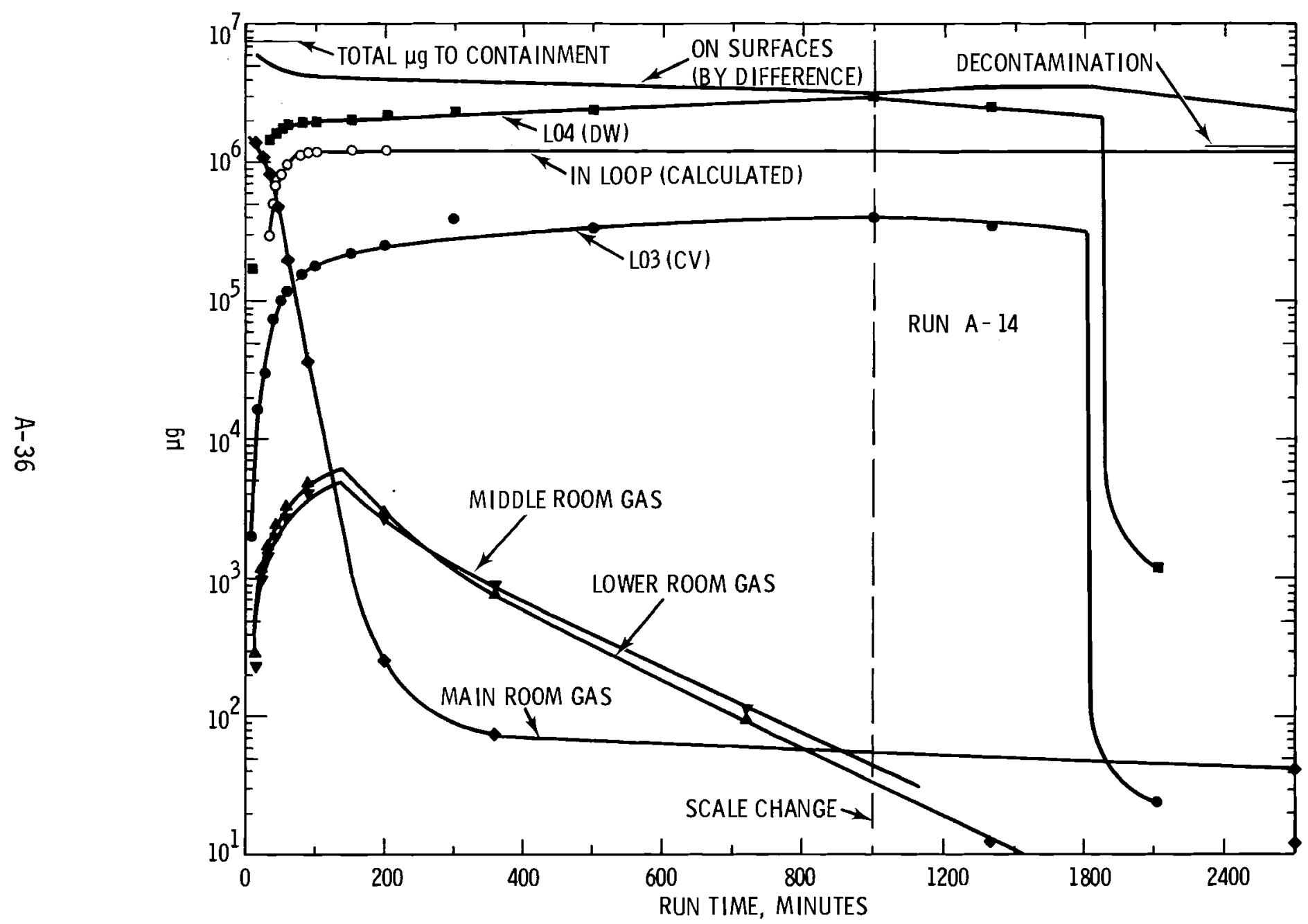

FIGURE A-31. Cesium Material Balance Versus Time for CSE Run A-14 


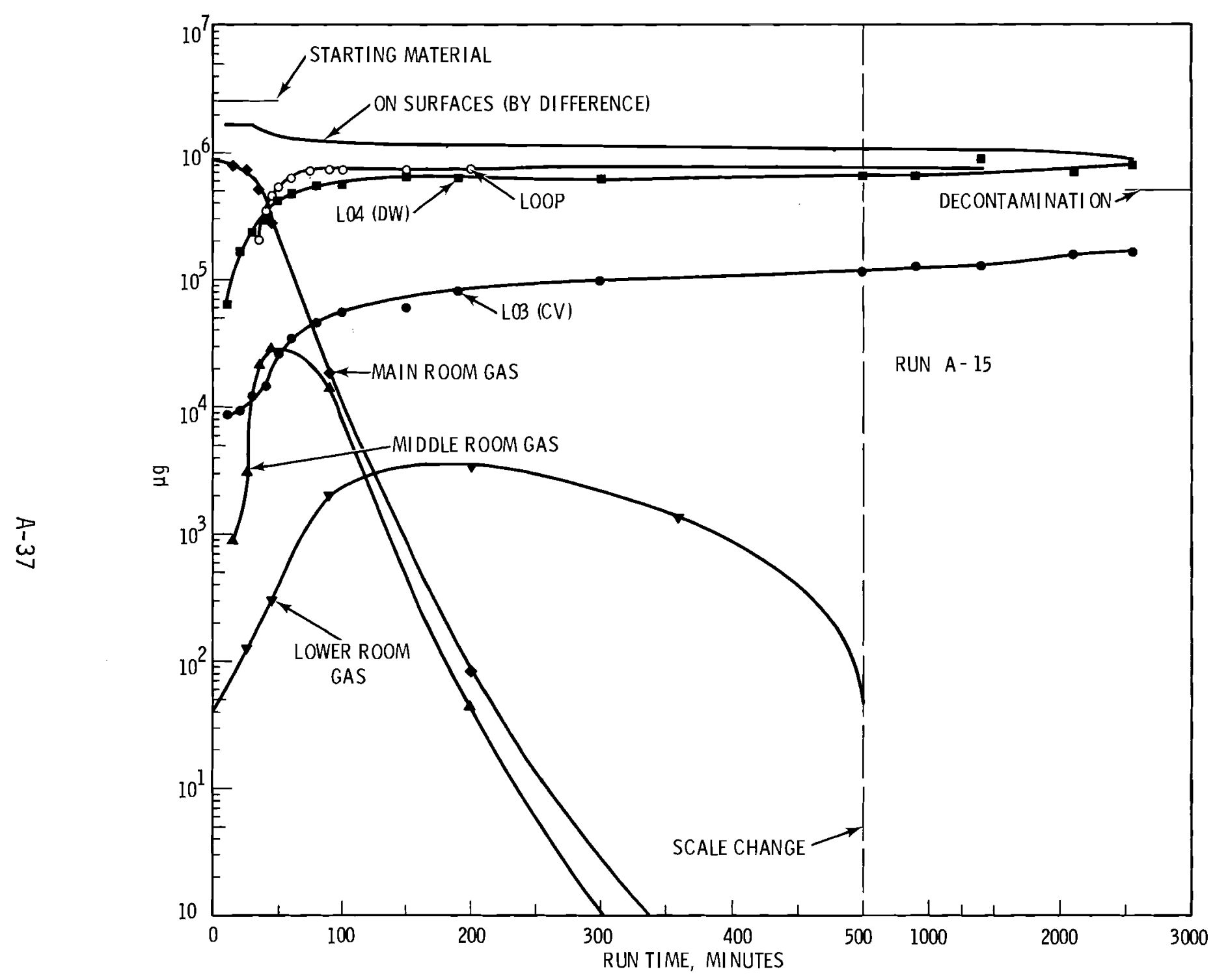

FIGURE A-32. Cesium Material Balance Versus Time for CSE Run A-15 


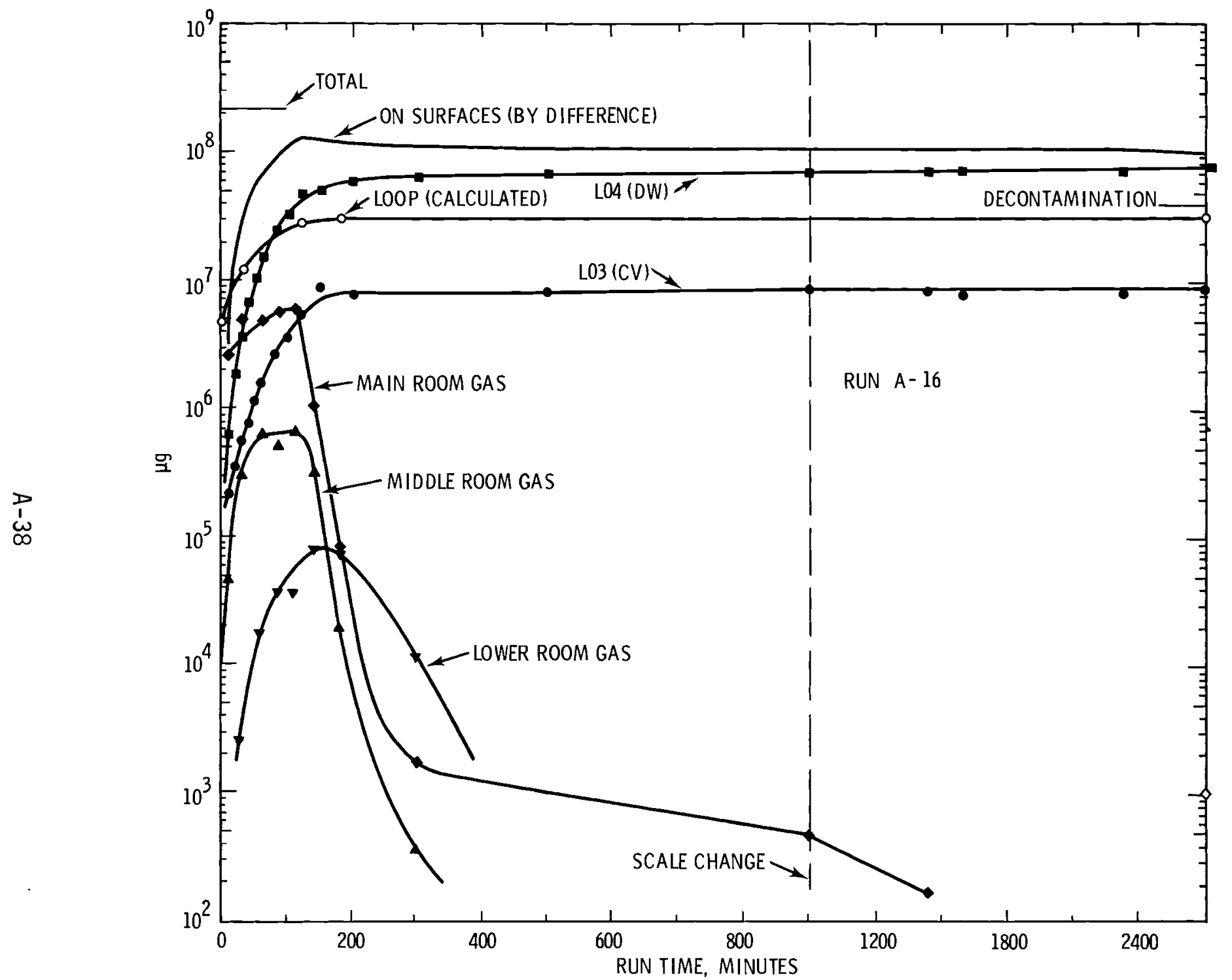

FIGURE A-33. Total Cesium Material Balance Versus Time for CSE Run A-16 


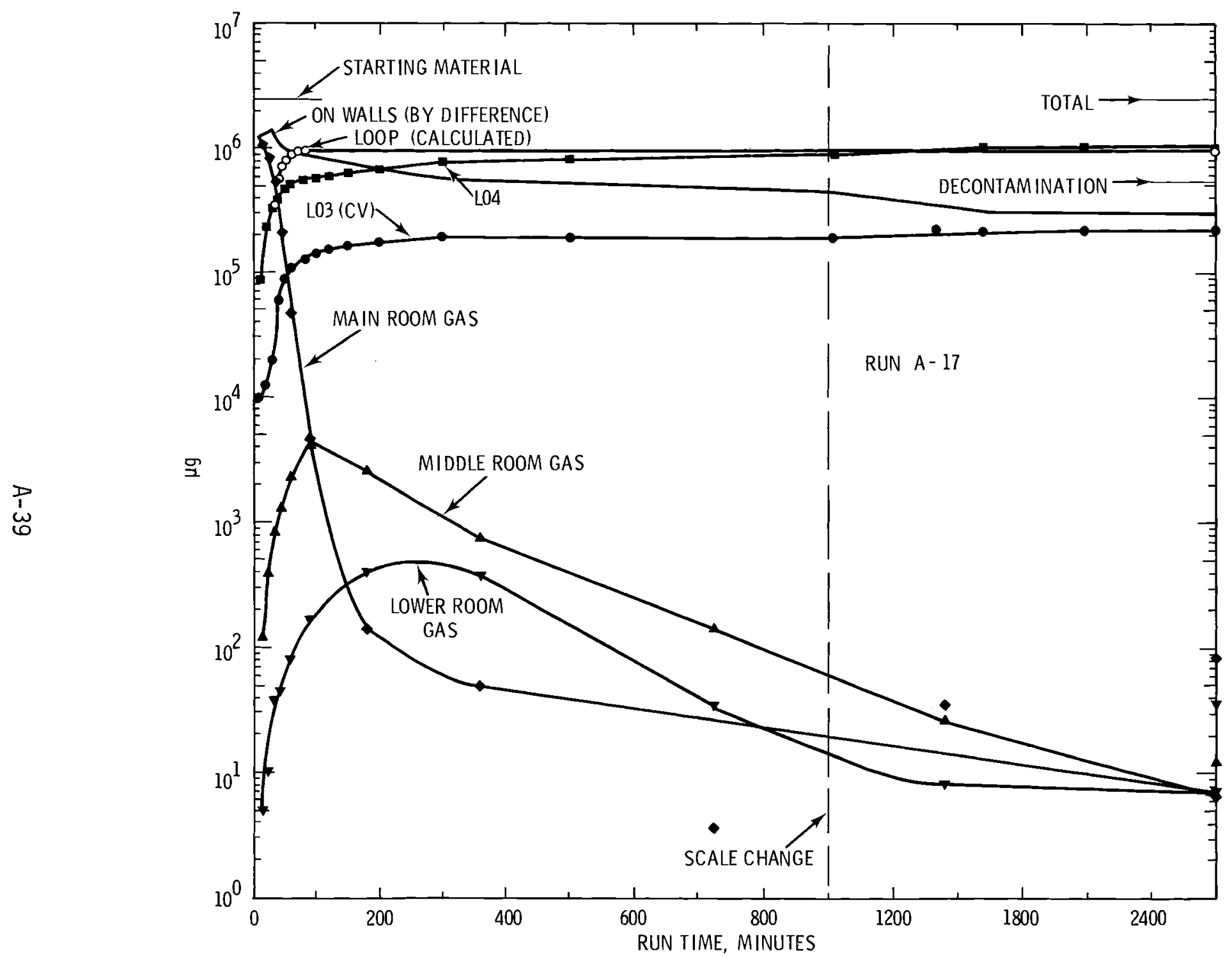

FIGURE A-34. Cesium Material Balance Versus Time for CSE Run A-17 


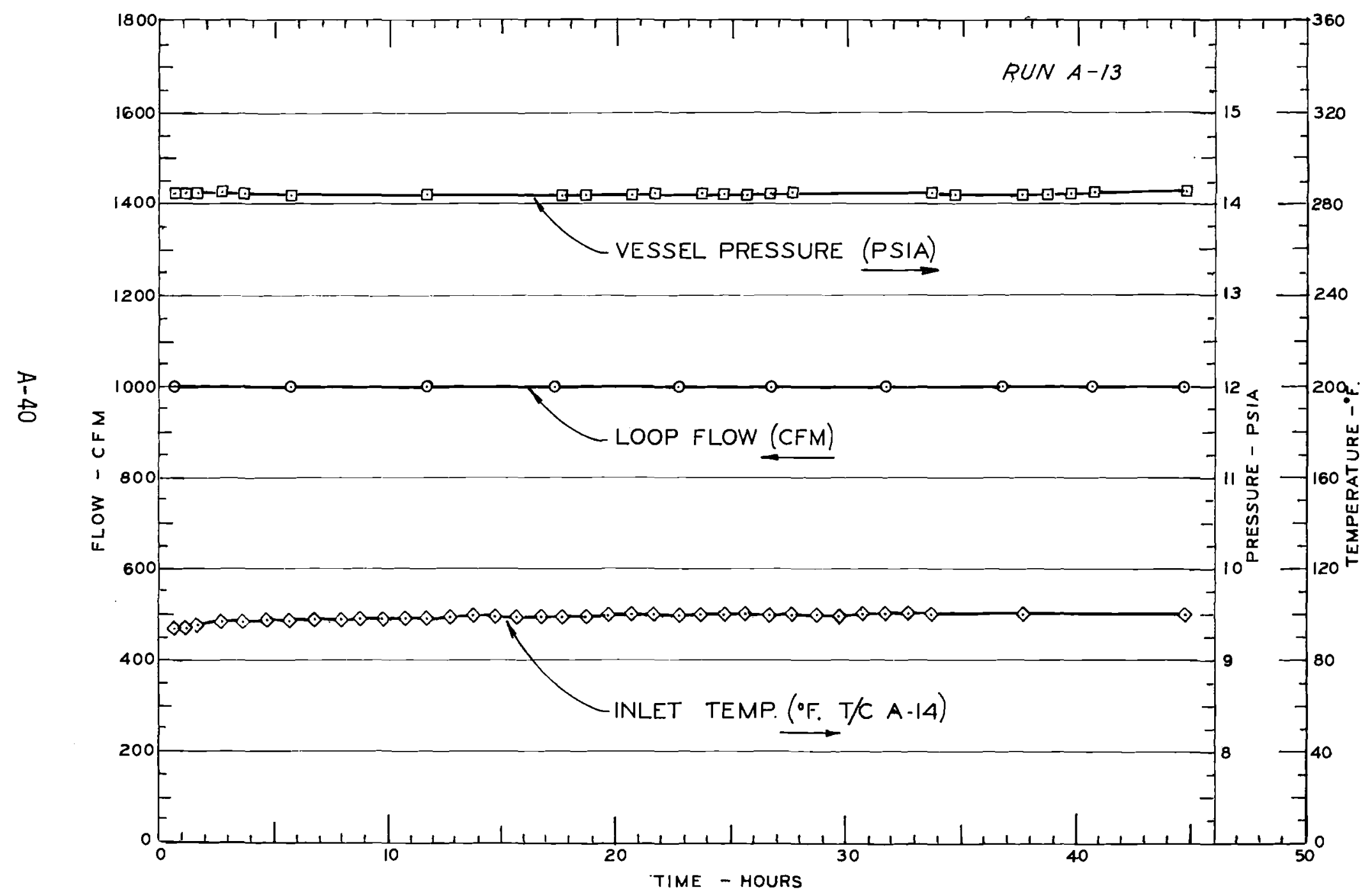

FIGURE A-35. Thermodynamic Conditions and Loop Flow for CSE Run A-13 


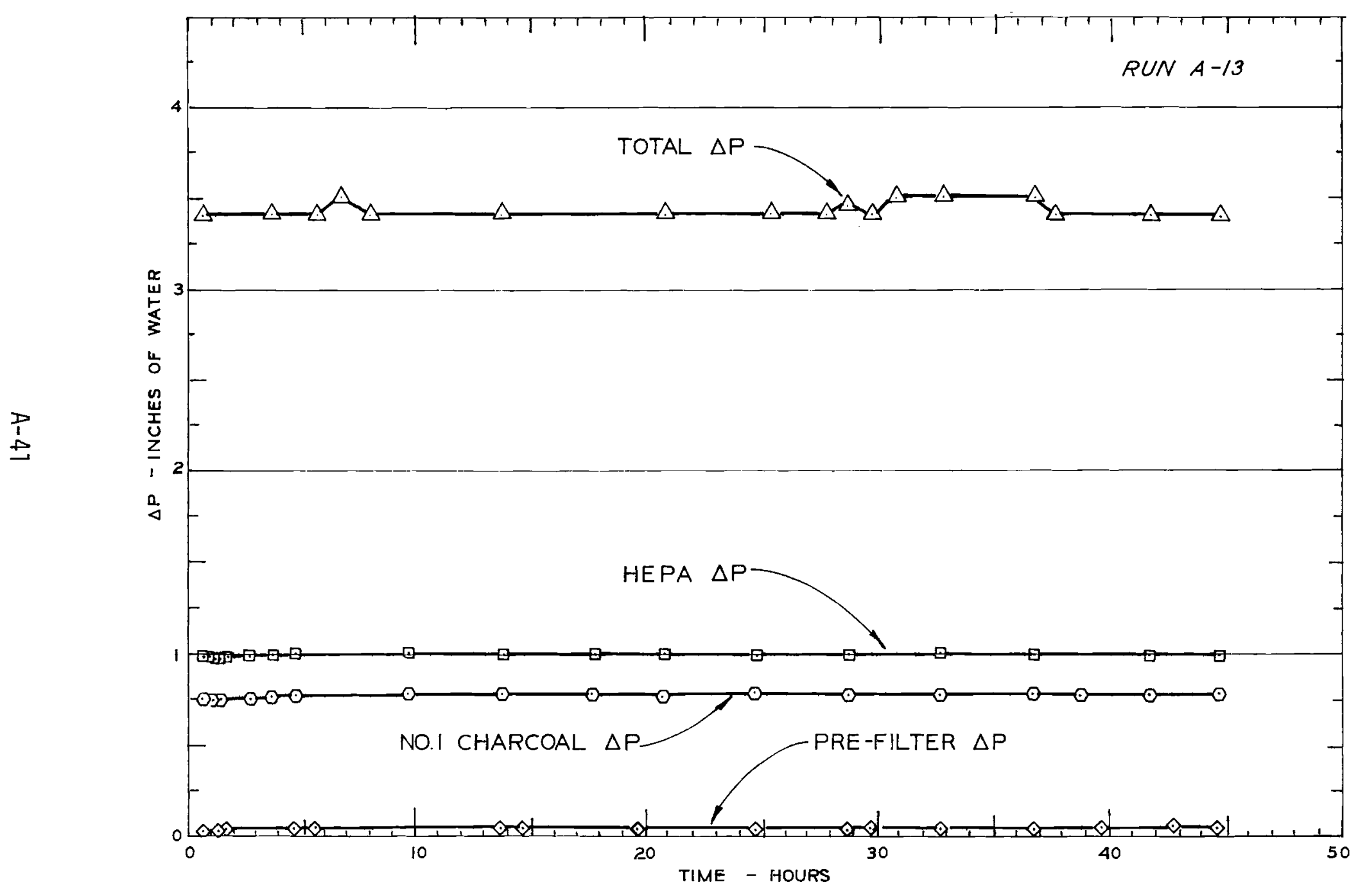

FIGURE A-36. Pressure Drop Across Loop Components in CSE Run A-13 


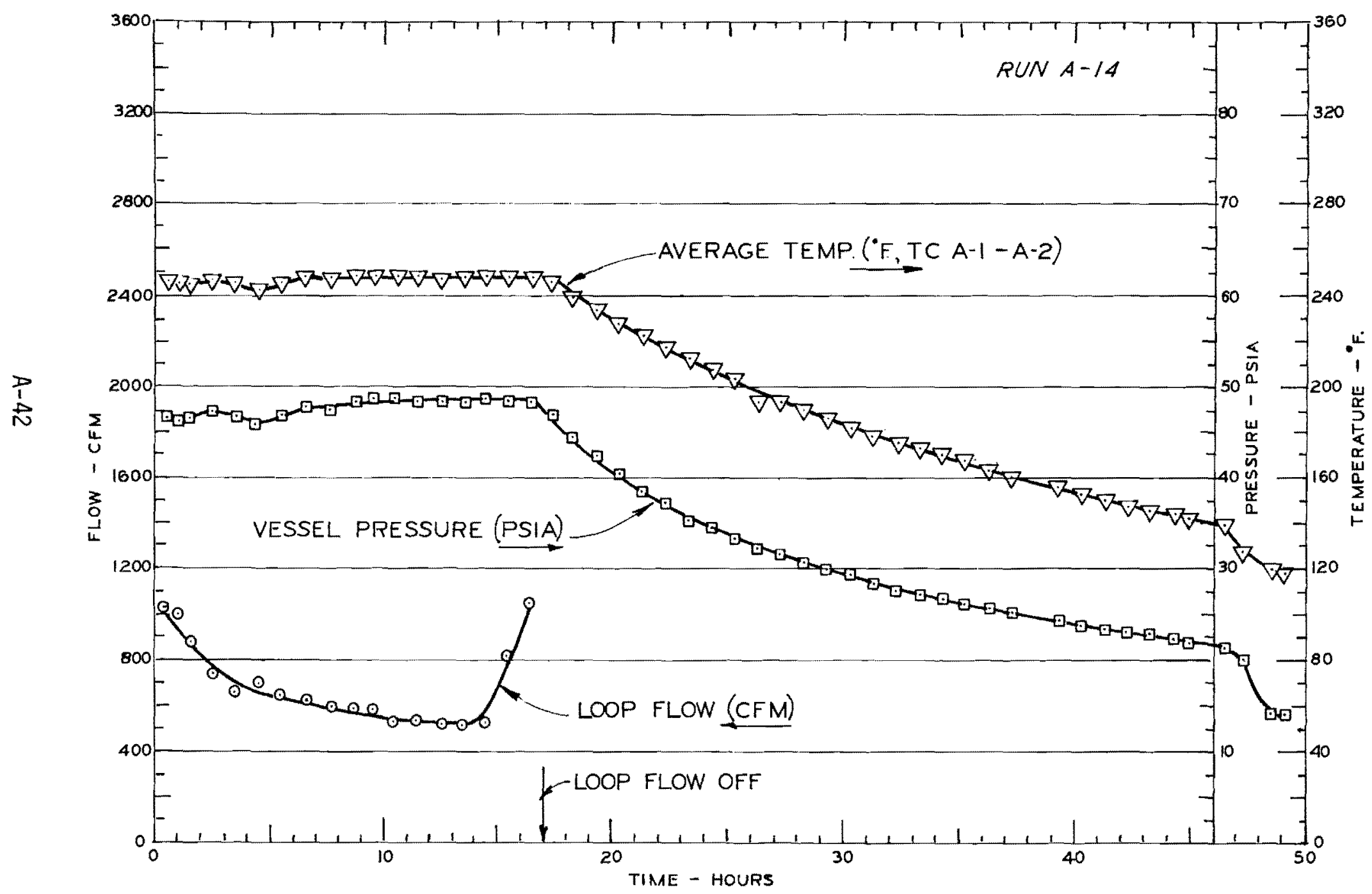

$\frac{\sum}{\substack{c \\ \hline}}$

FIGURE A-37. Thermodynamic Conditions and Loop Flow for CSE RUn A-14 


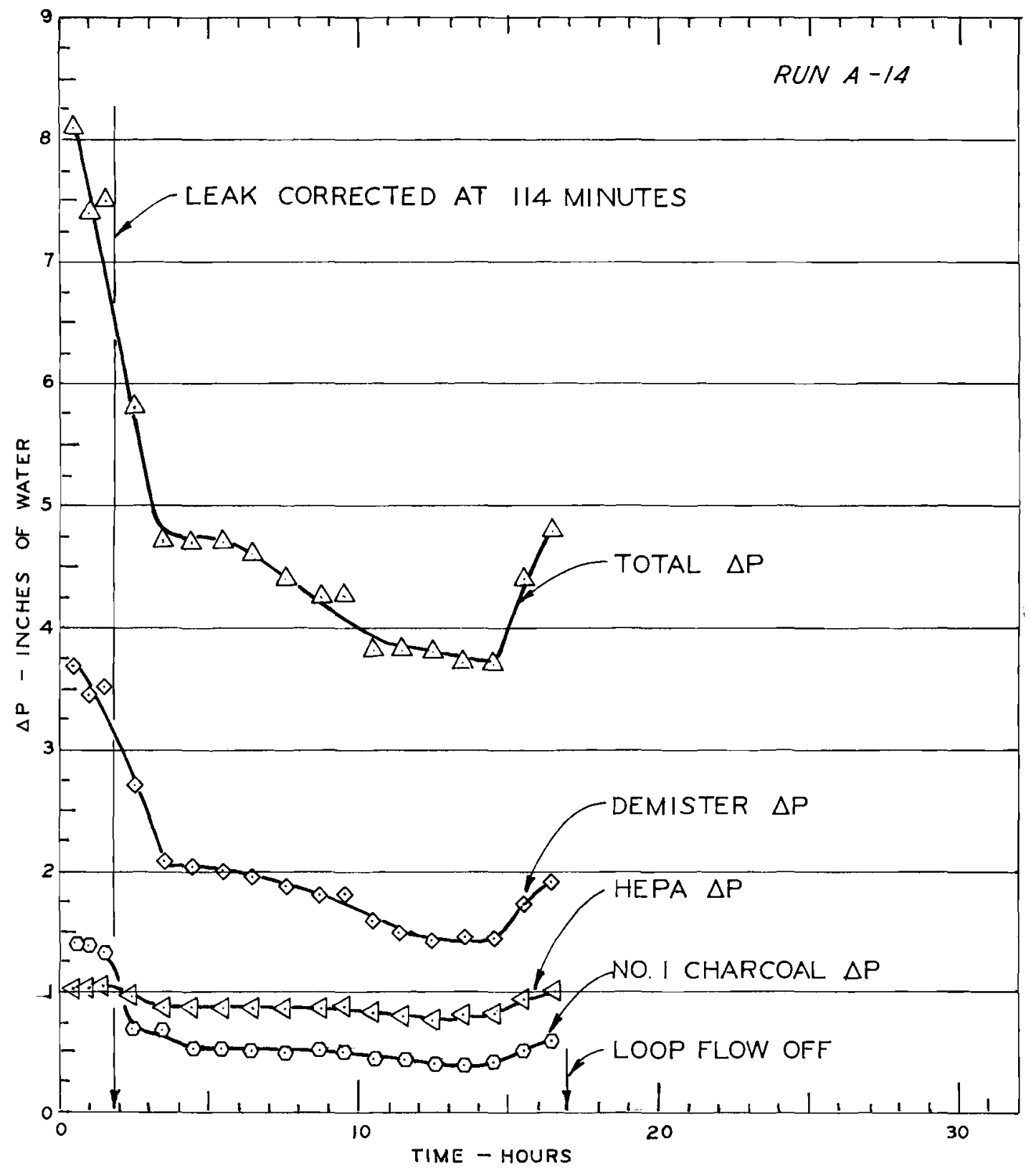

FIGURE A-38. Pressure Drop Across Loop Components in CSE Run A-14 


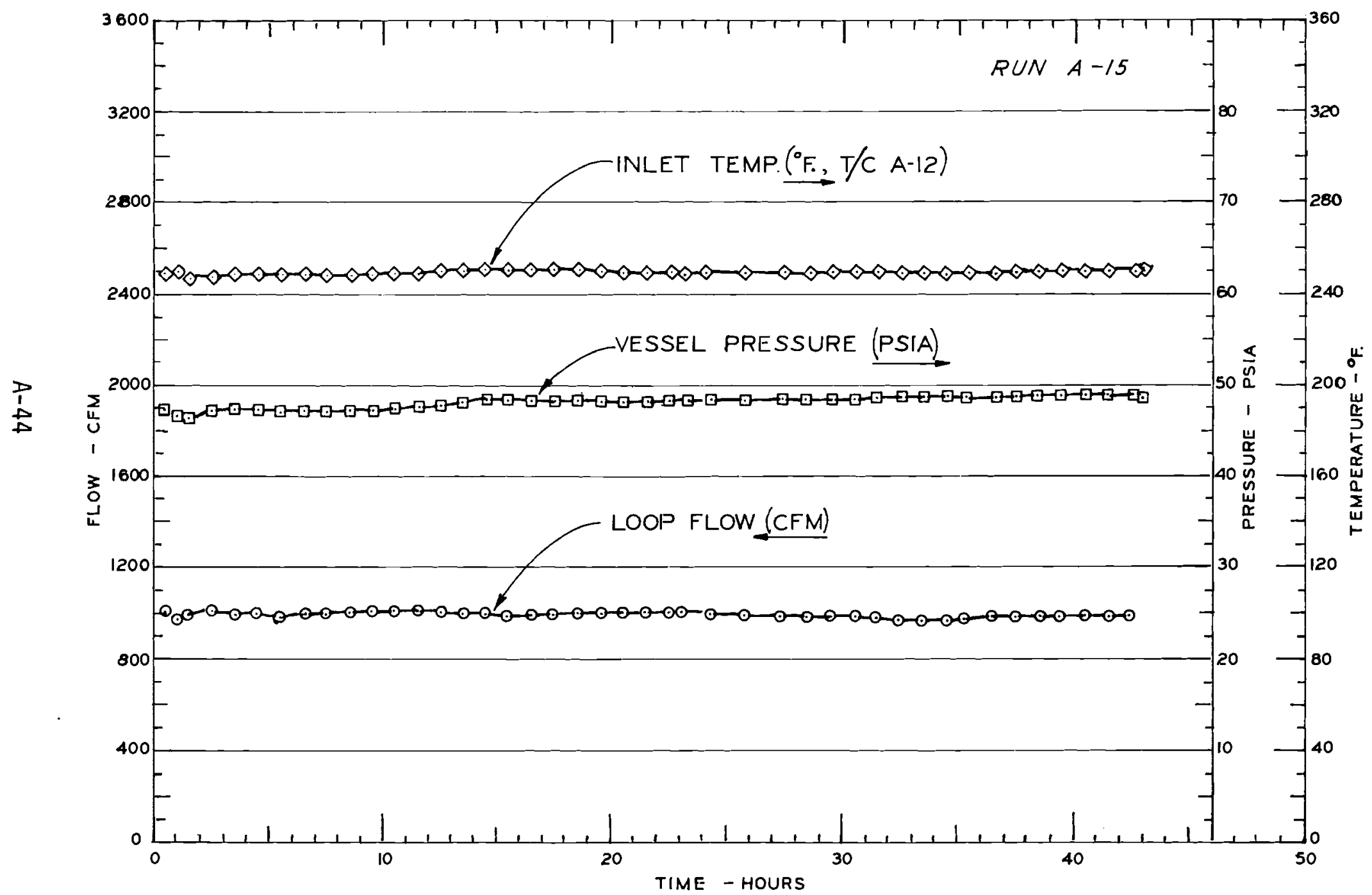

FIGURE A-39. Thermodynamic Conditions and Loop Flow for CSE Run A-15 


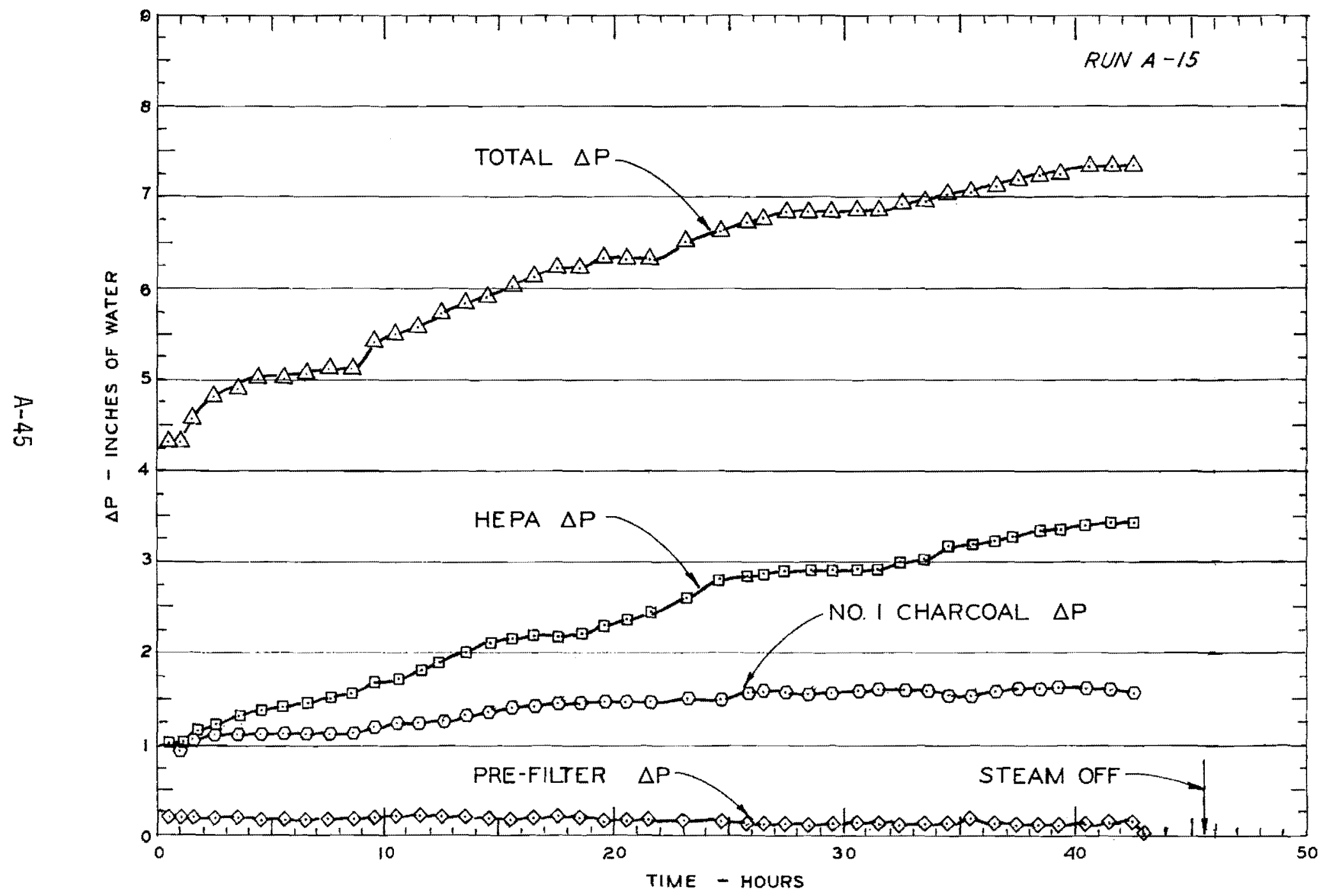

FIGURE A-40. Pressure Drop Across Loop Components in CSE Run A-15 


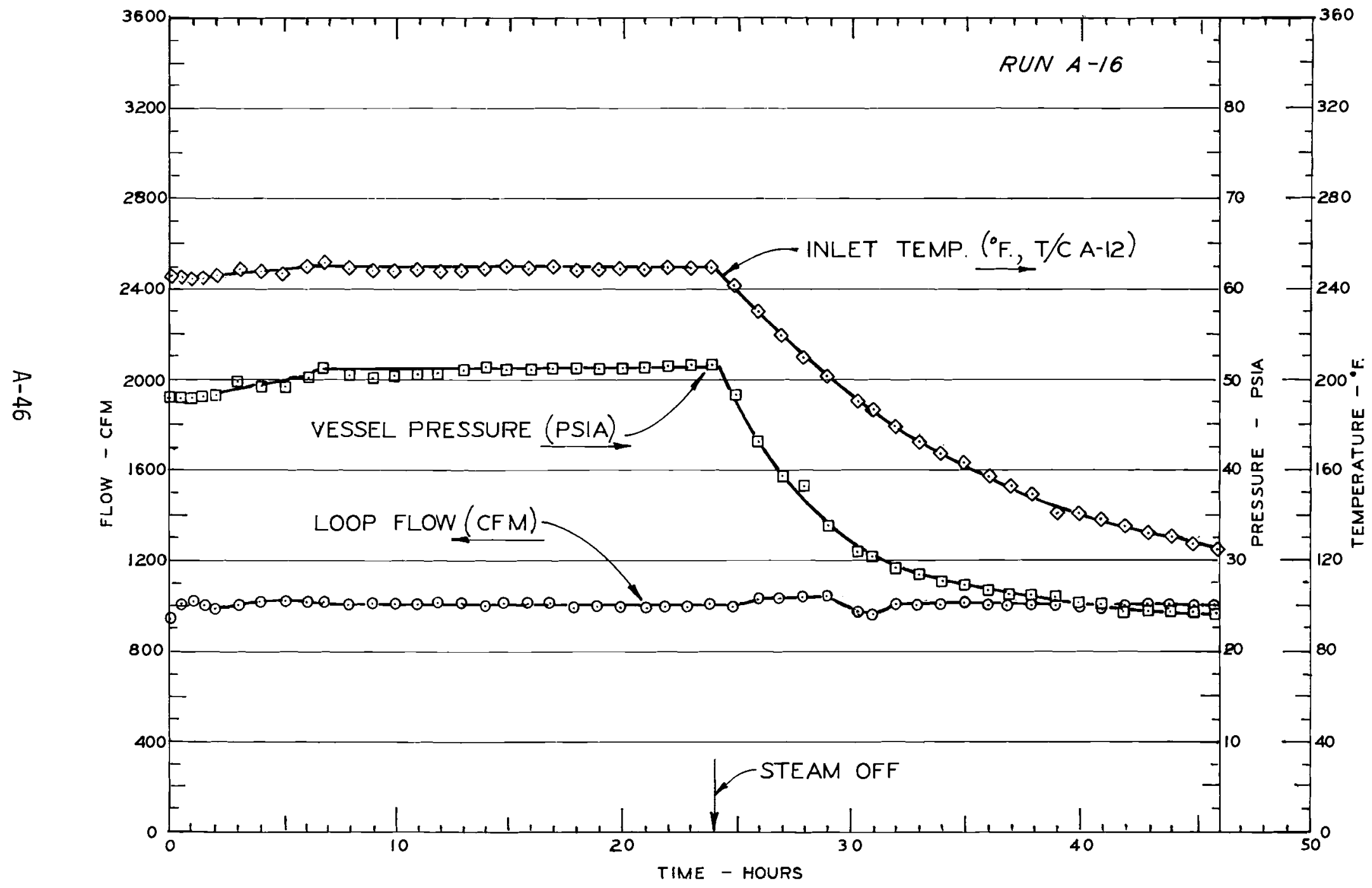

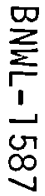

FIGURE A-41. Thermodynamic Conditions and Loop Flow for CSE Run A-16 


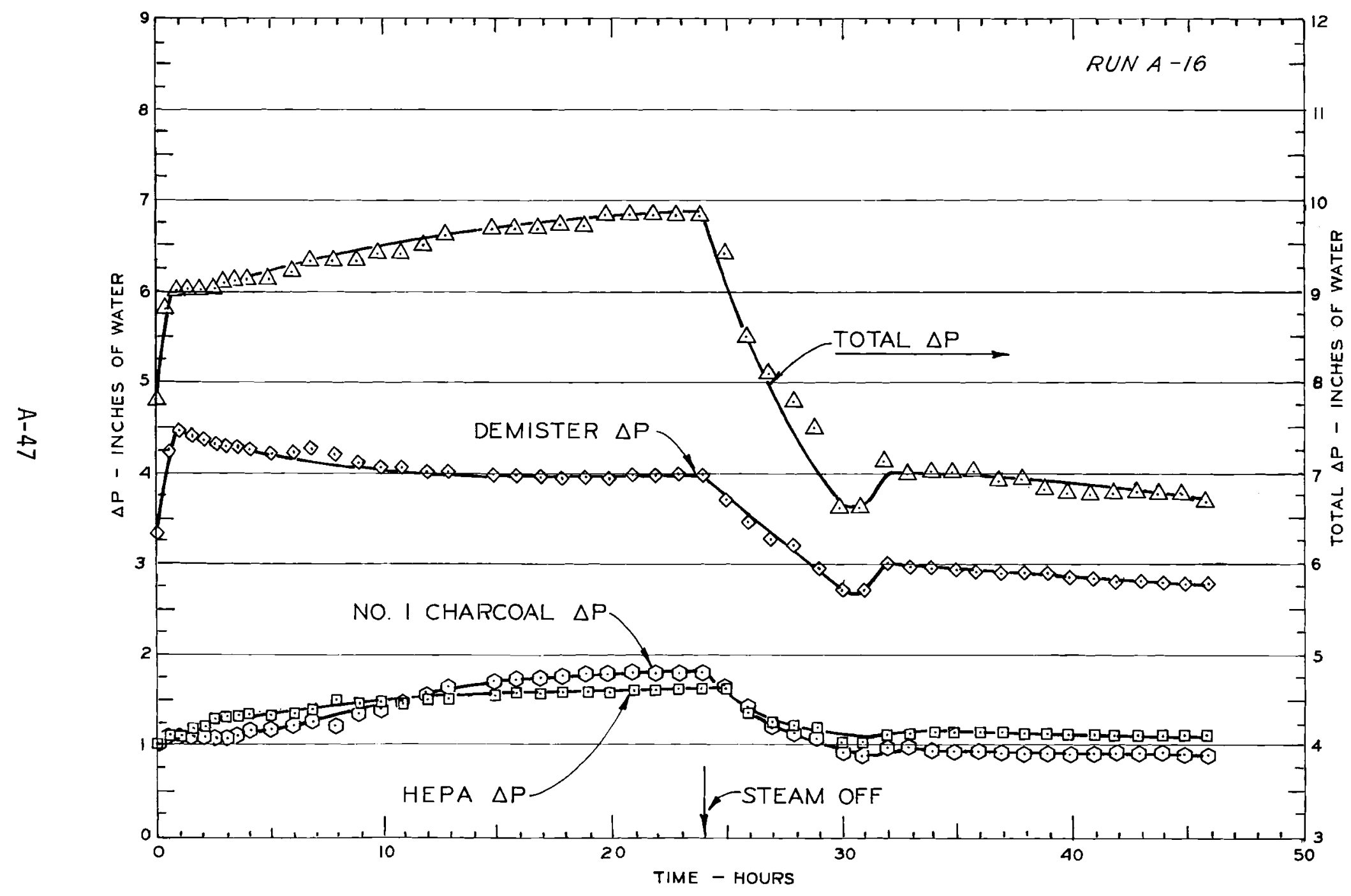

$\sum_{\substack{\infty\\}}^{\infty}$

FIGURE A-42. Pressure Drop Across Loop Components in CSE Run A-16 


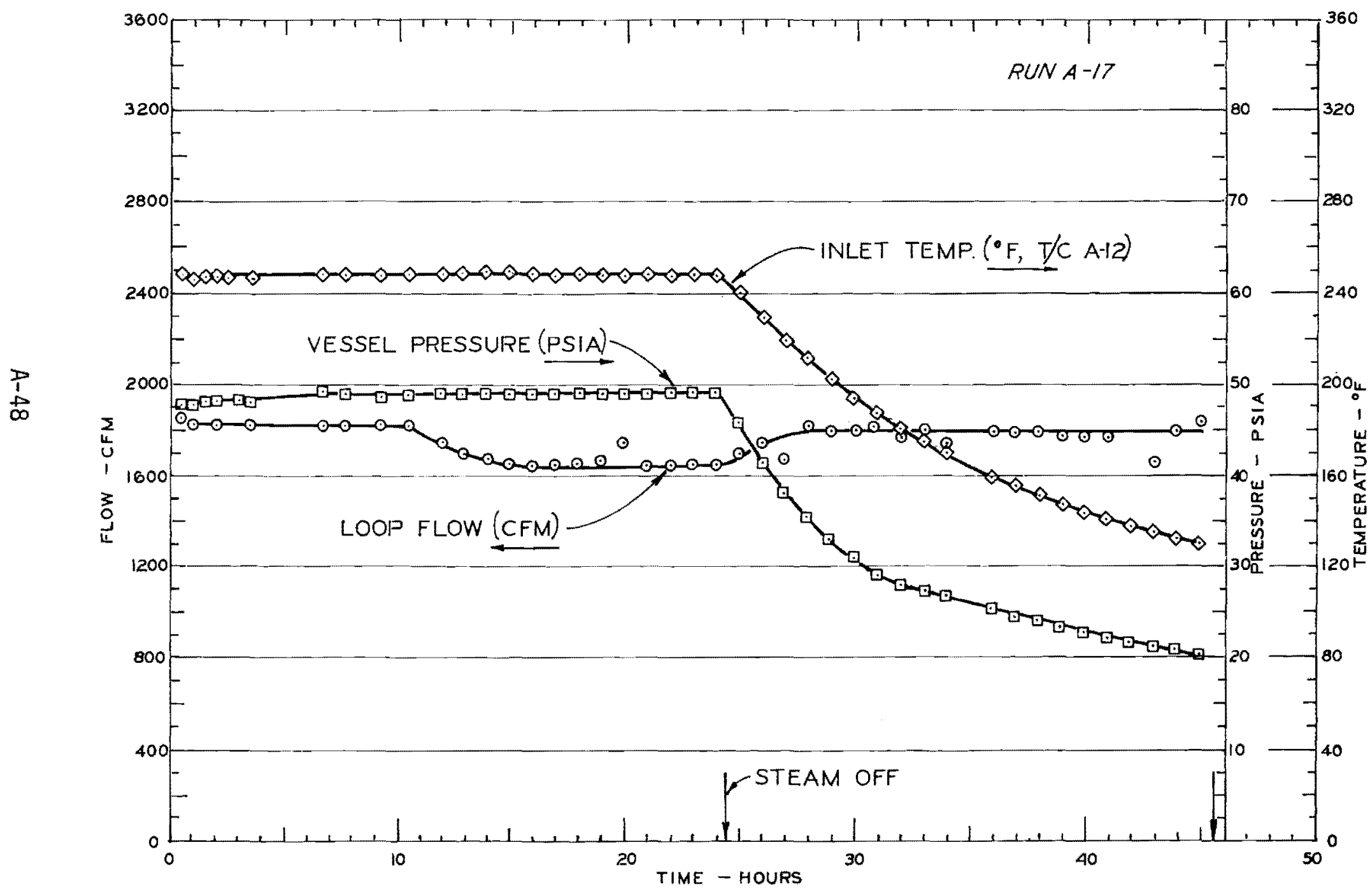

$\frac{\sum_{i}^{\infty}}{\substack{\infty \\ v}}$

FIGURE A-43. Thermodynamic Conditions and Loop Flow for CSE Run A-17 


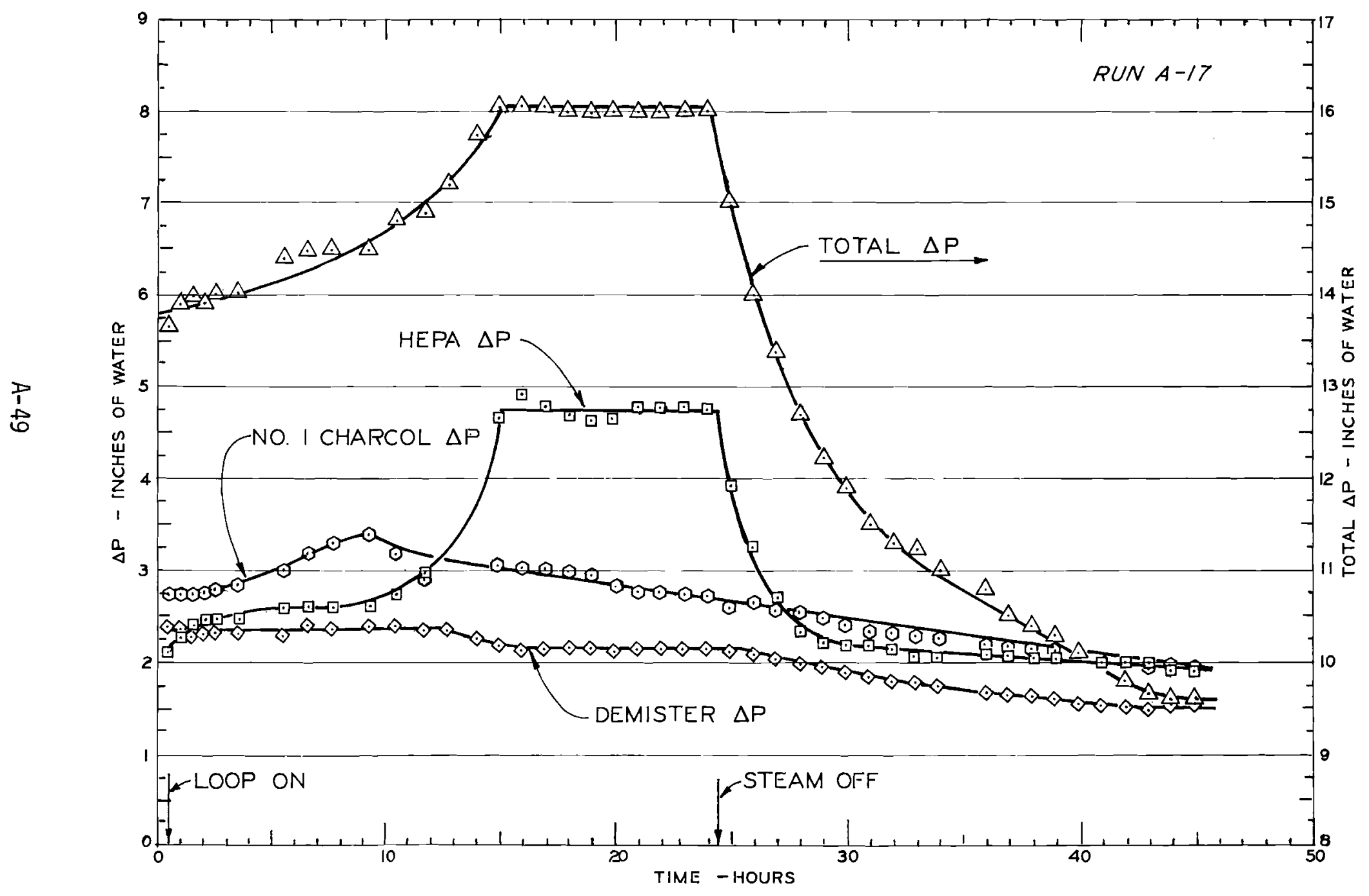

FIGURE A-44. Pressure Drop Across Loop Components in CSE Run A-17 

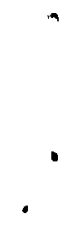

,

.

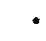


DISTRIBUTION

No. of

Copies

$\underline{\text { OFFS I TE }}$

AEC Chicago Operations office

D. M. Gardiner

1 AEC Chicago Patent Group

G. H. Lee

2 AEC Division of Naval Reactors

R. S. Brodsky

27 AEC Division of Reactor Development and Technology

Assistant Director, Project Management

Chief, Water Projects Branch

Chief, Gas Cooled Projects Branch (2)

Chief, Liquid Metal Projects Branch

Assistant Director, Reactor Technology

Assistant Director, Plant Engineering

Assistant Director, Reactor Engineering

Assistant Director, Nuclear Safety (5)

Chief, Research and Development Branch

H. L. Hamester

R. R. Newton (5)

Environmental and Sanitary Engineering Branch

I. C. Roberts

W. P. Gammi 11

Chief, Engineering and Test Br., N. S.

Assistant Director, Engineering Standards

Assistant Director, Program Analysis

Assistant Director, Army Reactors

269 AEC Division of Technical Information Extension

28 AEC Library, Washington

Advisory Committee on Reactor Safeguards

F. R. Fraley

Division of Compliance

L. Kornblith, Jr.

L. D. Low

Division of Compliance, Region IV

J. W. Flora

Distr-1 
No. of

Copies

Division of Operational Safety

H. Gilbert

Division of Production

G. B. Pleat

Division of Reactor Licensing

R. S. Boyd

Brian Grimes

P. W. Howe

S. Levine

D. J. Skovholt

AEC Division of Reactor Standards

M. Bolotsky

G. Burley

E. G. Case

A. B. Holt

R. Impara

J. R. Miller

P. Norien

I. Spickler

R. Waterfield

2

AB Atomenergi

Nykoping, Sweden

L. Deve 11

Studsvik, Sweden

L. Carlbom

1

$A E G$ - Telefunken

E-213

6 Frankfort/Main 70

AEG - Hochhaus Sud

Germany

Dieter Ewers

1

Aerojet General

Idaho Fal1s, Idaho

W. E. Nyer

Distr-2 
Aerojet-General

Sacramento, CaTifornia

F. L. Climent

American Electric Power Company

2 Broadway

New York, N. Y. 10004

Stephen J. Milioti

Argonne National Laboratory

C. E. Dickerman

S. Fistedis

R. 0 . Ivins

P. Lottes

H. O. Monson

D. Okrent

R. C. Voge 1

P. G. Shewmon

LMFBR Program office

A. Amorosi

L. Baker

C. E. Miller, Jr.

\section{Atomic Energy Control Board}

ottawa, Canada

F. C. Boyd

Atomics International

H. Morewitz (2)

Liquid Metals Engr Center

R. W. Dickinson

Auburn University

School of Engineering and Engineering

Experiment Station

G. H. Nix

4

$\frac{\text { Babcock \& Wilcox Co. }}{\text { P. Box }}$

Lynchburg, Virginia 24505

J. H. MacMililan

W. S. Delicate

D. A. Nitti

R. Wascher 
No. of

Copies

3

Baltimore Gas and Electric

Electric Engineering \& Construction Division Baltimore, MD 21203

J. W. Gore, Jr.

C. Poindexter

C. Lawrence, II I

8

Battelle Memorial Institute

505 King Avenue

Columbus, Ohio 43201

A. R. Duffy

D. L. Morrison

S. Paprocki (2)

R. L. Ritzman

D. N. Sunderman (2)

J. A. Gieseke

2

Battelle Institut e. V

6 Frankfurt/Main 90

Postschiessfach 900160

Germany

G. Leistner/K. J. Kober

N. Henze 1

2

Bechte 1 Corporation (AEC)

B. K. Lee

G. S. C. Wang

3

Bechtel Corporation

San Francisco, CaTifornia

R. F. Griffin

W. P. Neuendorf

K. Schwartrauber

$1 \quad$ Bechtel Corporation

P. 0. Box 607

Gaithersburg, Md. 20760

H. W. Osgood

1 Bettis Atomic Power Laboratory

P. 0. Box 79

West Mifflin, PA 15122

Dr. J. A. Redfield 
Brookhaven National Laboratory

A. W. Castleman

J. M. Hendri

Canadian General Electric Co.

Petersborough, Ontario

S. Davies

Canoga Park Area Office

R. L. Morgan

Centre d'Etudes Nucleaires de Saclay P. 0. Box 2

Gif sur Yvette

(Seine-et-0ise), France

$P$. Candes

Chalk River Nuclear Laboratories

Chalk River, Ontario, Canada

Station 3

G. Hake

Chicago Operations Office

Atomic Energy Commission

D. M. Gardiner

4

Combustion Engineering, Inc.

NucTear Power Department

Windsor, CT 06095

M. F. Valerino

J. M. West

B. J. Reckman

J. M. Martucci

Commonwealth Edison Co.

P. 0. Box 767

Chicago, Illinois 60690

Byron Lee, Jr.

G. T. Klopp

W. L. Stiede 
No. of

Copies

2

Consolidated Edison Company

J. J. Grob

R. H. Koppe

4

Consumers Power Company

Jackson, Michigan 49203

R. C. Youngdah 1

G. S. Keeley

G. B. Matheny

H. S. Tsai

1 Detroit Edison Co.

v. A. Walka

1 Dilworth, Secord, Meagher, and Associates, Ltd. 4195 Dundas St. Toronto, Ontario, Canada

I. J. Billington

$1 \quad$ Duke Power Co.

422 South Church Street

Charlotte, N. C. 28201

E. C. Fiss

1

du Pont Company, Aiken (AEC)

A. H. Peters

du Pont Company, Wilmington (AEC)

F. P. Allen for

Lombard Squires

1

Ebasco Services, Inc.

New York, N. Y. 10006

Harold Oslick

1 ENEL-DCTN

viaG. B. Martini, Roma, Italy

A. Turricchia 
$1 \quad H$. Etherington

84 Lighthouse Drive

Jupiter, Florida 33458

$1 \quad$ W. L. Faith

2540 Huntington Drive

San Marino, California 91108

3 General Atomic Division (AEC)

A. J. Goodjohn (2)

R. H. Ba 11

1

General Electric Company, Cincinnati (AEC)

J. F. White

12 General Electric Company

175 Curtner Ave.

San Jose, California 95125

L. F. Coleman

D. J. Liffengren

M. Siegler

D. P. Siegwarth

W. Vandenberg

G. E. Wade

E. Zebroski

J. M. Skarpelos

Fred Moody

P. Bray

W. A. Sutherland

D. A. Rockwel1

Harvard Air Cleaning Laboratory

Boston, Mass.

M. First

F. J. Viles

14

Idaho Nuclear Corporation

D. E. Black

G. 0. Bright

G. F. Brockett

J. A. Buckham

W. H. Burgus

C. Haire

J. H. Keller

L. T. Lakey 
Idaho Nuclear Corporation (Continued)

J. A. Norberg

D. T. Spence

D. M. Slansky

N. K. Sowards

D. H. Walker

W. A. Yuili

Idaho Operations office

D. Williams

IIT Research Institute

E. V. Gallagher

T. A. Zaker

Inst. f. Mass - u. Regelunstechnik D8046 Garching, Germany-West

Dr. H. Karwat

Institute fur Reactorsicherheit

5 Koln, Lukasstrasse

Germany

Heinz G. Seipel

Japan Atomic Energy Research Institute

Tokai Laboratory, Tokai Ibaragi, Japan

Masayoshi Shiba

1

Jersey Central Power and Light

Interplace Building

260 Cherry Hill Road

Parsippany, New Jersey 07054

J. P. Moore, Jr.

1 A. A. L'Kelly

2421 West Rowland Avenue

Littleton, Colorado 80120

Los Alamos Scientific Laboratory

J. H. Russel

W. R. Stratton 
No. of

Copies

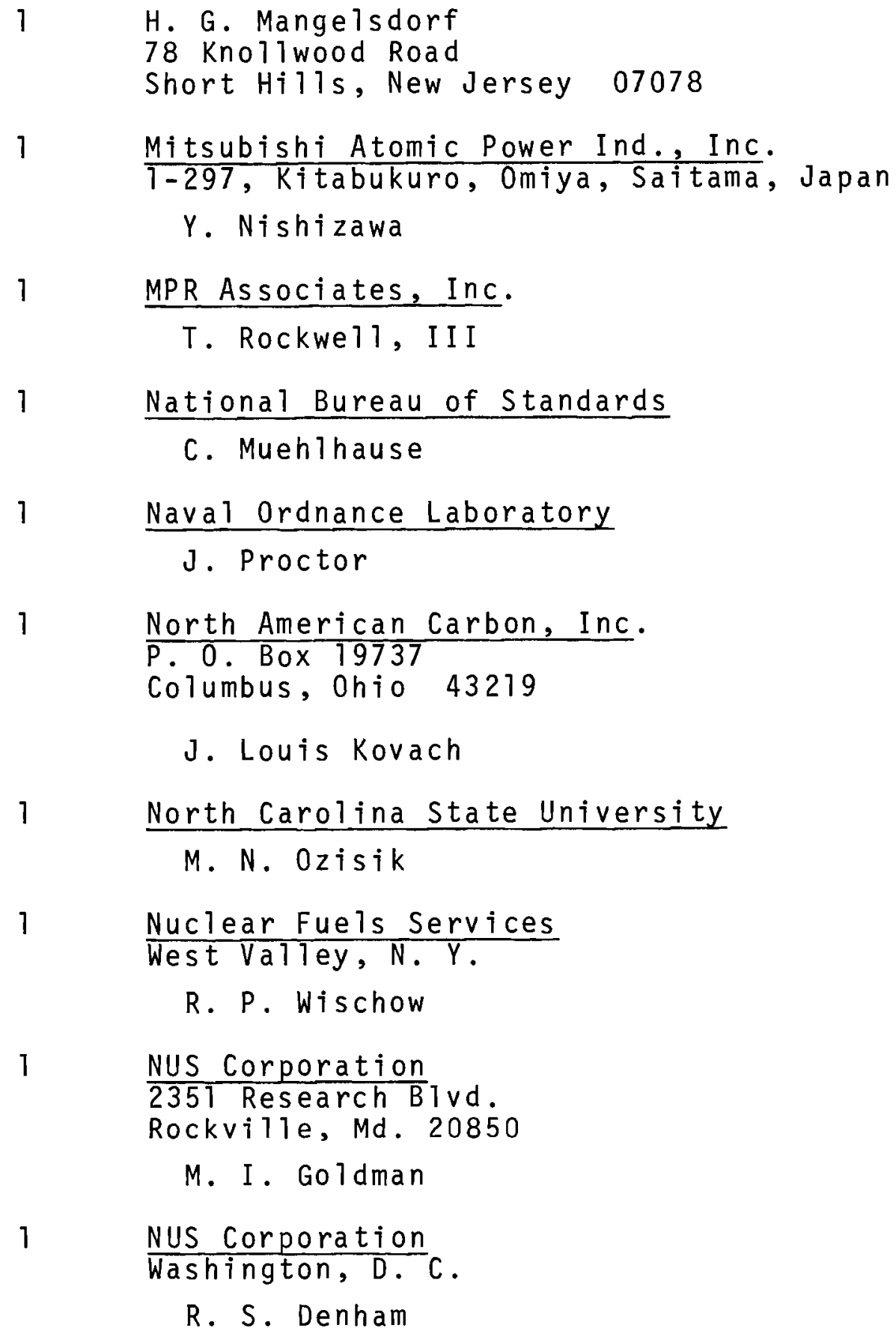


No. of

Copies

19

Oak Ridge National Laboratory

R. E. Adams

R. B 1 anco

J. Buchanan

W. B. Cottrel1

D. Ferguson

G. W. Parker

L. F. Parsly, Jr.

P. Rittenhouse

D. B. Trauger (2)

R. L. Bennett

M. H. Fontana

B. F. Roberts

T. H. Row

G. M. Watson

H. E. Zitte 1

Oak Ridge Operations office (AEC)

D. Cope (2)

E. Delaney

W. L. Sma11ey

1 Ontario water Resources Commission Water Quality Surveys Branch

Division of Sanitary Engineering

135 St. Clair Avenue West

Toronto 7, Ontario, Canada

W. A. Steggles

1 Oregon State University,

Corval1is, Oregon

James G. Knudsen

1 The Pennsylvania State University

College of Engineering

101 Hammond Building

University Park, Pennsylvania

N. J. Palladino

1 Pickard, Lowe and Assoc.

1200 18th St., N.W.

Washington, D. C.

Keith Woodard 
No. of

Copies

2

Portland General Electric Co.

621 S.W. Alder Street

Portland, Oregon 97205

E. C. Itschner

J. Grund

1 Public Service Electric and Gas Co. 80 Park PTace Newark, N.J. 07101

R. P. Douglas

2

San Francisco Operations office

Atomic Energy Commission

Lt. Col. J.B. Radcliffe

C. F. Backlund

2 Sargent \& Lundy

Engineers

140 South Dearborn Street

Chicago, Illinois 60603

0 . A. Hrynewych

F.A. Daugherty

2 Southern Nuclear Engineering, Inc.

P. 0. Box 10

Dunedin, Florida 35528

G. Brown

K. E. Roach

2

Stone and Webster Engineering Corp., Boston

L. P. Deackoff

J. H. Noble

1 Southern California Edison Co.

P. 0. Box 351

Los Angeles, California 90053

J. B. Moore

2 Southern Nuclear Engineering, Inc.

Gilbert Brown

R. L. Lyerly 
Southern Services, Inc.

Birmingham, Ala.

Ruble A. Thomas

F. E. Ehrensperger

1

Spray Engineering Co.

Burlington, Mass.

W. E. Hebden

Spraying Systems Co.

Be11wood, I11.

E. W. Gray

TRW Incorporated

TRW Systems Group (NASA)

D. B. Langmuir

S. M. Zivi

United Engineers \& Constructors, Inc.

1401 Arch Street

Philadelphia, Pennsylvania 19105

A. T. Molin

United Kingdom Atomic Energy Authority Authority Health and Safety Branch Risely Warrington, Lancs

England

$$
\text { A. R. Edwards }
$$

University of California, Berkeley

H. A. Johnson

V. E. Schrock

University of Houston

Houston, Texas 77004

C. W. Zabel, Dir. of Research 
University of Illinois

Department of CiviT Engineering 3129 Civil Engineering Building Urbana, Illinois 61801

C. P. Siess

1

University of Minnesota

Department of Chemical Engineering

Minneapolis, Minnesota 55455

H. S. Isbin

$\frac{\text { University of Pisa }}{\text { Pisa, Italy }}$

B. Guerrini

1

University of Tennessee

606 Dougherty Ha17

Knoxvilie, Tennessee 37916

S. H. Hanauer

1

University of Tokyo

Mechanical Engineering Section

Tokyo, Bunkyo-ku,

Tokyo, Japan

Prof. Hidao, Uchida

2

University of Washington

Prof. Wells Moulton

Prof. K. L. Garlid

USAEC Scientific Representative c/o Atomic Energy of Canada, Ltd.

Chalk River, Ontario, Canada

H. J. Reynolds

Virginia Electric and Power Co.

Richmond, Virginia 23209

Stanley Ragone

W. N. Thomas 
No. of

Copies

10

Westinghouse Electric Corp. (APD)
E. Beckjord
S. Fabic
W. D. Fletcher
H. Graves
J. D. McAdoo
F. M. Heck
R. A. Wiesemann
A. S. Neuls
J. L. Gallagher
W. D. Townsend

1 Westinghouse Electric Corp. (HTD)

A. Lohmeier

3

Yankee Atomic Electric Co.

441 Stuart St., Boston, Mass.

J. DeVincentis

P. S. Littlefield

R. J. Merlino

ONSITE-HANFORD

AEC Chicago Patent Group

R. M. Poteat

AEC RDT Site Representative

P. G. Holsted

J. B. Kitchen

(2)

2

AEC Richland Operations office

M. R. Schneller

W. E. Lotz

Atlantic Richfield Hanford Company

0 . F. $\mathrm{Hi} 11$

G. R. Kiel

ARHCO File

2 RDT Assistant Director for Pacific Northwest Programs T. A. Nemzek

9 Douglas United Nuclear

J. E. Mecca D. L. Renberger

N. R. Miller

J. R. Spink

W. F. Nechodom

R. W. Reid

R. H. Shoemaker

J. W. Riches

DUN Files 
No. of

Copies

Vitro/HES

A. J. McElfresh

WADCO Corporation
A. G. Blasewitz
J. J. Cadwel1
T. T. Claudson
J. P. Hale
J. W. Hagen
R. L. Junkins
R. D. Leggett
C. E. Linderoth
J. D. McCormack
D. P. O'Keefe
H. N. Pederson
R. E. Peterson
G. J. Rogers
D. E. Simpson
J. C. Spanner
N. P. Wilburn (2)
M. E. Witherspoon
J. A. Williams
J. M. Yatabe
WADCO Document Control

\section{Batte 11 -Northwest}

F. W. Albaugh

R. T. Allemann

(5)

J. M. Batch

R. E. Burns

S. H. Bush

L. A. Carter

D. L. Condotta

G. J. Dau

F. G. Dawson

R. F. Foster

J. C. Fox

J. J. Fuquay

W. A. Haney

H. Harty

M. M. Hendrickson

R. K. Hilliard (5)

J. M. Nielson

R. E. Nightingale

D. W. Pearce

L. T. Pedersen

A. M. Platt

A. K. Postma (5)

D. E. Rasmussen

D. L. Reid

R. L. Richardson

W. D. Richmond

L. C. Schwendiman

A. M. Sutey

E. E. Voiland

P. C. Walkup

R. G. Wheeler

N. G. Wittenbrock

F. R. Za loudek

J. F. Hons tead

Technical Information Files (5)

E. R. Irish

Technical Publications

R. T. Jaske

B. M. Johnson (20)

H. V. Larson 